\title{
The Canadian Approach to \\ The Protection of Victims of Human Trafficking
}

by

John A. Ferguson, B.A.

\author{
A thesis submitted to \\ the Faculty of Graduate Studies and Research \\ in partial fulfillment of \\ the requirements for the degree of \\ Master of Arts \\ Department of Law \\ Carleton University \\ Ottawa, Ontario \\ December $8^{\text {th }}, 2005$
}

(C) 2005, John A. Ferguson 


$\begin{array}{ll}\begin{array}{l}\text { Library and } \\ \text { Archives Canada }\end{array} & \begin{array}{l}\text { Bibliothèque et } \\ \text { Archives Canada }\end{array} \\ \begin{array}{l}\text { Published Heritage } \\ \text { Branch }\end{array} & \begin{array}{l}\text { Direction du } \\ \text { Patrimoine de l'édition }\end{array} \\ \begin{array}{l}\text { 395 Wellington Street } \\ \text { Ottawa ON K1A ON4 }\end{array} & \begin{array}{l}\text { 395, rue Wellington } \\ \text { Ottawa ON K1A ON4 } \\ \text { Canada }\end{array}\end{array}$

Your file Votre référence

ISBN: 0-494-13413-5

Ourfile Notre référence

ISBN: 0-494-13413-5

NOTICE:

The author has granted a nonexclusive license allowing Library and Archives Canada to reproduce, publish, archive, preserve, conserve, communicate to the public by telecommunication or on the Internet, loan, distribute and sell theses worldwide, for commercial or noncommercial purposes, in microform, paper, electronic and/or any other formats.

The author retains copyright ownership and moral rights in this thesis. Neither the thesis nor substantial extracts from it may be printed or otherwise reproduced without the author's permission.
AVIS:

L'auteur a accordé une licence non exclusive permettant à la Bibliothèque et Archives Canada de reproduire, publier, archiver, sauvegarder, conserver, transmettre au public par télécommunication ou par l'Internet, prêter, distribuer et vendre des thèses partout dans le monde, à des fins commerciales ou autres, sur support microforme, papier, électronique et/ou autres formats.

L'auteur conserve la propriété du droit d'auteur et des droits moraux qui protège cette thèse. $\mathrm{Ni}$ la thèse ni des extraits substantiels de celle-ci ne doivent être imprimés ou autrement reproduits sans son autorisation.
In compliance with the Canadian

Privacy Act some supporting forms may have been removed from this thesis.

While these forms may be included in the document page count, their removal does not represent any loss of content from the thesis.
Conformément à la loi canadienne sur la protection de la vie privée, quelques formulaires secondaires ont été enlevés de cette thèse.

Bien que ces formulaires aient inclus dans la pagination, il n'y aura aucun contenu manquant.

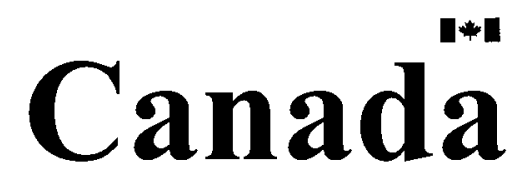




\begin{abstract}
The United Nations (UN) established the Convention to Combat Transnational Organized Crime in June of 2000 which included a protocol to: Prevent, Suppress, and Punish Trafficking in Persons, Especially Women and Children. The Protocol reflected a recognition by the international community that human trafficking is a serious international problem that requires focused and integrated global law enforcement strategies.
\end{abstract}

This study examines Canada's compliance with the specific victim protection provisions contained in the Trafficking Protocol. Chapters 2 through 4 examine the historical evolution of white slavery to human trafficking; the human trafficking debates; and explores the relationship between globalization, illegal migration and human trafficking. Chapter 5 outlines the global concerns of Non-Government Organizations (NGOs) regarding the Protocol's victim protection provisions. Chapter 6 entails a focused evaluation of Canada's compliance with the Protocol's protection provisions, with a succeeding chapter providing a comparative analysis between Canada's approach and those of the United States and Great Britain. 


\section{$\underline{\text { Acknowledgments }}$}

Embarking upon graduate studies requires a large commitment from any student. For those who have families, the commitment required to succeed transcends the student and becomes that of the family. For myself, I know that I would never have had the opportunity to participate nor succeed in this endeavour without the continued support of my wife, Charlotte. She is my greatest supporter and my greatest resource. I would like express my deepest appreciation for her commitment to my studies which made this experience possible.

One encounters many people during life that shape the person you become. Professors Alan Hunt and Doris Buss are two such people and it has been through their support, advice and counsel, that I have been able to achieve my goal and grow as a person. In addition, the thought provoking style and dedication to the vocation of teaching demonstrated by Professor Hunt has opened my mind to a world of new possibilities and viewpoints, and for that, I am truly grateful. 


\section{Table of Contents}

Chapter 1 - Introduction $\quad$..... 1

Chapter 2 - White Slavery $\quad$..... 14

- Moral Panic

- Moral Reform

- $\quad$ The White Slavery Victim

- The Transition from White Slavery to Human Trafficking

- Chapter 3 - Human Trafficking

- The Trafficking Panic

- The Prostitution Debate

- The Trafficking Definition

- The Trafficking Victim Constructs

- The Scope of Human Trafficking

- Summary

\section{- Chapter 4 - Globalization and Illegal Migration}

- The Moral Panic

- The Illegal Immigrant

- $\quad$ Summary

- Trafficking Protocol Protection Provisions

- $\quad$ Protection Provision Gaps

- Summary

- Chapter 6 - Canada's Approach

- Canada's Human Trafficking Strategy

- Human Trafficking Legislation in Canada

- The Treatment of Trafficking Victims in Canada

- Canada's Response to Protection Provision Gaps

- Conclusion 
- Chapter 7 - The Approaches of the US and UK

- The US Approach

- The British Approach

- Summary

- Chapter 8 - Conclusion

- Bibliography

- $\quad$ Surveys

- $\quad$ Case Law/Immigration Hearings

- Appendix

- $\quad$ Appendix 1: blank RCMP survey

- $\quad$ Appendix 2: blank DOJ survey

- Appendix 3: blank CIC survey

- Appendix 4: blank NGO survey

- $\quad$ Appendix 5: blank US government survey 


\section{Chapter 1}

\section{Introduction}

Human trafficking is a contemporary form of human slavery. For the victims of human trafficking, it is a world filled with fear, poverty, abuse, exploitation, and violence. Canadian Justice Minister, Irwin Cotler, has aptly described human trafficking as "a persistent and pervasive assault on human rights" (Cotler 2004: 2.). It is by its very nature, international in scope, involving a criminal element that preys upon the most vulnerable of society - those persons who seek, often in desperation, a better future for themselves and their families. Human trafficking is a global phenomena of the $20^{\text {th }}$ Century that necessitates a global response to combat, prevent, and most importantly, to protect its victims.

The creation of the United Nations Convention against Transnational Organized Crime - 2000 (Annex II- Protocol to Prevent, Suppress and Punish Trafficking in Persons, Especially Women and Children) is the most recent effort, within a series of international agreements over the past century, to address this growing social problem. ${ }^{1}$ It is the product of several years work and a reflection of the international community's committed effort to provide relief from a growing criminal enterprise that began to take on greater international significance during the late 1980's and early 1990's (Raymond 2003: 491-493).

During the $20^{\text {th }}$ Century, six international agreements were created starting with the International Agreement for the Suppression of the "White Slave Traffic" in 1904. Five of the six agreements came into existence between 1904 and 1950. 
Within the confines of the Trafficking Protocol, much of the focus to date by western nations, including Canada, has been to establish effective domestic and international enforcement strategies to combat and prevent human trafficking. However, as evidenced by Articles 6-8 of the Trafficking Protocol, I believe that there exists an equal priority to ensure the protection of trafficking victims by the signatories of the Convention. In particular, Article 6 requires the apprehending country to provide a safe haven, medical assistance, legal representation, employment and educational opportunities, as well as social and psychological rehabilitation to victims. Article 7 stipulates the need for a legal process to be established that will permit victims of human trafficking the opportunity to remain in the receiving country, temporarily or permanently. And, Article 8 relates to the obligations for the safe repatriation of the victims to their point of origin, preferably on a voluntary basis.

The central issue of this study is to assess Canada's compliance, as a signatory of the Convention, with the Trafficking Protocol's victim protection requirements. This has proven to be a complex and challenging issue, for the answer to Canada's compliance is not a simple case of yes or no. Numerous debates among international organizations such as the European Women's Lobby (EWL), Anti-Slavery International (ASI) and the Network of Sex Work Projects (NSWP) continue to percolate within the issue of human trafficking, especially the ongoing debates over the definition of victims of human trafficking, the issue of exploited victim versus willing participant, and the impact of globalization upon global migration in terms of illegal immigration. In 
addition, although human trafficking has been in existence for some time, it is a fairly new issue for Canadian legislators and policy makers. Thus, little quantitative and objective statistical information is available. As a result, much of the evaluation of Canada's compliance with the protection provisions of the Trafficking Protocol in this study will be suggestive and based on interpretations of information from a variety of sources.

This study is premised upon a broad examination of the interrelationships between globalization, illegal migration and human trafficking. Chapter 2 begins with an historical overview of the evolution of human trafficking from its initial concern with the 'white slavery' panic that emerged at the end of the $19^{\text {th }}$ and beginning of the $20^{\text {th }}$ Centuries to its current visibility. It will examine the issue of white slavery as a carefully constructed moral panic that nurtured the anxieties of a wide variety of interest groups reflecting the moral, social, economic and political crises of the day (Valverde 1991: 99). This chapter will adopt the position that those who encouraged the fear of white slavery were predominantly concerned with achieving support for legislation, domestic and international, under the guise of combating human trafficking but with the real objective of regulating morality through increased immigration restrictions.

This chapter will also look back at the purported victims of yesteryears. It will explore the narrative construction of those victims - who they were, the need for protection and from whom, and how the legislation that was created, ostensibly to protect 
them, actually impacted upon their lives. It will explore the literature of the day and how it acted as a tool to sway public opinion by containing numerous sordid accounts of white slavery which bore no resemblance to reality (Langum 1994: 33).

A main element of the second chapter, and one that will be carried throughout this paper, is the issue of prostitution and how it formed a central theme to the white slavery panic in the past and remains a critical focal point in the human trafficking discourses of today. It is recognized that there are many other forms of human trafficking but the predominant focus of the trafficking discourse has been the sex trade and as a result, it will be the main focus of this study. It should also be noted that this paper is not a commentary for or against prostitution but considers how the different views on prostitution affect the way various groups approach the issue of human trafficking.

Prostitution was viewed as a flash point for many of the social tensions that existed during the first decades of the $20^{\text {th }}$ Century because it was a readily visible symbol that nurtured the fear of a declining society (Langum1994: 16-17). Today, prostitution remains a central point of debate within the human trafficking discourse attracting considerable media attention. It is recognized that human trafficking is quite diverse in nature, involving men, women and children for a variety of exploitive objectives. But for the purposes of this paper, the research and analysis conducted has been confined to the trafficking of women, specifically in regards to the sex trade, and the 
issues surrounding their victimization and the resultant need for their protection.

Focusing solely on the trafficking in women for work in the sex trade has the inherent danger of implying that the majority of human trafficking involves only women when in fact no study has been done to determine the extent of trafficking in terms of either gender. In addition, it is also recognized that because this paper concentrates on only one category of human trafficking, it may not address related debates within the many human trafficking discourses that pertain to other types of trafficking. However, the issue of trafficking women for the sex trade was the dominant focus of the white slavery panic and remains the core of public focus today.

Chapter 2 introduces the role of the reformers in the white slavery panic and in particular, female reformers, many of whom were part of the then emerging feminist movement. The viewpoints expressed by various feminist organizations concerning white slavery will be outlined because the debates over white slavery carry forward and remain within the human trafficking discourses today. The emphasis of reformers in the past was on rescue and redemption while today it is on rescue and protection. Prostitution, the focal point of the white slavery debate by moral reformers, continues to be central to the debates within human trafficking. Today, prostitution remains an issue of moral turpitude versus legitimate employment and in many respects continues to instill a division amongst feminist organizations. 
Chapter 3 builds upon the historical review of the evolution of white slavery. It will focus on the current human trafficking discourses and the major related issues. It will start with the issue of 'moral panic' because this issue permeated the white slavery discourse and continues to maintain a strong presence within the human trafficking narrative. It will then provide an overview of the victims of human trafficking. And, like Chapter 2, it will focus on the female victims; who they are; their needs; and their need for protection.

Chapter 3 will revisit the debate within feminist organizations regarding prostitution as most female victims of human trafficking are believed to be destined to work in the sex trade. Thus, the conflicting viewpoints over prostitution and how they are incorporated into international agreements and related domestic legislation will have a bearing on how victims are constructed by the public and the legislated or regulated protections they are afforded. Included in this examination of feminist views will be the interrelated debate over the accepted definition of human trafficking that is incorporated into the Trafficking Protocol which, like its white slavery predecessor, continues to hinge on the issue of consent to being trafficked and the relationship between consent and prostitution.

A portion of the chapter will deal with identifying the types of human trafficking that are occurring, exploring who facilitates the crime based on a sliding scale of organized crime participation. Chapter 3 will include a contrary opinion to that of the 
more popular view presented by the media which holds that human trafficking is predominantly being conducted by hierarchal organized crime groups like the 'mafia'. Instead, this chapter will suggest that human trafficking is most often orchestrated by local independent operators and groups loosely connected on a global scale (Icduygu and Tokas 2002: 30).

Fundamental to the discussion of human trafficking will be an examination of the scope of the crime. The literature and studies that have been conducted to date have widely diverging assessments of the extent of human trafficking. Frequently, in order to lend legitimacy to their views, many articles, papers and studies claim large numbers of people being trafficked, often quoting statistics from other articles that have yet to be validated. Closer scrutiny of these claims challenge these numbers and undermine the credibility of the message being conveyed. In essence, instead of furthering the cause of anti-trafficking, they negatively impact its voice by causing its credibility to be questioned.

Part of the difficulty in determining the extent of human trafficking relates to the confusion that exists over the two major components of illegal migration, human trafficking versus human smuggling. Chapter 3 will examine this issue from the perspective that the two terms are not synonymous but rather, two distinct crimes. Yet, many people use the terms interchangeably and collectively, especially from a statistical point of view, such that the actual level of human trafficking is obscured. 
Chapters 2 and 3 concentrate on the offence of human trafficking, its history, and associated issues. Chapter 4 provides a broader understanding of the international reaction to human trafficking by placing it in the context of globalization and global migration. It will examine the moral panic that permeates the illegal migration discourse, especially in terms of the growing belief that globalization is a challenge to national identity and that unrestricted global migration undermines a country's sovereignty and culture. The chapter will show that this moral panic, in relation to globalization and global migration, underpins the justification for increased restrictions on immigration. Chapter 4 will touch upon the view that national identity and sovereignty are imperative for survival in a global world, with national identity being tied to a country's ability to regulate who can enter and leave its borders.

Chapter 4 will also put forward the view that increased immigration restrictions have been shown to have little impact on the degree of global migration which has been viewed as fairly stable for the past two decades, with the largest component of global migration, refugee migration, being related to a world crises such as war (Zolberg 2001: 1-15). The chapter will suggest that increased immigration restrictions have only resulted in creating new categories of criminals which previously did not exist. In particular, those people who no longer have legitimate access to migration are often left with no alternative but to seek another avenue, albeit illegal, to achieve their objectives. 
Chapter 4 examines the constructs of the illegal migrant and how these constructs have been changing as a result of the fear of globalization and global terrorism. It explores how these new constructs impact on refugee and trafficking victims because both these groups have become incorporated into the larger construct of the illegal migrant who is subject to public suspicion and hostility based on the growing fear of globalization. Included in the chapter is a recognition that the victims of human trafficking are not necessarily migrants by choice and thus, like refugees who must flee to safety, the victims of human trafficking are in need of protection.

Chapter 5 brings together the discussion that has taken place in the preceding chapters by introducing the reader to the debates regarding the protection of trafficking victims as a result of the 2000 Trafficking Protocol. It will set out the particular provisions embodied in the Trafficking Protocol and explore interpretations of those provisions. This will include identifying the perceived gaps or deficiencies based on the specific wording contained in Articles 6 through 8 in the Protocol.

Once the evaluation of the specific Protocol provisions has been provided, the chapter continues with an assessment by various NGOs as to the general application of the protection provisions by the international community. This will entail various evaluations, critiques and recommendations by a number of NGOs concerning the application of the Protocol's provisions by the signatories of the Convention. The objective is to set out the main areas that NGOs have identified as in need of 
improvement in order to provide the appropriate protection for trafficking victims.

The intent of Chapter 5 is to clearly establish what the Protocol provisions entail, what the international community is obligated to provide as a result of those provisions, and what are the major deficiencies within the Protocol that have been identified to date. This will provide the platform upon which to assess Canada's response to the protection obligations.

Having established an understanding of human trafficking and the Trafficking Protocol's victim protection provisions in the preceding chapters, Chapter 6 contains the evaluation of Canada's efforts to protect trafficking victims as required by Articles 6 through 8 of the Protocol. The chapter begins by outlining Canada's initiatives to combat and prevent human trafficking. It examines the roles and responsibilities of selected federal government departments, both individually and collectively, regarding anti-trafficking enforcement and victim protection strategies.

The chapter proceeds with an evaluation of Canada's new immigration legislation, the Immigration and Refugee Protection Act (IRPA - 2002), in terms of victim protection. It includes a review of Bill C-49, recently tabled in Parliament, which is designed to create the domestic offence of human trafficking through amendments to the Criminal Code of Canada (CCC). The evaluation concludes that neither of these two legislative initiatives contain any protection provisions for trafficking victims in support 
of the Trafficking Protocol.

The chapter continues with an evaluation of the current immigration process used to handle victims of trafficking - the Canadian Refugee System (CRS). Through a case analysis of available immigration hearings, the issue of how victims of trafficking have been processed and what protection they have been afforded by the CRS will be explored.

Chapter 6 revisits the two major victim protection criticisms provided by NGOs that were developed in Chapter 5: potential re-victimization of trafficking victims through prosecution and deportation; and the debates over temporary versus permanent resident status for victims. It examines the views of NGOs on these two issues from a Canadian context, incorporating the opinions of two research survey respondents associated with domestic NGOs.

Chapter 6 examines the results of the research surveys conducted with selected government departments that have primary responsibility to protect the victims of trafficking - Citizenship and Immigration Canada (CIC), the Royal Canadian Mounted Police (RCMP) and the Department of Justice (DOJ). Although the survey responses reveal that no new initiatives have been undertaken by the federal government in support of protecting trafficking victims, the surveys do reflect a commitment by these government agencies to secure the safety and well being of trafficking victims while 
acknowledging that there is room for improvement within the victim protection policies, processes, and procedures of the government.

The chapter concludes with an overall assessment of Canada's efforts to protect trafficking victims. It addresses the issues of what we have done right, what we have done wrong, and what needs to be changed.

Chapter 7 examines the trafficking victim protection approaches adopted by two other countries, the United States (US) and the United Kingdom (UK). The chapter is not intended to represent an exhaustive study of these two approaches. Rather, major aspects of these approaches are being highlighted in order to underscore and support specific conclusions that are made relative to Canada's response to victim protection as noted in Chapter 6.

In particular, the chapter explores the interrelationship between the provision of trafficking victim protection services and the victim's cooperation with law enforcement which is a criteria for trafficking victims in both the US and UK approaches. The chapter also highlights the value of implementing an evaluation process of victim protection initiatives which is lacking in Canada's approach.

The chapter begins with exploring the US approach which pursued a legislated trafficking victim protection response in line with the direction encouraged by 
NGOs as identified in Chapter 5. The US legislation, Victims of Trafficking and Violence Protection Act of 2000 (TVPA), identified protection entitlements, the government departments responsible for the delivery of protection services, the separate immigration process to be used for trafficking victims, and the requirement for an annual assessment of the US government's progress in meeting the protection needs of trafficking victims.

The chapter continues with a brief examination of Britain's victim protection response which is reflected by the pilot project known as the 'Poppy Project'. It outlines the main elements of this project which was designed to provide protection provisions directly to a limited group of trafficking victims. Contrary to the US and Canada, Britain's approach to victim protection is based upon a narrow definition of trafficking victims.

The final chapter returns to the central issue of this study - is Canada in compliance with Articles 6 through 8 in the 2000 Trafficking Protocol? Chapter 8 briefly touches upon the salient points raised in the preceding chapters and interprets their significance in terms of Canada's compliance. The chapter restates the main findings of Chapter 6, comments on Canada's current approach, and suggests measures that should be adopted to improve the victim protection process in Canada. 


\section{Chapter 2}

\section{White Slavery}

The white slavery images that were constructed at the beginning of the $20^{\text {th }}$ Century were designed to generate immediate fear and outrage among the general population in western European and North American countries. Images of white female virgins, abducted and held against their will through the use or the threat of violence, for the deviant sexual pleasures of unscrupulous men, were the most prolific (Levine 2002:135). These accounts were contrived to inflame public passions in order to garner support for legislation, domestic and international, ostensibly to protect the vulnerable of society. It was as a result of these colourful public accounts of victimization that most of the international trafficking agreements during the first decades of the century were successfully created.

\section{$\underline{\text { Moral Panic }}$}

It is evident that the white slavery panic was predicated upon the notion and fear that white women were being abducted off the streets by criminal organizations, transported around the world through the use of violence or threats, and forced into a life of prostitution (Valverde 1991: 89-99). It is also apparent that numerous prosecutions took place using domestic legislation in western nations such as the United States (US) in furtherance of the white slavery international agreements during the first few decades of the $20^{\text {th }}$ Century. For example, a study of white slavery prosecutions in Chicago between 1910 and 1913 under the White Slave Traffic Act, more commonly known as the Mann 
Act, revealed little evidence of organized crime's involvement in alleged white slavery offences nor any confirmation of abductions of white females against their will who were subsequently transported across borders and forced into a life of prostitution (Langum 1994: 35; Valverde 1991: 95). Rather, the evidence suggests that the majority of women involved were prostitutes who agreed to their movement between cities or across national frontiers in pursuit of the enterprise of prostitution (Langum 1994: 35-37). Thus, although much effort was made to create and enforce white slavery related legislation, there is virtually no evidence to support the concept that white slavery, as presented to the public, actually existed.

Mariana Valverde contends that the phenomenon of white slavery in Canada was the product of a complex moral panic reflecting the arrangements in play between a number of interrelated social issues rather than simply being the result of a unidimensional problem (Valverde 1991: 89-90). "Such unidimensional approaches do not help us to understand the complex ways in which a moral issue that appears to be singular serves as the site for social debate on a number of important and interrelated issues" ( Valverde 1991: 90). According to Valverde, the underlying fears of the white slavery panic were fostered by the concerns that the Protestant middle class held with respect to being able to manage the significant changes in social, economic, and cultural relations that were occurring at the beginning of the $20^{\text {th }}$ Century, and their concern of being able to ensure their continued economic superiority and cultural hegemony (Valverde1991: 103). 
David Langum echoes Valverde's position by expressing the view that the overarching elements that provided the foundation and the requisite social tension for the white slavery panic in the US are categorized as fears concerning immigration, urbanization, and the changing role and status of women in society (Langum 1994: 1517). Langum indicates that there was significant social tension over the migration of young girls from rural areas to the city. Industrialization and urbanization held out the potential of increased economic independence for women within a male dominated society and thus, migration, domestically and internationally, created significant social tension as it challenged the existing gender relations (Langum1994: 16-17).

Global migration at the end of the $19^{\text {th }}$ Century and beginning of the $20^{\text {th }}$ Century, in response to a number of contributing factors including industrialization, represented the first modern day upheaval and movement of people on a global scale (Baldwin \& Martin 1999: 3-58). It was this large scale global movement that manifested a fear of being overwhelmed and consumed by strange cultures within many western nations and led to those nations creating restrictive immigration policies as a means of securing and protecting their lifestyles, cultures and national identities (Baldwin \& Martin 1999: 3-58). The ruling interest groups in western nations were afraid of the new diversity that large scale immigration reflected. These fears not only resulted in increased restrictive immigration legislation but within the legislation were specific provisions that targeted individual characteristics of particular cultures as a means of preventing their continued access to a country (Rolph 1992: 4). 
There have been successive waves of global migration since the period of industrialization. In large part, these waves were precipitated by two World Wars which saw the redefining of national boundaries, the collapse of historic empires, and the emergence of new global alliances. And, as each new global immigration era dawned, nations moved forward with increased migration restrictions, including anti-white slave legislation, as a means of protecting their culture.

The white slavery panic, and the resultant international agreements ${ }^{2}$ that started and evolved during the $20^{\text {th }}$ Century, were a carefully orchestrated reaction to this large influx of immigrants. In reality, there was virtually no likelihood of preventing white slavery as there is no evidence to support that there was any substantive human trade of this type taking place (Levine 2002: 135; Langum 1994: 35, 75). Rather, the white slavery panic and the accompanying legislation permitted the governing bodies within western nations to impose their morality upon the new citizens of these western nations.

The International Convention for the Suppression of White Slave Traffic (May $\left.4^{\text {th }}, 1910\right)$ outlined the principal criteria necessary for an offence of white slavery.

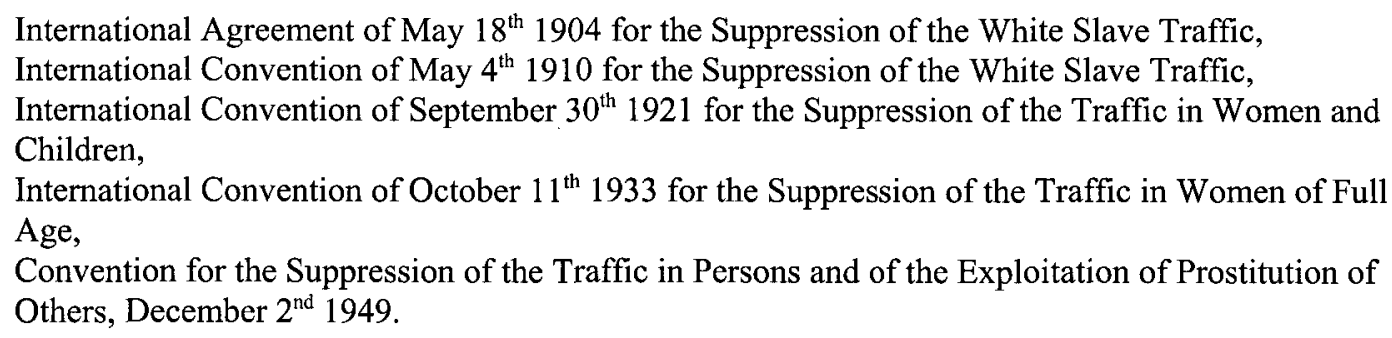
International Convention of May $4^{\text {th }} 1910$ for the Suppression of the White Slave Traffic, International Convention of September $30^{\text {th }} 1921$ for the Suppression of the Traffic in Women and Children, International Convention of October $11^{\text {th }} 1933$ for the Suppression of the Traffic in Women of Full Age, Convention for the Suppression of the Traffic in Persons and of the Exploitation of Prostitution of Others, December $2^{\text {nd }} 1949$. 
Articles 1 and 2 stipulated that an offence of white slavery must involve an adult woman or an under age female who is induced or forced into an immoral purpose in order to gratify the passions of another person (Dept. Of External Affairs 2004: 7). It rested with each country to determine what is an immoral purpose which gave the countries wide latitude to define their nations' norms of morality. What is most interesting about this international agreement, later clarified with an annexed protocol, is that compulsion or deception is not necessary in order to commit the offence. This and subsequent agreements, could and did allow western countries wide interpretation of what an immoral purpose was such that it could be used to suppress prostitution or any other perceived challenge to a country's moral values. In some cases, although domestic legislation appeared focused on white slavery, it was also used to subjugate elements of society that were not in line with the prevailing dominant moral viewpoint. ${ }^{3}$

Prostitution became the rallying point for all of these social tensions infused by global migration as it represented the 'problem' for all the ills of society, especially the growing concern over the changing role of women in society. Prostitution as 'the' problem, 'the social evil', was quite an attractive concept to moral reformers, religious organizations and Canadian feminist groups such as the Women's Christian Temperance Movement, the National Council of Women and the Young Women's Christian Association as it permitted the varying interest groups which were not order to suppress prostitution and any challenges to the moral values of a country is The Mann Act of 1910 in the United States which was used in the past to persecute selected individuals (Langum 1994: 3). 
necessarily in philosophical agreement in many areas to have one point of common purpose (Valverde 1991: 77-103). Defined as a form of slavery, prostitution provided the unifying ideological platform from which the framework for the rise of the white slavery panic could be constructed (de Vries 2005: 43).

Prostitution has been and is the critical reference point for the majority of the discussions that have taken place regarding white slavery and trafficking in women (Doezema 2005: 80). As a consequence, it is one of the influencing factors that ties together the historical relationship between these two concepts. Today, prostitution remains a central focus of many of the trafficking debates. In the past, prostitution afforded moral reform groups the platform from which to voice their perception of morality to society. "Indeed, if prostitution had not existed, the social purity movement would have had to invent it" (Valverde 1991: 79). Society's attention was focused by reformers on the world of prostitution which was often played out in the media by descriptive accounts of prosecutions.

In The Canadian Magistracy and the Anti-White Slavery Campaign 19001920, John McLaren analyzed the treatment of prostitutes by the Canadian courts during the first two decades of the $20^{\text {th }}$ Century in response to the white slavery panic. He noted that a number of changes occurred to the provisions of the Criminal Code of 1892 in support of the moral reform objectives within the anti-white slavery campaign. In particular, changes that took place within the procuring provisions in prostitution 
offences but which, he concludes, were designed solely to benefit virtuous womanhood (McLaren 1988: 331). ${ }^{4}$

McLaren's article from the book, Canadian Perspectives on Law \& Society: Issues in Legal History, touched upon the offence of 'keeping a common bawdy house' and the move to retain this offence as a strictly indictable offence instead of a dual procedure offence which would have normally been proceeded by way of summary conviction. By expanding this definition of a common bawdy house in 1907 to include the individual prostitute who worked out of her residence, the court could support moral reformers under the guise of responding to the anti-white slavery campaign (McLaren1988: 331). Rather than targeting criminal organizations which ran brothels and purportedly were the organizers of white slavery, moral reformers were successful in having the courts target the individual prostitute as she represented the more visible threat to their religious and moral views. Ultimately, the amendments to the law represented increased regulation of morality and greater penalties for those who transgressed the law. The only person given the court's protection would be the 'innocent' victim while in contrast, the 'fallen woman' would be dealt with harshly while her male customer received minimal punishment (McLaren1988: 331). common bawdy house such that it included individual prostitutes working out of a residence (McLaren 1988: 331 \& 350).

Criminal Code Amendment Act, S.C. 1913, c.13, s.9. \& Criminal Code Amendment Act, S.C. 1915 , c 12, ss. 5,7. -theoretically expanded protection for women relative to the procuring provisions by keeping the penalty for those living on the avails of prostitution (keeping a common bawdy house)as strictly indictable but in reality, used to increase penalties to individual prostitutes based on previous amendment (McLaren 1988: 331 \& 350). 
The magistrates, in effect, furthered the victimization of the prostitute as an attempt to control morality at a time when cultural standards were seen to be shifting, rather than advocating for the prostitute's protection. The Canadian magistrates' application of a double standard of treatment between males and females during the judicial process also reflected the social dynamics in play during the early $20^{\text {th }}$ Century (McLaren1988: 329-331).

In a related study of white slavery in Holland, An Image of Sexual Danger: The Dutch fight against the 'White Slave Trade' in early Twentieth century, Petra de Vries drew similar conclusions to those of McLaren. She wrote that these "new legal measures, together with other policies on trafficking ... made an increasing degree of control over some aspects of women's lives possible, while creating indifference to other aspects" (de Vries 2005:54). Moral reformers needed the picture of female helplessness in order to justify and reinforce their collective positions on morality which refused to believe that women could consent to prostitution

\section{$\underline{\text { Moral Reform }}$}

The moral reformers, temperance and purity groups, prison reformers, and suffragists that emerged at the end of the $19^{\text {th }}$ Century and into the beginning of the $20^{\text {th }}$ Century in North America and Europe, to varying degrees, all had a common concern over prostitution, with feminist groups such as the Women's Christian Temperance Union in the US being an example of a vocal faction in the struggle over prostitution 
policy (Hobson 1987: 5, 151). The collective understanding of moral reformers with respect to the plight of female prostitutes was shaped by the then existing moral middle class values which evolved into a high moral standard that moral reformers applied to both sexes. Due to their middle class consciousness, these reform groups were often "unable to grasp the motivations, moral codes, and survival strategies of poor women that prostitution could appear as a viable alternative to low wages and lack of employment options" (Hobson 1987: 5). Thus, their efforts were shaped by this predisposition to view the world in terms of the values of the Protestant middle class.

Feminist reform groups in Canada such as the Women's Christian Temperance Movement, the National Council of Women and the Young Women's Christian Association used the white slavery panic and the associated issue of prostitution as a means of advancing their own agenda to increase the recognition of women's political and social rights rather than understanding the root causes of prostitution (McLaren 1988: 329-330). Many feminist reformers viewed the participants in prostitution as being the product of moral and possibly mental weaknesses (McLaren1988: 330). This is not to say that all feminist activities were strictly moral crusades as there were other diverse groups who had different political and social ideologies but the moral reformers, who were one of the largest components within the emerging feminist movement, were the most successful in garnering public attention (Hobson 1987: 148; Irwin 1996:3). 
Contrary to the moral reformers, the socialist movement "echoed much of the existing publicity about white slavery as proof of the immorality and corruption of capitalism" (Newton 1989: 227). To them, white slavery was just another example of how the elite of society dehumanized the working class under the capitalist system (Newton1989: 228). Prostitution represented how capitalists took advantage of low wage earners, forcing women to seek this type of employment to feed themselves, and male workers to use the services of prostitutes because they did not earn enough to get married (Newton 1989: 223-224).

Women socialists did not always agree with the viewpoint of their male counterparts. Some feminists such as Mary Cotton Wisdom of the US, advocated that prostitution was not only a reflection of the traditional political capitalism versus socialism issue but that in its complexity were equally important issues of the economic exploitation of women by men and the problem of unfettered male sexual domination and oppression of women (Newton1989: 228-230). As a consequence, female socialists lobbied their male counterparts to speak out on these issues and to seek a resolution, other than just economic, to the problem of prostitution. Despite their efforts, women were only a small minority within the left movement and thus, the male dominated leadership refused to accept this challenge to their views as it would require them to reflect upon their own behaviour in relation to women and repudiate the sexual oppression of women by men, a viewpoint which they did not share with their feminist colleagues (Newton1989: 231). 
The construct of a prostitute prior to the white slavery panic, that of a fallen woman or a sexual deviant, was not one that garnered much public sympathy or support for the anti-prostitution movement of the day (Doezma 1999: 6). The white slavery panic, however, represented an opportunity for moral reformers, and particularly feminist moral reformers, to reshape the construct of the prostitute such that they could be seen as victims in need of saving. The white slavery discourse eliminated the issues of voluntary prostitution and/or deviant behaviour within the anti-prostitution debate and instead, constructed all prostitutes as innocent victims who had been victimized by unscrupulous traffickers (Doezema1999:7). As a consequence of this shift in approach by the feminist moral reformers, anti-prostitution was aggressively pursued within the boundaries of the white slavery discourse due to assured public support for the victim who was in dire need of rescue.

Although there were various feminist viewpoints on the issue of white slavery, sometimes conflicting, one major thrust of the feminist movement during the early $20^{\text {th }}$ Century was to use the moral cause of white slavery as a way of advancing their political emancipation. By becoming a voice against white slavery, feminist groups such as the National Council of Women (NCW) in Canada, enhanced their presence and political influence within society (Valverde 1991: 93).

Like the socialist movement, however, there were elements present within moral reform organizations that took the position that economic exploitation of women 
by men was at the root of women's vulnerability. Further, there was also an awareness, albeit small, that most of the potential victims of white slavery were not white. "But they did not openly and consistently challenge the racist undertones of the moral panic. To do so would have necessitated revising their views about men of colour" (Valverde1991: 95). Thus, beyond the issue of female exploitation, racism and discrimination are recognized by some moral reformers as a component of this elaborate charade but not issues that they were willing to undertake at the time.

The campaign to combat white slavery that the moral reformers and other like interest groups embarked upon can best be described as having been founded upon a mythical person. And, this fabricated victim had the role of capturing the imagination of the public, their sympathies, and their outrage, in order to create a public panic such that the government would be encouraged to act in the strongest terms to protect these innocent victims. The result was public acquiescence to greater government regulation over their own morality. "The myths around 'white slavery' were grounded in the perceived need to regulate female sexuality under the guise of protecting women. They were indicative of deeper fears and uncertainties concerning national identity, women's increasing desire for autonomy, foreigners, immigrants and colonial peoples" (Doezema 1999: 3).

\section{The White Slavery Victim}

Clifford Roe's book, Panders and Their White Slaves, published in New 
York in 1910, which provided his first hand account of a white slavery case, is a typical representation of the then existing literature that captures the essence of the narrative construct of white slavery victims. Appealing to the readers' passions, Roe described the victim as she enters court seeking justice against her abusers: "A thin, frail young woman, aided by a physician, walked slowly into the court room and took her place on the witness stand. Her face seemed care worn, and her languid expression suggested that she had passed through some terrible crisis" (Roe 1910: 11). Roe went on to carefully articulate how slave traffickers took advantage of this innocent woman, forcing her into the sex trade, and only through this type of narrative can the secrecy of their actions be revealed and the public encouraged to act.

Critical to Roe's account is that the victim was totally innocent of the events that transpired to enslave her. She had met a young gentleman of apparent reputable character and joined him for a glass of lemonade which turned out to be drugged. When she awoke, she found herself imprisoned in a brothel and forced into prostitution. Only through her own guile was she able to contact her parents after many days who in turn, effected her rescue. Roe was a former Assistant State's Attorney working out of Chicago and this book was his impassioned plea to combat white slavery. He declared in the book's preface that this was an actual case that came before the courts. However, it is impossible to attest to the validity of the account as Roe, through his own admission in the preface, changed the names of the brothels mentioned so as not to advertise them and changed the names of the persons involved for what he deemed are 
'obvious reasons'.

According to Petra de Vries, the image of the white slavery victim was extremely powerful and could not include the concept of voluntary prostitution (de Vries 2005: 45). The victim could not be held responsible for her situation if the white slavery campaign was to succeed. If she could not be a victim in the purest sense then other methods had to be employed to nurture sympathy for the victim. A prostitute constituted an immoral person and hence not a victim. As a consequence, prostitutes became cast as feeble-minded women, irresponsible and lacking the ability of normalcy such that traffickers could take advantage of these vulnerable persons (de Vries 2005: 45).

To the Dutch abolitionists in the late $19^{\text {th }}$ and early $20^{\text {th }}$ Centuries, prostitution was a local immoral issue. "Prostitutes figured as victims with no agency"(de Vries 2005: 44-45), while the female victim involved in white slavery was enveloped in a shroud of innocence. Most importantly, they were 'white', a constructed identity based on a Eurocentric world view that could easily attract public support (de Vries 2005: 46). It was easy for the public to have an affinity with the victim of white slavery as their depiction as pure white vulnerable innocent women struck a sympathetic cord.

The victims of white slavery had their innocence reaffirmed on a constant basis by having colourful accounts of their misery published such as the one provided by 
Roe which stressed their youth and virginity; their whiteness; and most importantly, that the poor unfortunate woman was an unwilling prostitute. Innocence versus evil simplified the reality of prostitution and female migration into simple terms of victim and villain (Doezema 1999: 7). For Canada, the image often used in the public domain was that of an innocent girl from a farm who was tempted to move to a large urban centre in the US, such as Chicago, in the hopes of securing reputable and high paying work but rather, found themselves trapped in a brothel in need of rescue (Valverde 1991: 92).

Reformers reinforced this conceptual framework for white slavery victims at every opportunity. The public came to view these victims not as 'fallen women' of their own agency but as victims of malignant external forces in need of pity and rescue (Irwin 1996:20). This basic image of the white slave victim transcended national boundaries; was promoted on the international stage; and centred the debates on antiwhite slavery legislation. It also created a sense of urgency to act in order to protect these most deserving of people.

\section{The Transition from White Slavery to Human Trafficking}

The first few decades of the $20^{\text {th }}$ Century saw the rhetoric about white slavery and the resultant need to act frequently published in North America and Europe. While little action was taken to protect the mythical victims of white slavery, a number of steps were implemented to suppress prostitution. And, as noted above, the suppression of prostitution was approached from the perspective of applying a double standard to ensure 
that the female prostitute became the focus of the suppression of prostitution and not the male consumer of the service.

The two World Wars shifted public attention away from white slavery, but did not totally erase the issue. There was the creation of the Convention for the Suppression of the Traffic in Persons and of the Exploitation of Prostitution of Others which was signed in December 1949 but it did not receive much international support, with fewer than seventy-one signatory countries (Sullivan 2003: 69). Between 1949 and 2000 , no major undertaking was tabled in the international arena with respect to white slavery, yet, the various discourses on trafficking continued.

As the moral panic over white slavery dissipated in the succeeding decades following the 1949 UN Convention, various changes began to take place within the white slavery debate. One major change that occurred during these years was that white slavery shed its visible racial delineation and evolved into the broader all encompassing issue of 'human trafficking'. Trafficking victims were no longer only white women but were from both genders regardless of ethnicity, with an emphasis on minority women and children. But, the focus remained on the sex trade and the exploitation of women, leading in turn, to the emergence of a renewed moral panic.

Although there were limited public claims of trafficking, periodic episodes did capture the public's attention. In 1965, for example, a Spanish professor alerted 
authorities in Britain and France to a large prostitution trafficking ring in both those countries. This received extensive coverage in the British newspapers of the day (Altink 1995: 16). And, Max Kassel, dubbed the Red Max, was investigated for taking young girls to Paris from England and forcing them into prostitution. Later, it was purported that his agents would sell these girls to brothels in other countries (Altink 1995: 16). By the 1980 's and early 1990 's, more accounts of human trafficking began to surface in the media and once again, attention began turning towards prostitution and its correlation to what was becoming known as human trafficking (Sullivan 2003:69).

The $20^{\text {th }}$ Century provided the maturing environment for the issue of human trafficking. It began with the myth of white slavery, imbedded within a moral panic that reflected the evolving, and frequently competing, social tensions of the day. And, although it has evolved to the point where the victim is no longer an innocent white female virgin through the global inclusion of who is being victimized, the human trafficking discourses of today continue to use the verbiage of white slavery and remain focused on prostitution (Doezema 1999: 10-18). The danger of this approach is that people will argue there is a correlation between the myth of white slavery and the current debate involving human trafficking. In other words, is the advancement of human trafficking simply a continuation of the white slavery myth in order to achieve a greater regulation of morality?

The answer is not simple. There are many sensational, unverifiable 
accounts, being published today similar in context to that of Clifford Roe's eloquent account of a mythical white slavery victim rescued from a brothel which fuels the debate on this issue (Doezema1999: 10-18). However, in rebuttal, there are also, albeit limited, documented accounts of verifiable human trafficking victims as per the definition within the Trafficking Protocol. ${ }^{5}$ Yet, there still remains quite divergent and residual views on the issue of morality and the related issue of prostitution which precipitated the white slavery panic and continues to be a source of debate within the human trafficking discourse.

Examples of documented instances of human trafficking:

US prosecution of Kil Soo Lee, owner of a factory in American Samoa, for human trafficking 2003. Largest trafficking case prosecuted in the US which involved slave labour in a factory using illegal immigrants through violence and threats of violence (Ashcroft 2004: 1-4; Wong 2003: 1-7). Report of Amy Richard which contains a summary of eight major trafficking prosecutions in the US between 1995 and 1998 involving varying degrees of deception, force, confinement and human rights abuses (Richard 1999: 47-50).

UK Home Office Report (2000) detailing the extent of and responses to trafficking in women in the UK (Kelly \& Regan 2000: 1-50).

R. v. Chen, [2001] B.C.J. No. 2983, 2001 BCSC 1865. \& ‥ v. Li, [2001] B.C.J. No. 748, 2001 BCSC 458 - Canadian human smuggling prosecutions with references to human trafficking components in the court decision. The offence of trafficking had yet to be created in Canada. 


\section{Chapter 3}

\section{Human Trafficking}

Is today's human trafficking panic simply an extension or has overtones of the white slavery panic? Is it a further attempt to regulate morality on a global scale while quietly pursuing restrictive immigration policies? Contrary to the white slavery myth of the past, there is no doubt that instances of human trafficking as defined in the 2000 UN Convention have taken place. There are victims who have been forced, coerced, threatened, abducted or deceived into being trafficked. Their human rights have been violated, and they are in need of protection. But, although the human trafficking panic has legitimacy, is it also a vehicle through which interest groups are attempting to impose their view of morality based on the ongoing social tensions related to global migration?

This chapter will attempt to answer these questions by exploring the transition of the moral panic of white slavery into its modern counterpart, human trafficking. It will include an examination of the trafficking discourse in terms of the ongoing debate related to prostitution. It will explore how conflicting constructs of the victim, primarily based on contrasting views of morality, have shaped the human trafficking narratives and the associated human trafficking panic. Intrinsic to the foregoing treatment will be the related debate over the definition of human trafficking which was incorporated into the Trafficking Protocol of the 2000 UN Convention. And finally, this chapter will provide a brief analysis of the inherent problems in determining 
the scope of human trafficking and the role that organized crime plays in its facilitation.

\section{The Trafficking Panic}

Jo Doezema believes that "trafficking in women is the re-telling of the myth of white slavery in a modern form, a new 'moral panic' arising in the context of 'boundary crises' involving fears of loss of community identity” (Doezema 1999: 5). She takes the position in her paper, Loose Women or Lost Women?, that the push for efforts to combat human trafficking is a reaction to nations facing an identity crisis due to global migration and globalization. For her, the myth of white slavery, fulfilled by the innocent white female victim narrative, and the ensuing moral panic to protect her virtues, continues to be perpetuated because of an unwillingness of countries to accept the rights of sex industry workers (Doezema 1999: 1-35).

From Doezema's perspective, the continuation of the white slavery myth is premised on a continued emphasis of morality that follows the evolution of white slavery into human trafficking. Voluntary prostitution could not be accepted in the white slavery discourse and it is her viewpoint that opposing feminist organizations such as the International Human Rights Network (IHRN) are trying to block its acceptance today (Doezema 2005: 67). The white slavery myth is perpetuated within the human trafficking discourses by being tied to a crusade against prostitution, couched in religious and moral overtones, by feminist organizations (Doezema 2005: 72). “Thus, while incidents reported in accounts of 'trafficking' may be 'true', they may be at the same 
time mythical, to the extent that the events are (re)constructed in such a way as to conform to the framework established by the myth" (Doezema 1999: 5). The end result is a recognition that human trafficking does exist but it is presented in such a fashion as to manipulate western public sentiment in order to achieve underlying objectives. It is these objectives, such as anti-immigration, that are at the root of much of today's human trafficking discourses.

Wendy Chapkis postulates that the common denominator for human trafficking discourses are the misleading claims concerning the scope of the trafficking problem by various interest groups such as the US National Organization for Women (NOW) which are designed to promote a strong response from the public (Chapkis 2003: 925-926). In Chapkis' view, in spite of the fact that most published accounts of human trafficking reflect diverse definitions of trafficking which in turn have led to sliding scales of victimization dependent upon which definition is accepted, public sentiment in Europe and North America is focused against the traffickers orchestrating the sex trade (Chapkis 2003: 926). The result is an obscuring of the larger issue of human trafficking as it becomes equated to simply combating sex traffickers. Chapkis holds that this focus on sex traffickers results in linking the responsibility for all migrant abuse to the traffickers and conceals the role that exploitative employment practices, restrictive immigration legislation and policy, and the economic disparity between the have and have-not nations may play in the human trafficking narrative (Chapkis 2003: 925-928). 
Feminist, Kathleen Barry, opposes the feminist viewpoints of Doezema and Chapkis in as much as she takes the position that street prostitution and trafficking are synonymous crimes, with women as unwilling participants (Doezema 2005: 70, 7374). According to Doezema, Barry, in her 1995 book, The Prostitution of Sexuality: The Global Exploitation of Women, expressed the view that prostitutes are innocent victims who only became prostitutes as a result of their forced exploitation by men in a male dominated society (Doezema 2005: 70, 73-74). In an earlier book in 1979, Female Sexual Slavery, which refocused western public attention on the growing issue of human trafficking, Barry stated that every effort should be focused on saving these victims from the sex trade and that should be the predominant objective of any trafficking enforcement strategy (Barry 1979: 3-11).

Extensive media attention, facilitated by today's technology (T.V., Internet, Electronic news), has expedited the publishing and the sharing of stories that recount trafficking violations which advance the human trafficking panic by inundating the public with seemingly endless accounts of sex trafficking offences. As an example, during a 31 day period, there were 40 news releases from around the world dealing with different stories that related to human trafficking. ${ }^{6}$ The focus of many of these media stories dealt with the trafficking of women and children. Though there are news releases

6 Methodology: an automated 'Google Alert' search on the Internet for 'United Nations - Human trafficking' during the period of May $1^{\text {st }}$ to 31 st, 2005, initially resulted in 50 media releases contained in various newspapers from around the globe. But, after duplicate stories were eliminated, 40 separate news releases regarding 40 different human trafficking stories were published. 
depicting men being trafficked under horrific conditions, the generally held belief by the public that continues to emerge in the face of this reality is that it is mainly women and children who are being trafficked, and the main destination of their trafficking is the sex trade (Bandyopadhyay et al 2004: 104).

The following represent the major types of human trafficking that are occurring beyond female victims who are forced into prostitution: men, women and children who have been exploited for the purpose of providing slave labour in 'sweat shops', factories, farms and restaurants; women providing slave labour and/or forced sex in domestic servitude situations; and women being violated through arranged marriages (Aronowitz 2001: 171-172). As noted in the introduction of this paper, although there exists different types of human trafficking, for the purposes of this study, it has been confined to examining the issue of women being trafficked into the sex trade as that is the predominant view being promoted in published accounts of trafficking in western nations.

As a consequence of this preoccupation with sex trade trafficking stories, and the continued unreliability of claims pertaining to the scope of the trafficking problem, the public, government and NGOs run the risk of being panicked into getting ahead of the theoretical understanding of human trafficking and the factual evidence of human trafficking (Salt 2000:32). This may result in erroneous perceptions of human trafficking by governments and NGOs which may negatively impact policies that they 
implement to combat a trafficking problem which does not reflect reality, and may lead to unintended side effects (Salt 2000:32).

Like the white slavery panic of the past, there is a belief that today's panic about human trafficking results in the hidden objective of greater immigration control through the creation of domestic immigration legislation in support of the $2000 \mathrm{UN}$ Convention. Although created ostensibly to combat and prevent human trafficking, it is contended that portions of new domestic immigration legislation achieve the underlying objective of preserving a nation's existing culture and identity through increased immigration regulation (Doezema 1999: 20-27; Hollifield 2000: 151-162).

\section{The Prostitution Debate}

One hundred years later, many of the complex issues that permeated the prostitution debates during the white slavery era are still seeking resolution within the discourses to define the victims of human trafficking. As mentioned, past moral reformers adopted the one-sided view of morality expressed by the dominant Protestant middle class as it provided a way of achieving their objectives. Today, there exists two distinct and opposing viewpoints within the trafficking discourses regarding the issue of prostitution and its relationship to victims of human trafficking. It is recognized that there can be multiple views on this issue but this paper will focus on the two views that are the most dominant within the prostitution debate and the trafficking discourses. 
One view is that prostitution, by its very nature, is an exploitation of women by a male organized sex industry, a patriarchal institution, that affects all women and gender relations (O’Neill 2001: 16). Feminists such as Barry promote the concept that the only way to end trafficking is to engage various strategies to eliminate prostitution (O’Neill 2001: 15-16). This can only be accomplished by implementing action plans that suppress prostitution which leads to the decrease in the demand for prostitutes and the inherent need for trafficked women in order to fill that demand (O’Neill 2001: 16-32; Hughes 2000: 625-651).

The Coalition Against Trafficking in Women (CATW), represented by Janice Raymond before a US House of Representatives Sub-Committee on human rights, believes "that State-sponsored prostitution is a root cause of sex trafficking." (Raymond 2003: 4). Like other organizations, the CATW believes that prostitution is the exploitation of women. They argue against the view that prostitution is legitimate employment for women. In their view, "State-sponsored prostitution is a form of statesponsored sexual terrorism posing as sexual and economic freedom for women." (Raymond 2003: 4) In essence, “... the State effectively becomes another pimp, living off the earnings of women in prostitution"(Raymond 2003: 4). "There is a fundamental connection between legal recognition of prostitution industries and the increase in victims of sex trafficking" (Raymond 2003: 4). This view is also shared by the European Women's Lobby who note that the exploitation of women is integral to the sex industry, rather than accidental as some governments profess (Raymond 2001: 5). 
The other predominant view is that prostitution is an acceptable employment enterprise "and women working in the sex industry deserve the same rights and liberties as other workers, including freedom from fear, exploitation and violence in the course of their work." (O’Neill 2001: 16). The Network of Sex Work Projects (NSWP), contrary to the views promoted by the CATW, maintains that prostitution is an acceptable form of labour. The NSWP advocates on behalf of the sex trade workers in order to protect their interests with respect to their health, safety and rights (Murphy \& Ringheim 2005: 13-15). This organization rejects the CATW approach out of concern that the focus on protecting the 'innocent' trafficking victim strengthens the government's ability to justify repressive measures against prostitutes who enter or wish to remain in the sex industry (Murphy \& Ringheim 2005: 14).

In 2003, Barbara Sullivan of the University of Queensland in Australia conducted an analysis of these two main theoretical positions regarding prostitution and its relationship to the debate to define the victims of human trafficking advanced by feminists in the human trafficking discourses. She describes these two conflicting viewpoints as 'radical feminism' as reflected by the CATW and 'sex work feminism' which is ascribed to by the NSWP. Sullivan's study looked at these two positions in terms of the Trafficking Protocol and the feminist dialogue leading to its creation. Sullivan concluded that the radical feminist approach is seriously flawed as it relies on "a totalizing account of the relationship between prostitution and trafficking, sex and subjectivity. For radical feminists, trafficking and prostitution are indistinguishable; both 
are conceptualized as the 'foundation' of a global system of male violence" (Sullivan 2003: 74). In essence, for radical feminists, the victim can only be seen in one dimension. There is no room for different constructions, varying degrees of victimization, nor varying narratives concerning the prostitution discourse.

The sex work feminists, on the other hand, had the primary objective of moving the debate over trafficking and prostitution from issues of exploitation and morality to consideration of issues such as the health and safety of workers, working conditions, and power relations between employers and clients (Sullivan 2003: 70). Sullivan argues that the sex work feminists are the most appealing to the public, and the most likely to successfully advance the position of both the sex workers and the trafficking victims because it provides the prostitute and the victim with a voice (Sullivan 2003: 68).

\section{In Prostitution in Canada: The Invisible Menace or the Menace of} Invisibility (1994), Sylvia Davis and Martha Shaffer advocate for the decriminalization of prostitution. Their position on prostitution comes from a recognition that government strategies and policies to deal with prostitution will fail if prostitutes are not a visible and integrated part of the community (Davis \& Shaffer 1994: 2). In other words, the reason society has failed to this point in time to come to terms with the issues surrounding prostitution is because everything that has been undertaken has been premised on the idea of keeping the industry of prostitution invisible and thereby failing to provide prostitutes 
with a means of entering the prostitution discourses.

This view of visibility is championed by the sex worker feminists, the NSWP, who seek to reconstruct the identity of prostitutes in terms of prostitution being an acceptable, and by extension, visible means of employment in the community. Conversely, organizations such as the CATW seek to eliminate prostitution and by extension, any identity construct for the willing prostitute. These two conflicting feminist opinions represent a struggle of ideals about defining the victims of trafficking in relation to the ongoing debates over prostitution.

\section{The Trafficking Definition}

The Ad Hoc Committee on the Elaboration of a Convention against Transnational Organized Crime that was established in December of 1998 held 11 sessions in Vienna between January 1999 and October 2000. During these sessions, various representations were made by over 120 participating countries and numerous interest groups. Regarding the Trafficking Protocol itself, a considerable amount of the debate revolved around deriving an acceptable definition of trafficking. The two principal feminist groups, as reflected by the CATW and the NSWP, view trafficking from quite divergent perspectives such that reaching consensus on a definition was a significant challenge.

The CATW, European Women's Lobby (EWL) and similar NGOs wanted 
a definition that included protection for all victims of trafficking and not just those who could prove that they were forced into the sex trade. This would result in all women involved in prostitution being viewed as victims of trafficking based on the underlying belief that no woman could or would voluntarily participate in prostitution. The sex trade workers associations and related NGOs on the other hand, wanted the trafficking definition limited to trafficking being defined as forced, or the result of deception, or the coercement of victims with no reference to trafficking for prostitution or sexual exploitation (Raymond 2001: 3-4). Several drafts later and after much discussion, the following became the agreed definition incorporated into the Trafficking Protocol:

\section{Annex II, Article 3 For the purposes of this Protocol:}

“(a) "Trafficking in persons" shall mean the recruitment, transportation, transfer, harbouring or receipt of persons, by means of the threat or use of force or other forms of coercion, of abduction, of fraud, of deception, of the abuse of power or of a position of vulnerability or of the giving or receiving of payments or benefits to achieve the consent of a person having control over another person, for the purpose of exploitation. Exploitation shall include, at a minimum, the exploitation of the prostitution of others or other forms of sexual exploitation, forced labour or services, slavery or practices similar to slavery, servitude or the removal of organs;

(b) The consent of a victim of trafficking in persons to the intended exploitation set forth in subparagraph (a) of this article shall be irrelevant where any of the means set forth in subparagraph (a) have been used;

c) The recruitment, transportation, transfer, harbouring or receipt of a child

for the purpose of exploitation shall be considered "trafficking in persons" even if

this does not involve any of the means set forth in subparagraph (a) of this article;

(d) "Child" shall mean any person under eighteen years of age."

(UN Convention against Transnational Organized Crime, Annex II: Protocol to Prevent, Suppress and Punish Trafficking in Persons, Especially Women and Children, U.N.G.A. Resolution 55/25) 
The definition, following its formal acceptance, has proven to be liberally interpreted by both sides in the prostitution debate which has only served to muddy the waters. The two main conflicting feminist groups each see a victory in the definition based on their interpretation of 'trafficking'. The CATW and similar NGOs have chosen to ignore the apparent limitation imposed on the issue of 'consent' as stipulated in Article 3(b) and have interpreted the subject of consent as to being broadly applied. From their unique perspective on prostitution, the definition in the Protocol is in line with their views that all women, regardless of consent, are trafficked if destined for the sex trade or already employed in prostitution. (Munro 2005: 95-100).

The sex work feminists such as the NSWP argue that the definition clearly states that only where consent has been obtained through force, threats, fraud or coercion are prosecutions for trafficking warranted. The CATW rejects the position advocated by the sex workers and argues that if governments accept the sex worker feminist interpretation, it would have a significant negative impact on the creation of related national legislation. In particular, domestic trafficking legislation may not be designed to suppress prostitution as it would not be recognized as a form of trafficking (Raymond 2002: 497).

With little agreement between these two competing factions, there is an even greater danger and risk. Failure to reach a consensus could result in marginal legislation being enacted that would do little to assist achieving the international 
objective of combating trafficking and protecting its victims. Sullivan is concerned that this ongoing disagreement over the definition of trafficking does not bode well for the Protocol because it defuses and detracts critical energies away from the larger issue of combating this serious crime (Sullivan 2003: 82)

There is no debate over whether or not victims of trafficking are in need of protection. Regardless of the interpretation of the definition in the Trafficking Protocol, there is common agreement that those identified as victims must be freed from traffickers, the related violence, and from the fear of reprisals by traffickers (The Foundation of Women's Forum 1998: 7).

There is also unanimous agreement for groups to speak out against state action that results in the re-victimization of trafficked women if they are treated as criminals and face prosecution and subsequent deportation. NGOs such as the International Human Rights Law Group (IHRLG) object to governments who view trafficked women as another form of illegal immigration and thus, deport the victims. They encourage people to speak out against those governments who view trafficked women as violators of laws related to the sex industry and ignore the violations committed against these vulnerable persons (Jordan 2001: 1). While there are points of agreement among organizations, the difficulty still remains with defining and in turn determining, who is a victim. 


\section{The Trafficking Victim Constructs}

The constructs of a human trafficking victim are quite diverse and different from those of the white slavery victim. They incorporate many potential victim identities based on the numerous interpretations of the Trafficking Protocol. While the white slavery image rested predominantly on a solid moral panic foundation with the victim being perceived as an innocent white female, not responsible for her circumstances, the face of a human trafficking victim can cover a broad spectrum of potential identities interdependent on what definition of trafficking is accepted by such organizations as the CATW and the NSWP which will result in defining the perceived degree of victimization.

As has been demonstrated by an examination of the prevailing views regarding the definition of human trafficking, there exists the potential for a continuum of victimization based upon the accepted definition (Aronowitz 2001: 166). For the purposes of this paper, these have been grouped into four broad categories devolving from the general viewpoints expressed regarding the accepted definition of human trafficking. The first group of victims is based on the traditionally accepted moral panic construct contained within the white slavery discourse. This refers to the innocent female, abducted, coerced, threatened and or physically forced, against her will, into the sex trade. This view reflects a victim that the public can readily identify with and in turn, mobilize their support and energies in order to combat or prevent this crime (Aronowitz 2001: 166). 
The second victim category is another accepted construct by most interested organizations, and these casualties of trafficking continue to resonate a need for rescue with the public. This victim is perceived as having been completely deceived regarding an offer of legitimate employment abroad only to be forced into the sex trade upon arrival (Aronowitz 2001: 166). In both the first and second divisions, the victim is an innocent unwilling participant in the sex trade in need of rescue. Like the white slavery victim, the human trafficking victims of these first two groups are shrouded in a veil of innocence, and it is this picture that is often portrayed by the media as a means of garnering public compassion and outrage.

The remaining two victim categories move along the continuum of victimization towards including victims that could be viewed as consenting to their participation in the sex trade but finding themselves being victimized by the traffickers. The third category relates to a woman duped by half-truths. She knows she will be working in the entertainment industry as a dancer and/or stripper but finds herself forced into prostitution after arrival at her destination (Aronowitz 2001: 166). And, the final category of victimization pertains to the voluntary participant who willingly permits herself to be trafficked to another country for the purposes of prostitution but finds herself in an untenable situation due to intimidation, the control exercised by the traffickers through violence, and the unacceptable exploitation that occurs after arrival at her destination (Aronowtiz 2001: 166; Kelly and Regan 2000: 2-5). 
Today's images of human trafficking victims cannot be contained in one overall description. The potential victim constructs provided in this paper, coupled with other factors such as the level of deception used on victims and the degree of exploitation which the victim endures will further shape victim narratives exponentially. These perceptions of the victim, as noted above, are further complicated when taking the trafficker narratives into consideration - individuals in loose criminal networks or highly organized criminal groups, or some variation in between (Aronowitz 2001: 191). The end result will be that these and other factors yet to be defined will contribute to a broad spectrum of victim constructs.

Central to the discourses on victim identity, although there are quite a number of diverse factors in play, is the generally held belief by those involved in combating this affront to human rights that there exists a number of commonalities between victims. It is their position that most victims seek immigration due to poverty, discrimination (including gender discrimination), and political or economic instability within the countries of origin (Zwerver 2003: 1; Manohar 2002: 14-15; The Foundation of Women's Forum 1998: 1; Jiwani\& Brown1999: 9). As a consequence, the victim is constructed as a poor uneducated female, vulnerable at home to male exploitation, who, lacking in understanding the ways of the world, becomes the perfect victim for a trafficker.

Although the dimensions of the victim constructs have changed 
significantly over time, common features between the white slavery victim and today's human trafficking sufferer are clearly evident. Innocence, for those who have been forced into the sex trade, is one of the major concepts incorporated into the constructs that echo across the span of time. In addition, the human trafficking victim can also be projected as vulnerable, influenced by traffickers, and in need of rescue, drawing the parallel to the white slavery victim who, when lacking innocence, became feeble minded and vulnerable to unscrupulous men. In the ideal victim construct, the consistent theme resonating between the white slavery panic and today's human trafficking panic is that the victim is not responsible in any manner for her situation and thus, has no autonomy or agency.

\section{The Scope of Human Trafficking}

As difficult as it is to achieve consensus on a definition of human trafficking, determining the scope of the problem of human trafficking, given the information currently available, is virtually impossible. However, this does not seem to deter many publications, studies, and articles from speculating on the extent of trafficking on the international and domestic stage. Estimates of human trafficking occurrences range from hundreds of thousands to that of millions of persons being trafficked annually with little or no corroborative or validated statistical evidence to substantiate such estimates ${ }^{7}$. Agency (CIA), with no evidence to substantiate the claim that estimated between 700,000 and 2 million women and children were trafficked annually. (Richard 1999: 3). The US government's annual 'Trafficking in persons report' for 2003 estimated global trafficking victims between 
Most of the literature recognizes that the estimates contained in their reports and articles lack veracity as to their accuracy (Doezema 1999: 11; Vocks \& Nijboer 2000: 379; Zhoa 2003: 84). These articles claim that the nature of the crime limits their ability to determine its extent. "It is hard to know exactly how many women are involved in this particular trafficking trade annually because the trade is secretive, the women are usually silent and the traffickers are dangerous and not many agencies are able to provide an accurate count" (Zhoa 2003: 84). Although faced with an abundance of uncertainty, newspaper articles are not deterred and will not hesitate to provide estimates as to the scope of human trafficking with little or no supporting evidence. It is presumed that for the most part, these implausible estimates are provided for the 'shock' value with the objective of obtaining the reader's moral outrage and encouraging their support for more restrictive immigration policies.

It is recognized that some of the confusion regarding the extent of trafficking may relate to the confusion over the difference between human smuggling and human trafficking. People often use these terms interchangeably when referring to the scope of the human trafficking problem. As a result, the actual number of trafficking victims becomes obscured when lumped together with the participants in human smuggling.

800,000 and 900,000 annually with no validated evidence, relying on sources such as unverified newspaper accounts and NGO publications (US Government 2003: 7). This same report for 2005 estimated annual global trafficking at between 600,000 to 800,000 (US Government 2005: 2). 
For example, the 'Factbook on Global Sexual Exploitation' published by the CATW indicates that according to a 1998 study done by the then Canadian government department of the Solicitor General of Canada (now the Public Safety and Emergency Preparedness Canada - PSEPC), 8,000 to 16,000 people are being trafficked into Canada each year (Hughes et al 1999: 1). However, when examining the actual report quoted, although the portion referred to by Hughes is titled 'The Impact of Migrant Trafficking', the actual number refers to Canadian government estimates of people having been smuggled into Canada, not trafficked as the offence of trafficking did not exist at that time in Canadian law (PSEPC 1998: 13-15). It is recognized that a portion of the statistics quoted in this report probably represent victims of trafficking but what percentage consists of trafficking victims is unknown. Many authors and researchers create a similar problem when they also fail to make the distinction between the two crimes thus compounding the confusion by providing unreliable estimates of trafficking offences.

In Canada, the confusion over these two offences is further accentuated because the offence of human trafficking did not come into existence until 2002. Reports like the one prepared for the Solicitor General of Canada on organized crime in 1998 often use the terms of smuggling and trafficking interchangeably as prior to 2002 there was no legal difference. In 2002, the situation changed and in response to its commitment to the 2000 UN Convention, Canada introduced new legislation, the Immigration and Refugee Protection Act (IRPA), which included for the first time the 
specific offence of human trafficking - Part 3, Section 118 (1) of IRPA - "No person shall knowingly organize the coming into Canada of one or more persons by means of abduction, fraud, deception or use or threat of force or coercion" (Department of Justice 2004: 16). ${ }^{8}$

Human smuggling is defined in IRPA under Part 3, Section 117 - "No persons shall knowingly organize, induce, aid or abet the coming into Canada of one or more persons who are not in possession of a visa, passport or other document required by this Act" (Department of Justice 2004: 16). The illegal migrant contracts with a smuggler to effect their entry into the country of destination for an agreed fee. Once the individual has received the service and has been smuggled into the Canada, the relationship between the illegal immigrant and the smuggler ends. Traffickers, on the other hand, do not necessarily end their relationship with those that are being smuggled into a country.

Confusing human smuggling with human trafficking results in inconsistencies in statistics. Tracking illegal migration through enforcement interdiction statistics, refugee, and asylum claims can assist in providing a reasonably accurate picture of the movement of illegal migration, and the means by which it is affected. But, the percentage of this illegal migration that constitutes human trafficking remains the trafficking of women into the sex trade, the offence created in IRPA in 2002 is not limited to just that type of exploitation but includes all forms of human trafficking. 
unknown factor.

It should be stressed that lack of clarity regarding the scope of human trafficking does not negate the need for action to protect the victims of this crime, regardless of which definition is accepted. Continued attention to this crime will inevitably lead to verifiable evidence of its depth. But, it is suggested that caution be used to justify action or to develop strategies for enforcement based upon unsubstantiated projections that could result in a misunderstanding of the scope of the problem which, in turn, could undermine the development of effective approaches to assist and protect victims.

Determining the scope of the problem is further complicated by the current belief that much of the human trafficking trade is orchestrated by highly structured organized crime groups. Like the continuum of victimization, it has become evident that there is a continuum of organized crime activity and its involvement in the facilitating of human trafficking. At one end of the spectrum are the claims that highly sophisticated organized crime syndicates are the prevailing entity that directs global human trafficking (Shelley 2003: 231-249). And, at the other end are those who argue that traffickers are not necessarily a part of a centralized criminal organization but rather, are individuals or independent groups that specialize in certain stages of the trafficking within the smuggling process (Icduygu and Toktas 2002: 25-54). 
Recent studies in Canada tend to confirm this continuum of organized criminal activity. An initial assessment of organized crime's involvement in human trafficking by the Criminal Intelligence Directorate (CID) of the RCMP, in 2002, indicated that there was an ever increasing presence of more highly organized crime groups entering this criminal activity (CID 2002: 1-22). A subsequent study by the Research and Evaluation Branch of the RCMP, in 2004, expanded this assessment and recognized varying degrees of criminal activity participating in human trafficking. According to the document, Organized Crime and Human Trafficking in Canada: Tracking Perceptions and Discourses, traffickers can span the spectrum of an individual who compromises a relative into a trafficking situation to that of a highly sophisticated criminal organization that organizes the transportation of human trafficking victims across multiple national boundaries (Bruckert and Parent 2004: 35-37). Given the potential profit to be realized by participation in this criminal venture, it is anticipated that organized crime, in its various forms, will continue to expand its influence.

Because it is difficult to clearly substantiate the scope of human trafficking, government approaches that have and will be implemented around the globe to combat this phenomena may be negatively impacted. Without internationally agreed evaluation standards to derive reliable statistics, human trafficking enforcement and protection strategies will constantly be challenged as to their effectiveness due to the lack of verifiable data. This should not deter governments from seeking solutions to fight those who traffic in persons but it should encourage governments to reach consensus on 
what it is they are measuring and how they measure the crime. Effective strategies are interdependent on a clear understanding of the problem.

\section{Summary}

Today's human trafficking discourses retain significant elements of the moral panic that was entrenched in the white slavery panic, especially with respect to the prostitution debates. In many respects, it mirrors much of the discourses that took place in the past and has again led to the creation of legislation and immigration policies purportedly designed to combat and prevent human trafficking. But, in effect, new trafficking legislation re-enforces cultural identity by limiting immigration (Doezema 1999: 27-28). It is also suggested that increased restrictions on migration only force the migrant to resort to irregular migration avenues which fosters an environment wherein the migrant faces a higher risk of exploitation by the trafficker (Richards 2004: 147-151).

The recent fear of terrorism is a new dimension for consideration in the trafficking discourses. It is anticipated that this fear of terrorism will impact on the human trafficking debates by encouraging increased immigration restrictions. It is surmised that in light of the involvement of organized transnational traffickers, the fear of terrorism will blend well within the human trafficking panic by focusing State efforts, individually and collectively, on the restriction of the migration of certain ethnicities (Saunders and Soderlund 2003: 21). 
Today, as governments struggle to develop strategies to address this growing crime, with widely divergent understandings of trafficking, and human trafficking projections that have little legitimacy upon which to base enforcement approaches, the victims of trafficking continue to suffer. It is suggested that through a global response by the international community, recognizing the diverse nature of trafficking and the diversity of organized crime's involvement, appropriate strategies can be developed and implemented to meet the needs of all victims. 


\section{Chapter 4}

\section{Globalization and Illegal Migration}

Although the term 'globalization' is used widely, it is often misunderstood due to an abundance of conflicting definitions. Like the debates that revolve around the definition of human trafficking, the meaning of globalization is a focal point for considerable debate. However, there is no intention in this paper to enter these debates. Rather, it is sufficient for the purposes of this study that the concept of globalization be accepted in a most general and broad understanding - unfettered global interaction between the same spheres of interest, such as economic, across national boundaries beyond the normal interdependence of State activity (von Bogdandy 2004: 888; Wolf 2005: 1-2; Ellwood 2002: 19).

Most theories of globalization contain the common influencing factors of 'nation' and 'migration' due to the perceived fluidity of movement that these global theories imply and the projected impact that they have on the nation state and the movement of people therein (Dauvergne 2004: 593). This chapter is focused on globalization in terms of illegal migration and the movement of people covertly through irregular means, human smuggling and human trafficking, across national borders. It should not be construed as a definitive study of the enormous complexities and relationships that exist within the concept of global illegal migration. Rather, the chapter will set out certain parameters related to this concept which can be applied to the more specific issue of human trafficking. 
Earlier, I discussed the moral panic within the white slavery discourse and by extension, the human trafficking discourses, with the view that it was encouraged because of the underlying perception that increased migration posed a threat to national identity and the existing dominant culture. This chapter looks at this panic on the international stage and the panic's relationship to sovereignty, and the resultant increased restrictions to migration in defense of that sovereignty.

This chapter will also explore the illegal migrant construct, in general terms, of a person seeking to migrate through irregular means, and the construct's relationship to the demand for increased migration restrictions. Illegal migration, by its very existence, arguably represents a challenge to any nation's sovereignty and will touch upon the issue of human security versus national security.

\section{The Moral Panic}

Many nations, especially European and North American countries, have a perception that they are losing control over the social and economic forces at play within their boundaries due to globalization (Dauvergne 2004: 588-589). As a consequence, they have a growing belief that globalization is a threat to their national identity and sovereignty. This fear of a loss of control is nurtured in terms of the concerns raised over global migration and the tangible threat this migration is projected to represent to national interests (Dauvergne 2004: 588-615). Immigration, and the immigration management within a country, represents the rallying point for a nation to strongly re- 
establish the State's identity. It provides the nation the opportunity to reaffirm its control over the challenges to its sovereignty that globalization represents by imprinting a sense of 'nation-ness' through increased and reinforced immigration laws. To reassert its identity and justify greater regulation, western nations promote, overtly or covertly, a sense of crisis by projecting significant negative consequences if global migration is left unchecked ((Dauvergne 2004:588; Hollifield 2000: 138-139; Brennan 2003: 1-8).

Although global migration has increased over the past decades, growing from an estimate of 76 million global migrants in 1960 to 175 million in 2000 (UN General Assembly 2004: 4), this represents only a small increase in relative terms of world population. Contrary to the panic that is being promoted in strong western nations, statistically, global migration is the exception rather than the norm (Hollifield 2000: 138; Zolberg 2001:2). However, in a publication titled World Population Policies, 2003, a survey of governments revealed that the percentage of nations that felt that immigration levels were too high had risen from 7 to 21 percent between 1975 and 2003 (UN General Assembly 2004: 4). I argue that this significant increase in government concern over global migration, and its perceived affect on national identity and sovereignty, is directly related to the ongoing moral panic over the perception of uncontrolled migration.

The nation-state derives its legal basis from the historic concepts of sovereignty. Under international law, the state is provided with legitimacy through the law's governing of relations between independent states and by providing legal 
protections to the nation-state entity from foreign interference (von Bogdandy 2004:

887). Philosophically, the nation-state binds a group of people together in solidarity and identity through the promotion of a common (national) language, political system, literature, culture and economy (von Bogdandy 2004: 887). Today, global migration, as a result of globalization, is viewed as a threat to the continued existence of the nation's identity and solidarity.

Recent concerns by western nations over global migration have become focused on the issue of illegal migration. Nations view illegal migration as an affront to a country's sovereignty because it demonstrates that a country is not able to control its borders, undermining the essence of their nation-state identity (Dauvergne 2004: 598). It is believed that only through the introduction of increasingly restrictive immigration legislation, the development of associated policies, and the introduction of new enforcement initiatives can the state reassert its control over their national boundaries and reaffirm their sovereignty and identity (Dauvergne 2004: 600-602).

Aristide Zolberg probed the issue of why the 'immigration crisis' has received such a favourable hearing from western nations in light of his belief that an evaluation of forced or voluntary migration does not support the rationale for the existence of such a crisis (Zolberg 2001: 1-15). He suggests, as do others such as Catherine Dauvergne, that much of the panic is dependent upon the psychological issue of racial balance, the fear of the 'other', and the fear of the unknown. The public in 
countries such as the US are continually exposed by the media to the fear that uncontrolled migration from developing countries with large population growth will overwhelm the culture and lifestyle of western nations which have experienced little or zero population growth (Zolberg 2001: 6; Hollifield 2000: 141; Dauvergne 2004: 598; Canadian International Development Agency 1996: 2 ).

The moral panic that emerges from this fear manifests itself within the public such that immigrants, and in turn immigration, are viewed with suspicion. The public reacts to its fear by calling for stronger immigration restrictions and enhanced enforcement efforts which further impact and shape the direction of global migration. Many countries among western nations have responded to these public pressures by introducing new or renewed legislation which represent visible attempts to assert sovereignty and appease the public outcry. The new legislation of these countries, such as Canada, increases the authority of the government to manage immigration and may lead to an expanded criminalization of irregular migration. Although the numbers who seek to migrate will likely not change substantially in the near future, the percentage of illegal global migration may grow significantly as a result of further criminalization.

\section{The Illegal Migrant}

In the broadest sense, "anyone who is present in a nation state without either nationality or authorisation under law is an illegal immigrant" (Dauvergne 2004: 599). It is recognized that the constructs of an illegal immigrant can run the gamut from 
the back-packing tourist who overstays their visa by a few days to the individual who enters the country through illegal channels with no documented authority. It is also acknowledged that the construct of an illegal immigrant is extremely complex and well beyond the simplified rendition that this definition of an illegal immigrant implies. However, Dauvergne's definition does provide a critical reference point for the discussion that will follow concerning the distinction between legal versus illegal migration.

Most research supports the general viewpoint that illegal migration is predominantly economically motivated (UN Dept. Of Economic and Social Affairs 1998: 209; Friebel \& Guriev 2002: 4). People living in a world of abject poverty will understandably seek to escape a life with no apparent hope as will those persons who simply aspire to improve their current lifestyle and economic situation. If this cannot be accomplished through legal channels then it is acknowledged that they may resort to the use of illegal means to achieve their perceived freedom. The advent of global communication has resulted in increasing the awareness among the disadvantaged poor to the potential possibilities of alleviating their suffering that exist in distant countries. This increased knowledge and awareness, linked to instant communication with those who can facilitate their illegal migration, influences their migrating decisions (UN Dept. Of Economic and Social Affairs 1998: 209).

Faced with the growing knowledge of increasing disparities between the 
have and have not countries, in terms of wealth and lifestyle opportunities, combined with demands for cheap labour from affluent countries, the poor of the world are strongly motivated to emigrate (Brolan 2003: 567). It is believed that few of these immigrants have much direct knowledge of the law, especially immigration law, and it is understood that the concept of law and its application to emigration plays virtually no role in their decision to migrate (Schuck 2000:189).

During the 1990s, the world experienced a social reclassification of illegal immigrants as the shift towards increased immigration restrictions was implemented in response to the growing moral panic about the issues of national identity and sovereignty. In the past, to varying degrees, illegal immigrants have been accepted as guest labourers in many countries. As concerns rose in western countries about the presence of illegal migrants in their respective nations, illegal immigrants were quietly tolerated as a necessary work force for specific types of labour. However, more recently, as the panic over globalization and illegal migration has gained momentum, illegal migrants have become an undesirable presence within the community because they are perceived as posing a threat to the continued existence of the defined community and by extension, to that of the country (Engbersen and Van Der Leun 2001: 54-55).

The image portrayed of the illegal immigrant today is that of a poor, nonwhite and destitute individual (Dauvergne 2003: 14). This construct of an illegal immigrant, in and of itself, is a difficult construct to present to the public as a threat to a 
nation's sovereignty. The fear of the unknown, however, can produce strong emotional reactions. Thus, the construct of an illegal immigrant is further expanded to capitalize on public fear in terms of the illegal immigrant representing a threat to public safety through a projected predisposition to partake in criminal behaviour (Engbersen and Van Der Leun 2001: 57-68).

The migrant has 'illegally' entered a country and as a consequence, they fulfill the social myth that associates crime with migrants. They are cast as a greater threat to the nation because they are regarded as individuals who will resort to a life of crime in order to achieve their specific ends (Engbersen and Van Der Leun 2001: 54-55). Although this is the image that is generated by the moral panic, there is little evidence to support this claim. Studies to date clearly establish that most illegal migrants refrain from any criminal activity other than the use of false documents in order to gain entry into the country of destination (Engbersen and Van Der Leun 2001: 57-68).

The growing moral panic over immigration, reflected by increased immigration restrictions and immigration enforcement, shifts the understanding of western nations and their image of who is included and acceptable within the community of a nation. The panic focuses attention on redefining ourselves while redefining the construct of the 'other' in a re-examination of the terms of legal and illegal migration. "When a part of the population is acknowledged to be 'illegal', they are excluded and erased from within. Even when sovereignty at the border is breached, labeling people 
within one's territory 'illegal' imprints sovereignty" (Dauvergne 2003: 17).

Globalization is perceived as a threat to a nation's sovereignty which can be demonstrably safeguarded by creating restrictions that define the nation by establishing who is entitled to enter and leave a country. Those who are not entitled are constructed as a threat to the nation's continued existence and must be dealt with in order to preserve the nation's culture.

As indicated above, the majority of illegal migration is economically motivated. But, there is another significant component within the construct of the illegal immigrant, the refugee, which has created a moral dilemma for the international community. The Universal Declaration of Human Rights in 1948 through Article 14.1 introduced the right to asylum in a country from persecution in another country for all persons. The concept of refugee was clearly defined ${ }^{9}$, and protection afforded by the international community, through the creation of the 1951 UN Convention Relating to the Status of Refugees and the subsequent 1967 UN protocol (Haddad 2003: 4-7).

In Canada, the refugee Convention definition was incorporated into law in

A Convention refugee is a person who by reason of a well-founded fear of persecution for reasons of race, religion, nationality, membership in a particular social group or political opinion,

(a) is outside the country of the person's nationality and is unable or, by reason of that fear, is unwilling to avail himself of the protection of that country, or

(b) not having a country or nationality, is outside the country of the person's habitual residence and is unable or, by reason of that fear, is unwilling to return to that country.

(Shoyele 2004: 550) 
1973 and is referenced in the new immigration legislation of 2002 (Immigration and Refugee Protection Act - IRPA) at Section 96 with the inference being that Canada only recognizes refugees who qualify with respect to the 1951 Convention (Shoyele 2004: 550). The web-site for Citizenship and Immigration Canada (CIC) reaffirms that refugees are defined as per the Convention but also references protection for those persons that could be removed from Canada to their country of origin, but may be subject to torture, cruel and unusual treatment or punishment or there is a risk to their lives if they are returned (CIC In-Canada Refugee Process 2005: 2).

While the moral panic currently residing within the illegal migration discourses encourages nations to take steps to suppress illegal immigration, the refugee becomes trapped in the illegal immigration panic because they often resort to the use of illegal means in order to migrate to safety (Dauvergne 2003: 18; Koser 2003: 182). Contrary to the general class of economically motivated illegal immigrants, the refugee migrates not from choice but as a result of necessity due to persecution (Brolan 2003: 563). The refugee symbolizes the tension between the nation's sovereign right to exclude and the international human rights imperative on the nation to include (Haddad 2003: 1). As a result, the immigration panic which incorporates this tension promotes further immigration restrictions and increased enforcement such that bonafide refugees see the narrowing of opportunities to seek safe haven.

During the 1990s, illegal immigrants have come to be constructed as 
undesirable and suspicious people. And refugees, like illegal immigrants, are also beginning to be viewed with the same suspicion by the general public. They are perceived as a group of have nots who hope to benefit from the benevolence of a generous country (Dauvergne 2003: 18). As a result, it is becoming increasingly difficult for governments to distinguish between the economic illegal migrant and the legitimate refugee as the moral panic converges their respective image constructs from two separate identities into one (Koser 2001: 88). In addition, the picture is further complicated by an increase in refugee claims from the economically motivated illegal migrant group who will avail themselves of whatever means available in order to attempt to stay in a country of destination. These fraudulent claims result in undermining the public confidence in an already overburdened refugee system (Koser 2001:88).

An example of government response to growing public concern over the refugee system is The Safe Third Country Agreement between Canada and the US which came into effect on December $29^{\text {th }}, 2004$. This agreement is a part of the Smart Border Action Plan signed between Canada and the US following '9-11'. The agreement obligates both countries to jointly manage refugee claimants. Specifically, if a refugee presents themselves at a land port of entry in either Canada or the US to make an asylum claim while departing from Canada or the US, they will be returned to the country from which they are attempting to depart while their claim is processed (CIC 2004 Fact Sheet: 1). According to a Canadian government news release announcing the agreement in December 2004: "The objective of the Safe Third Country Agreement is to create an 
effective measure of control, necessary to better manage access to Canada's refugee determination system" (CIC 2004 News Release: 1).

A recent newspaper article, Treaty slams door on refugees - Numbers down $40 \%$ from 2004, infers that rather than providing effective management of the refugee process, The Safe Third Country Agreement has actually resulted in deterring claimants (Simpson 2005: A1). This view is shared by Nick Summers of the Canadian Council for Refugees, who expresses in Simpson's article that refugees will try and enter the country illegally if legitimate avenues are being blocked (Simpson 2005: A9). The Canadian government's position in response to these concerns has been that it is still too early to attribute the decline in refugee claims as being the result of this agreement. In support of the government's position, it is noted that, between 2004 and 2005, there has been an overall decline of 23 percent in refugee claims at other points of entry such as airports which are not covered by the agreement (CIC 2005 First Statistics:1)

As these statistics only cover a short period, it is reasonable to be cautious about drawing definitive conclusions as to why there has been a decline in refugee claims. There is no question that further study is required. However, increased immigration enforcement brought about by the globalization panic, coupled with more formalized restrictions through international agreements and domestic legislation, will inevitably have some impact on global migration movement and the construct of the illegal migrant, especially with regards to refugees. 
To this point, this paper has explored the illegal migrant construct in terms of often being a person of colour, suffering a life of poverty, motivated to migrate from economic considerations in order to seek a better life. It has also examined this construct in relation to the inclusion of refugees in this discourse as a result of the ongoing moral panic over immigration. However, often lost in the debates over illegal migration is the impact that the illegal migrant construct has on the victims of human trafficking. Contrary to the prevailing public view regarding illegal migration, human trafficking is a non-voluntary, highly abusive form of illegal migration (Brolan 2003: 579). The challenge for those who advocate on behalf of the victims of trafficking is to separate the constructs of the trafficked migrant from that of the generally accepted negative constructs of the illegal migrant.

Like the bonafide refugee, the constructs of the victim of human trafficking are often overshadowed by that of the illegal migrant leading to public misunderstanding and distrust of trafficking victims. Included in the confusion is the phenomenon known as the feminisation of migration which reflects an ever increasing presence of women in migration streams, particularly those who are destined for the sex trade (Uherek, Skirvanlova \& Weinerova 2001: 2). The global sex tourism industry adds another dimension into the illegal migrant constructs by objectifying and commodifying those females who are trafficked in conjunction with the voluntarily female migrant involved in the international sex industry. This creates the illusion that female migrants, regardless of whether they are illegal or trafficked, are young, third world women of 
colour who are sultry, welcoming, and submissive (Pessar \& Mahler 2001: 21). Thus, it becomes increasingly difficult for the public to differentiate between the construct of trafficking victims and that of economic migrants. The result is that the victims of trafficking become lost in the illegal migrant discourse and are treated as illegal immigrants rather than victims of a crime.

Today's illegal migrant construct has been premised on a desire for nations to reaffirm their sovereignty in a world of globalization. In order to maintain the perception of control over a nation's destiny, illegal migrants are cast as an economic threat, emerging from third world countries, that undermine national objectives and identity. More recently, as a result of international terrorist incidents such as ' $9-11$ ', the illegal immigrant construct, enveloped in various racial and ethnic overtones, is not only perceived as an economic threat to the nation brought about by globalization but is also deemed to be a security threat (Yuval-Davis 2004: 1-43; Hollifield 2000:154-155; Dauvergne 2004: 588).

Asylum seekers and refugee claimants are being reconstructed within the illegal migrant discourse from that of people in need of 'human security', a safe haven, to the broader concern emerging over illegal migrants, that they also represent a security threat to the nation (Yuval-Davis 2004: 22; Loescher 2003: 31). But, contrary to illegal migrants, refugees still have a certain degree of protection that a country is obligated to 
provide as a result of international human rights legislation ${ }^{10}$ (Yuval-Davis 2004: 22).

\section{Summary}

It is believed by a large portion of the public in Europe and North America that uncontrolled migration challenges the authority and sovereignty of all nations. To that end, many western countries during the past few decades have instituted an immigration system that regulates who enters and exits a country. And, it has been argued that the motivation behind this regulation of the movement of people is precipitated by a desire from within the most dominant group of a nation's society to protect their continued influence within the power structure of the nation and by extension, their influence within the nation's cultural and moral systems. Globalization challenges this precarious balance of power within the construct of a nation because by its very nature, it ignores the traditional sovereign boundaries and the influence of any particular dominant group.

This chapter explored the ongoing moral panic that has been created relative to the fear of globalization. In particular, it focused on the position that the moral panic promoted within the public translates into a fear of uncontrolled migration as migration provides the tangible threat to sovereignty. Further, it has touched upon the viewpoint that through the skillful manipulation of public sentiment, various interest groups have been able to implement a strategy to increase immigration restrictions as it is 
perceived this action is necessary in order to protect the interests of those groups.

As a result of this global panic, the constructs of the illegal immigrant have also changed in recent years. They have evolved from a position of being welcomed unofficial guest labourers to unwanted people from third world countries that pose an economic threat to the nation's well being. More recently, as a result of global terrorist acts, they have also become constructed as potential national security threats and thus, suffer the inherent suspicion and hostility of the public.

Caught up in this immigration panic have been refugees and victims of human trafficking. Both groups find themselves being subjected to the suspicion that is normally reserved for the illegal economic migrant. And, both groups have suffered to varying degrees as a result. But, in contrast to the illegal immigrant and the victim of trafficking, the refugee claimant does have some level of protection afforded by the international community that will ensure some degree of objectivity and fairness when processing their claims for safe haven, and the protection that safety represents.

Until the 2000 UN Convention, the victims of human trafficking had no significant legislated protection provisions and often suffered the same destiny as illegal immigrants - deportation. ${ }^{11}$ The UN Convention changed this situation by recognizing minimal references to qualified protection for victims but nothing that would ensure the provision of a safe haven and the protection of victim rights. For example, the only protection provision in the 1904 agreement was Article 4 which stipulated that if a victim could not pay for her return, the 
that trafficking victims are the victims of a crime and not violators of immigration laws.

The Convention also reflects the international community's awareness of the complexities of the crime of trafficking and its understanding that no one international organization, country or non-government organization (NGO) can cope with this problem in isolation (Everts 2003:152). "Combating trafficking in women ... requires a two-fold approach: a criminal justice response, to prevent the crime and deter the offenders, and a human rights response to protect the trafficked persons and their rights" (Chin \& Dandurand 2001: 3). Trafficking victims lose their rights and ability for selfdetermination. Every effort by law enforcement and governments, domestically and internationally, should be towards protecting the victim and restoring to them control over their own destiny (Iselin 2002: 2).

government would assume that debt; Article 6 of the 1921 agreement required signatories to ensure appropriate domestic legislation was created to protect women seeking employment in another country; and Article 19 of the 1949 Convention was the first time that countries were obligated to provide food and shelter but only to destitute victims. 


\section{Chapter 5}

\section{Victim Protection}

The 2000 UN Convention Trafficking Protocol represents the international community's response to the growing concern regarding the trafficking of human beings. Recognizing that trafficked persons are victims of a crime, vulnerable members of society, and not illegal immigrants, the Trafficking Protocol provides specific provisions to ensure their protection from traffickers, and also the provision of basic necessities. Until the creation of this Protocol, trafficking victims were, by and large, constructed as illegal immigrants by western nations, and routinely deported. The Protocol distinguishes trafficking victims from the construct of the illegal immigrant by establishing them as victims of a crime.

This chapter will cover two main areas related to the protection provisions contained in the Trafficking Protocol. The first part will guide the reader through the specific provisions relating to victim protection, with the focus being upon the interpretive comments and critiques from NGOs about those provisions. In many instances, NGOs ${ }^{12}$ represent a counter balance to the governments that are tasked with general perspective. It includes organizations such as: International Human Rights Law Group, Anti-Slavery International, Eaves Housing for Women, On the Road, European Council on Refugees and Exiles, Minnesota Advocates for Human Rights, CATW, The Human Rights Caucus (includes such organizations as: Amnesty International, Human Rights Watch and Human Rights Alliance), NSWP.

It is recognized that these organizations periodically have conflicting opinions/viewpoints and where appropriate, the name of a specific $\mathrm{NGO}(\mathrm{s})$ will be used to highlight their specific views. 
implementing the Protocol. Therefore, as a result of this relationship, NGOs have assumed a role of overseers, monitoring the actions and implementation strategies of Convention signatories. The first section of the chapter will identify the protection Articles in the Protocol that NGOs believe are in need of clarification and will also include an outline of areas that NGOs believe were not adequately addressed in the current protection provisions.

The foregoing section will then be followed by a discussion of the critiques by NGOs regarding the actual application of the Protocol protection provisions. It will include NGO recommendations for improvements to the existing provisions in order to ensure that trafficking victims are adequately protected. It is intended that through this specific analysis, in conjunction with the broader interpretive assessment of how the provisions have been applied, a basic understanding of the current status of the Protocol's protection provisions will be established and position the reader to apply this understanding to the specific assessment of Canada's efforts to comply with the Protocol's protection provisions which is covered in Chapter 6.

\section{Trafficking Protocol Protection Provisions}

Articles 6 through 8 obligate the signatories of the convention to provide specific protection provisions solely for trafficking victims. There are additional protection provisions within the body of the main Convention to which the Protocol is annexed but they apply to all victims and/or witnesses of transnational crimes and were 
not specifically created for trafficking victims. ${ }^{13}$

Article 6 of the Trafficking protocol is the first of the victim protection requirements:

"Article 6 - Assistance to and protection of victims of trafficking in persons

1. In appropriate cases and to the extent possible under its domestic law, each State Party shall protect the privacy and identity of victims of trafficking in persons, including, inter alia, by making legal proceedings relating to such trafficking confidential.

2. Each State Party shall ensure that its domestic legal or administrative system contains measures that provide to victims of trafficking in persons, in appropriate cases:

(a) Information on relevant court and administrative proceedings;

(b) Assistance to enable their views and concerns to be presented and considered at appropriate stages of criminal proceedings against offenders, in a manner not prejudicial to the rights of the defence.

3. Each State Party shall consider implementing measures to provide for the physical, psychological and social recovery of victims of trafficking in persons, including, in appropriate cases, in cooperation with non-governmental organizations, other relevant organizations and other elements of civil society, and, in particular, the provision of:

(a) Appropriate housing;

(b) Counselling and information, in particular as regards their legal rights, in a language that the victims of trafficking in persons can understand;

c) Medical, psychological and material assistance; and

(d) Employment, educational and training opportunities.

4. Each State Party shall take into account, in applying the provisions of this article, the age, gender and special needs of victims of trafficking in persons, in

13 For example, Articles 24 of the main Convention provides protection provisions for witnesses against transnational organized crime groups. And, Article 25 provides provisions for the protection and assistance to victims of transnational crime. Neither of these Articles add any additional protection to Trafficking victims beyond what is covered in Articles $6-8$ of the Trafficking Protocol. 
particular the special needs of children, including appropriate housing, education and care.

5. Each State Party shall endeavour to provide for the physical safety of victims of trafficking in persons while they are within its territory.

6. Each State Party shall ensure that its domestic legal system contains measures that offer victims of trafficking in persons the possibility of obtaining compensation for damage suffered."

(UN Convention against Transnational Organized Crime, Annex II: Protocol to Prevent, Suppress and Punish Trafficking in Persons, Especially Women and Children, U.N.G.A. Resolution $55 / 25)$

In summary, Article 6 requires that each signing country provide victims with: a degree of identity protection in legal proceedings such as criminal prosecutions; legal representation and information concerning their respective legal proceedings such as immigration hearings; medical, psychological, and social assistance; employment and educational opportunities; a safe haven; and the ability to seek compensation for their victimization.

Much of the criticism of Article 6, which is also relevant to all three protection provisions within the Protocol, relates to certain wording that NGOs see as ambiguous and non-binding (Anti-Slavery International 2003 - Migration: 8; European Council on Refugees and Exiles - ECRE 2001: 4; Jordan 2002: 19-28). Examples of this criticism begin with the first sentence of Article 6 and relates to a term that is frequently used in these protection provisions - 'in appropriate cases'. The Protocol does not define under what circumstances cases will be 'appropriate' or in-appropriate' and other such 
ambiguous terms like 'shall consider' and 'shall endeavour'. Nor do the interpretative notes for the official records (travaux préparatoires) shed any light on this issue (UN General Assembly - Crime 2000: 13-14). It is left to the signatory of the Convention to decide the scope of these terms in relation to how they will be interpreted and applied within a country's domestic law and related processes (ECRE 2001: 4; Jordan 2002: 1928). It is for this reason that NGOs such as Anti-Slavery International voice their concerns over the Protocol's wording because they believe that this ambiguity within the protection provisions will lead to divergent understandings and inequitable applications of these provisions to the detriment of victims (Jordan 2002: 19-28).

In addition to concerns over the ambiguity in the wording, one of the two major deficiencies identified by NGOs regarding Article 6 relates to protecting the confidentiality and identity of trafficking victims during legal proceedings. Specifically, the perceived 'gap' in protection occurs in Article 6 when the domestic law of a signatory is not established to protect the identity of a victim before, during and after testifying in a legal proceeding. Article 6 does not obligate a country to establish domestic law to protect victim privacy nor to provide asylum as a means of avoiding retribution by traffickers should an individual's identity become known, especially when returned to their country of origin (Jordan 2002: 19; Minnesota Advocates for Human Rights 2003: 1; OSCE 2003: 2).

I recognize that Convention Article 24 provides for the protection of 
witnesses in general before and during court proceedings but NGOs such as the International Human Rights Law Group (IHRLG) point out that there is no obligation to maintain that type of protection after the court proceedings have been completed (Jordan 2002: 23). Consequently, trafficking victims, whose identities have been published during legal proceedings, are perceived as being at greater risk once their cooperation is no longer required. NGOs express the belief that the Protocol should be amended to reflect a commitment on the part of the signatories of the Protocol to provide physical protection to victims on a long term basis (Jordan 2002:19; Erakat et al 2004: 16).

The second major area of criticism in relation to Article 6 pertains to victims seeking compensation. NGOs have expressed the view that the wording of Article 6.6 is insufficient to ensure that countries will institute a mechanism or process such that trafficking victims will be able to thoroughly explore, through civil or criminal proceedings, financial redress from their traffickers (Jordan 2002: 23). In support of this view, a 2002 report by the UN High Commissioner for Human Rights (UNCHR) to the UN Economic and Social Council recommended that signatories of the $2000 \mathrm{UN}$ Convention implement a process whereby the assets of traffickers are confiscated and possibly used to compensate victims but it is unknown if any country has actioned this recommendation (UN Economic \& Social Council 2002: 4).

Article 7 represents one of the main sources of debate within victim protection discourses. This is largely due to the conflicting opinions concerning Article 7 
as it relates to the question of victim entitlement to temporary versus permanent resident status, and the consequences if receiving countries are not obligated to provide either status. The discussion of this issue will be pursued further later in this chapter but for now, the focus of is in regards to the actual wording of the Article:

\section{"Article 7 - Status of victims of trafficking in persons in receiving States}

1. In addition to taking measures pursuant to article 6 of this Protocol, each State Party shall consider adopting legislative or other appropriate measures that permit victims of trafficking in persons to remain in its territory, temporarily or permanently, in appropriate cases.

2. In implementing the provision contained in paragraph 1 of this article, each State Party shall give appropriate consideration to humanitarian and compassionate factors."

(UN Convention against Transnational Organized Crime, Annex II: Protocol to Prevent, Suppress and Punish Trafficking in Persons, Especially Women and Children, U.N.G.A. Resolution $55 / 25$ )

The thrust of the argument put forth by NGOs is that this Article does not actually oblige a receiving country to do anything for the victims other than to recognize that trafficking victims require some form of legal immigration status (Jordan 2002: 26). The wording clearly shows that this Article lacks any mandatory requirement of a signing country to establish a process to ensure that a victim can remain within the country, either temporarily or permanently. Countries are only obligated to "consider" creating a process for "appropriate cases" and it is left to the signatories to decide the depth of the consideration they wish to apply, and to interpret what are appropriate cases. 
This perceived 'gap' in the Protocol has led NGOs to call upon the signatories to not only consider adopting a special process designed for trafficking victims which would provide the victims with permanent or temporary residence status in receiving countries but also to make the establishment of such a process mandatory (UN Commission on Human Rights 2003: 2). In addition, NGOs are now actively lobbying western governments to go beyond a limited process that would provide victims with immigration status and institute a broader immigration process for victims that addresses a number of interrelated issues that will be covered later in the chapter concerning the resident status of trafficking victims (UN Commission on Human Rights 2003: 2; Trafficking Conference 2003: 1; Anti-Slavery International 2003 - Migration: 8-9).

Article 8 deals with the safe return of a trafficking victim to their country of origin and reads as follows:

\section{“Article 8 - Repatriation of victims of trafficking in persons}

1. The State Party of which a victim of trafficking in persons is a national or in which the person had the right of permanent residence at the time of entry into the territory of the receiving State Party shall facilitate and accept, with due regard for the safety of that person, the return of that person without undue or unreasonable delay.

2. When a State Party returns a victim of trafficking in persons to a State Party of which that person is a national or in which he or she had, at the time of entry into the territory of the receiving State Party, the right of permanent residence, such return shall be with due regard for the safety of that person and for the status of any legal proceedings related to the fact that the person is a victim of trafficking and shall preferably be voluntary.

3. At the request of a receiving State Party, a requested State Party shall, without 
undue or unreasonable delay, verify whether a person who is a victim of trafficking in persons is its national or had the right of permanent residence in its territory at the time of entry into the territory of the receiving State Party.

4. In order to facilitate the return of a victim of trafficking in persons who is without proper documentation, the State Party of which that person is a national or in which he or she had the right of permanent residence at the time of entry into the territory of the receiving State Party shall agree to issue, at the request of the receiving State Party, such travel documents or other authorization as may be necessary to enable the person to travel to and re-enter its territory.

5. This article shall be without prejudice to any right afforded to victims of trafficking in persons by any domestic law of the receiving State Party.

6. This article shall be without prejudice to any applicable bilateral or multilateral agreement or arrangement that governs, in whole or in part, the return of victims of trafficking in persons."

(UN Convention against Transnational Organized Crime, Annex II: Protocol to Prevent, Suppress and Punish Trafficking in Persons, Especially Women and Children, U.N.G.A. Resolution $55 / 25)$

NGOs are relatively satisfied with this particular Article as it is designed to meet many of the protection needs for repatriated trafficking victims. Most importantly, this Article obliges both the receiving country and the country of origin to place the safety of the victim in the forefront of their decision process. However, although there is an apparent obligation to ensure the trafficking victim's safety on the part of both States, this is not always practiced and governments need to be closely monitored to ensure compliance (Pearson 2002: 58).

One deficiency in Article 8 that has been identified is the aspect of a 'stateless' person and how they would be dealt with when a potential country of origin 
refuses to recognize the victim's entitlement to return to that country (Jordan 2002: 28). The Protocol does not address this situation and NGOs have suggested it be incorporated into the Protocol that when this situation develops, the receiving country should treat the stateless person as a refugee with an entitlement to remain in the receiving country (Jordan 2002: 28).

\section{Protection Provisions Gaps}

NGOs view themselves as the lead spokepersons on behalf of trafficking victims because they believe that most countries have not adequately applied the protection provisions within the Protocol such that victims are receiving the necessary protection (Tzvetkova 2002: 60). In support of this viewpoint, at the UN Commission on Human Rights working group meeting on 'Contemporary Forms of Slavery' in June of 2003 , it was reported in general that countries are not doing enough to protect victims in compliance with the Trafficking Protocol (Anti-Slavery International 2003 - Support: 1). A specific study by Anti-Slavery International in 10 countries $^{14}$, referenced at this meeting, indicated that trafficking victims continue to suffer human rights abuses because governments fail to take adequate steps to protect and support the victims (Anti-Slavery International 2003: 1).

To this point, the critiques of the protection provisions have been confined to the perceived deficiencies in the wording of the Articles. The following section delves 
into two major areas of critique by NGOs in relation to the gaps that have surfaced as a result of the inconsistent application of the Protocol's protection provisions. In particular, there are the debates involving the potential re-victimization of trafficking victims through their prosecution and deportation, and the ongoing debates over temporary versus permanent resident status for victims.

In a 2000 report by the US Committee on Refugees (USCR), a coalition of NGOs (Human Rights Caucus) was cited as indicating that because there is a priority on immigration enforcement within many countries, victims of trafficking are re-victimized due their treatment as illegal immigrants and/or because they are perceived and treated as criminals (US Committee on Refugees 2000: 6). Habitually, victims have not been afforded the opportunity of support as detailed in the Protocol's provisions but rather were quickly dealt with by enforcement agencies through the victim's removal from the respective country as quickly as possible (US Committee on Refugees 2000:6).

A delay of deportation and detention or a suspension of prosecution is often held out to trafficking victims by law enforcement agencies on the condition that they cooperate with authorities in the prosecution of traffickers (Pearson 2002:56). In essence, the victim becomes victimized again because the inference is that they can only secure protection if they cooperate with authorities. According to Ryszard Piotrowicz, upon reviewing the European Commission 2002 proposal for providing temporary resident status for trafficking victims who cooperate with police, this type of victim 
protection scheme has the real objective of securing compliance with the State's immigration restrictions, with victim protection being only a secondary priority (Piotrowicz 2002: 263 -278).

NGOs have argued that trafficking victims that are interdicted by enforcement agencies during criminal investigations are emerging from highly abusive situations, frightened and unaware of what protection is available (OSCE 2003: 2). To avoid the potential of further victimization of trafficking victims by pressuring them into cooperating with the police, NGOs have suggested that a 'cooling off' period or 'reflection' period of 90 days be instituted for victims (Anti-Slavery International Migration 2003: 9; Piotrowicz 2002: 269). This would remove pressure on the victim from having to make a decision respecting their cooperation with law enforcement until they have had sufficient time to distance themselves physically and psychologically from their trafficker, receive appropriate support as per Article 6 in the Trafficking Protocol, and be provided legal counsel and information as to their rights (OSCE 2003: 3; Trafficking Conference 2003: 1).

The 'reflection' period concept is strongly promoted by NGOs as a first step in providing necessary support to trafficking victims. Some governments, such as Belgium and the Netherlands, have already implemented this type of an approach and have established a 'reflection' period of 45 days in Belgium and 90 days in the Netherlands (Perarson 2002: 57). During this period of time, support services are 
provided including medical, financial assistance and legal services (Pearson 2002:57). However, the major draw back or critique of this initiative is that the victim's ability to remain in the destination country after the expiration of the 'reflection' period is still contingent upon cooperation with the police and prosecutors (Pearson 2002: 57-58). Thus, the NGOs suggest that the 'reflection' period offered is tainted by the thinly disguised objective of inducing cooperation from trafficking victims with the law enforcement authorities (Pearson 2002: 58).

This position, advanced by NGOs regarding the 'reflection' period, flows into the next major debate within the victim protection discourse - temporary versus permanent resident status. If it is accepted that victims should be provided immediate relief and support from their situation (a 'reflection period' or temporary resident status) such that they can appreciate their legal position, rights and protection, at what point does this temporary reprieve stop and the victim repatriated to their country of origin? NGOs suggest that trafficking victims are mostly interested in remaining within the country of destination primarily for protection purposes from trafficking organizations but also because of the economic and social circumstances they likely have left behind in their country of origin (Anti-Slavery International - Migrant 2003: 1-27). Understandably, as noted in previous chapters, immigrants seek to migrate in order to improve their lives and it is presumed that trafficking victims, exposed to the benefits that exist within the society of destination, would also be interested in remaining in that country for the same reasons as an illegal migrant. 
Piotrowicz suggests that if governments hope to secure the cooperation of victims during their 'reflection' period, there must be some form of guarantee that cooperation leads to an entitlement to remain on a permanent basis (Piotrowicz 2002: 278). Conversely, NGOs also suggest that governments should adopt the approach that exists in Italy where the victim's continued residency is premised on the concept of social protection, a protection of their safety and well being, rather than their willingness to cooperate with law enforcement (Pearson 2002: 58). In either case, the intent is to secure a recognition and practice from destination countries of providing trafficking victims with the option of receiving permanent resident status.

Clearly, NGOs would like the receiving State, as per Article 7, to commit to providing long term security for victims by agreeing to a victim's right to remain permanently in the destination countries. However, governments have been reluctant to pursue this option as they fear such special recognition or status would lead to an overwhelming significant number of false claims by illegal immigrants (Anti-Slavery International - Support 2003: 2). According to Anti-Slavery International, a review of the applications for permanent resident status in Italy by trafficking victims have shown that there has been no appreciable increase in 'false' applications since the foregoing approach was adopted. And further, a review of trafficking victim claims in Belgium and the Netherlands where there are 'reflection' periods, revealed that these two countries have not experienced any appreciable rise in 'false' claims by alleged trafficking victims (Anti-Slavery International - Support 2003:2). 
Aside from the criticisms pertaining to the two major gaps surfaced by NGOs relevant to the application of the protection provisions, there is a third area of concern raised by NGOs that relates directly to the efforts by the signatories to provide protection to trafficking victims. In particular, NGOs have noted a wide divergence of the provision of victim support in relation to the requirements identified in Article 6. This, in their opinion, has resulted in a disparity between countries as to the provision of such critical victim protection support as medical assistance, housing, legal counsel, and education opportunities (Munro 2005: 100; Hughes 2000: 638). According to NGOs, the result of this disparity in the provision of protection support services reinforces the need to have strong NGOs engaged in the trafficking protection discourses in order to ensure that government's provide a minimum standard of these essential victim services (Munro 2005: 100).

\section{Summary}

It is evident that NGOS critiques of the Protocol's protection provisions are intricately interwoven. It is doubtful that the debate over re-victimization will ever be satisfactorily resolved until the issue of temporary versus permanent resident status has been put to rest. Trafficking victims need confidence that their protection is the first priority of the government, reflected within the domestic law, and demonstrated by the application of the law. This links directly to the issue of victim confidentiality and the protection of their identity during legal proceedings which is projected to place victims at risk as long as no offer of permanent resident status in conjunction with long term 
protection is available. Long term solutions to these issues require a long term strategic approach which should also incorporate a strategy to address the disparity that exists with regards to the availability of support services for trafficking victims. Many NGOs, and associated world organizations, are attempting to promote such a strategy.

Organizations such as the UN High Commissioner for Human Rights (UNCHR -2002), International Labour Organization (ILO - 2002) and the International Organization for Migration (IOM - 2003) have produced reports with similar recommendations that support long term permanent solutions to these problem areas (Richards 2004: 161-163). The first guiding principle of the 2002 UNCHR report states that: "The human rights of trafficked persons shall be at the centre of all efforts to prevent and combat trafficking and to protect, assist and provide redress to victims" (UNCHR 2002: 3). In other words, governments must accept the protection of trafficking victims as a main priority if success in combating and preventing human trafficking is to be achieved. Unfortunately, this and other like reports are not a legal obligation that is binding on any country. 


\section{Chapter 6}

\section{Canada's Approach}

"The test of a just society, a society organized around the principles of equality and human dignity, is how it treats the most vulnerable of its members" 15

(Cotler - Ontario Bar Association 2004: 2)

It has been four and half years since the Trafficking Protocol was

officially signed by Canada. In some respects, it could be argued that this amount of time is more than sufficient for a country to demonstrate its commitment to comply with the Protocol by enacting legislation, implementing anti-trafficking programs and antitrafficking policies, all of which should be in line with the Protocol's objectives. But, it could just as easily be argued that creating new legislation, funding new programs as a reflection of new responsibilities, amassing the necessary personnel and other logistical necessities, takes time. So, the question becomes, what has Canada done with this time? What new legislation has it enacted that supports the Protocol and most importantly, protects victims? What system has Canada implemented to provide protection for trafficking victims? And, has Canada's approach to the protection of victims been effective?

Portion of speech given by the Minister of Justice and Attorney General of Canada, Irwin Cotler, at the Ontario Bar Association on June 17, 2004. Cotler's presentation related to mapping out his priorities for the Justice Department agenda and this quote is taken from the second priority he identified which outlines his initiatives to prevent and protect trafficking victims. 
This chapter assesses Canada's efforts to comply with the victim protection provisions of the Trafficking Protocol. It will detail what has been done, what has not been done, and what needs to be done. It begins with a brief overview of Canada's strategy to prevent and combat human trafficking. This will include an overview of the mandate of the Interdepartmental Working Group (IWG) established by the Canadian government to coordinate Canada's response to human trafficking.

The chapter will then assess what Canada has done with respect to the introduction of legislation in support of trafficking victim protection. In particular, it will touch upon the new Immigration and Refugee Protection Act of 2002 (IRPA) and the more recent draft legislation dealing with domestic human trafficking, Bill C-49, which was tabled in Parliament for 'first reading' May $12^{\text {th }}, 2005$.

This chapter examines the Canadian Refugee System (CRS) within the Canadian Immigration System (CIS) which is the process by which Canada determines the eligibility of trafficking victims to remain in Canada. It will critique the CRS's effectiveness based on the deficiencies in the process identified by NGOs. And, this chapter will include an analysis of CRS - Immigration Review Board (IRB) hearings in order to assist in evaluating Canada's treatment of trafficking victims.

Following the review of CRS judicial decisions, the chapter will revisit the two major criticisms provided by NGOs regarding the international community's efforts 
to protect trafficking victims. Through a blending of global and domestic NGO literature, and limited NGO survey results ${ }^{16}$, the global NGO criticism will be examined in the Canadian context. My analysis will balance these critiques against the results of research surveys ${ }^{17}$ conducted with the primary federal agencies responsible for the protection of trafficking victims - Citizenship and Immigration Canada (CIC), Royal Canadian Mounted Police (RCMP), and the Department of Justice (DOJ).

The final component of the chapter will provide an overall summary of Canada's efforts to protect trafficking victims. What have we done right? What have we done wrong? And, where do we go from here?

During the course of research for this study, representatives of the following 7 NGOs in Canada were contacted with the view to soliciting their participation in a survey: UNANIMA International, MOSAIC Multicultural Victim Program of BC, Congregation of the Sisters of St. Agnes (CSA), Sisters of Holy Names of Jesus \& Mary (HNJM), the Canadian Religious Conference (CRC), Westcoast Legal, Education \& Action Fund (LEAF), Congrégation de Notre Dame.

Unfortunately, after numerous emails and follow-up, only 2 people (Issacs \& Boissé) were willing to respond to the survey, and only from an individual perspective and not as a representative of any of the foregoing agencies. Given the importance that NGOs have placed on the issue of human trafficking, their apparent lack of interest and/or reluctance to participate in an opportunity to put forward their concerns is very surprising. I have no explanation for this result.

The survey responses from the 3 government departments (CIC, DOJ \& RCMP) are a compilation of opinion from within each department and is not presented as a response of one representative of the department but instead represents the department's opinion.

The individual surveys were customized for each department including the survey used in seeking the opinions of NGOs. The questions for the surveys were based on the main human trafficking issues as identified in Chapters 3,4 and 5. All the survey's have some questions in common while each has distinct questions relative to the respondents' area of responsibility or interest. A blank copy of each of the surveys is contained in the Appendix. 


\section{Canada's Human Trafficking Strategy}

Prior to the Trafficking Protocol in 2000, Canada had been a leading participant in the UN deliberations that led to the creation of the Trafficking and Migrant Smuggling Protocols (CIC 2000: 1). Canada's contribution to these two Protocols was reflected in the work of two separate federal Interdepartmental Working Groups (IWG) IWG on Trafficking and the IWG on Migrant Smuggling. These two IWGs were eventually merged into the current federal IWG on Trafficking in May of 1999 in recognition of a government policy vacuum on trafficking which might inhibit Canada's ability to respond appropriately to the new international anti-trafficking direction as represented by the Trafficking Protocol (CIC 2000: 1). Thus, the objective of the new IWG on Trafficking is to coordinate all federal activities to comply with the Trafficking Protocol (DOJ Survey 2005: 1). By February 2004, the mandate of the IWG was expanded to include responsibility for developing a comprehensive federal government human trafficking strategy (DOJ - Trafficking in Persons 2005: 2; Cotler - Forum on Human Trafficking 2004: 3).

At present, the IWG is chaired by two government departments, the Department of Justice (DOJ) and the Department of Foreign Affairs Canada, with 15 other federal departments and agencies participating (DOJ - Trafficking in Persons 2005: $1)^{18}$. To date, the IWG has not published a national human trafficking strategy and has

18

Other departments/agencies involved: Canada Border Services Agency, Canadian Heritage, Canadian International Development Agency, Canadian Security Intelligence Service, Citizenship and Immigration Canada, Health Canada, Human Resources and Skills Development Canada, Indian and Northern Affairs 
provided no indication as to when one will be available. But, participating departments, such as the RCMP, indicate that the IWG is committed to developing a comprehensive national strategy that links the efforts of all government departments together to ensure a coordinated and effective anti-trafficking response (RCMP Survey 2005: 1).

Although no national strategy has yet to be published, the IWG has implemented a number of consultative, enforcement and awareness initiatives in support of substantive anti-trafficking measures. From a consultative perspective, IWG representatives participate in numerous discussion forums around the world presenting Canada's approach to anti-trafficking and seeking international anti-trafficking best practices that may be adaptable to the Canadian enforcement environment (CIC Survey 2005: 8; RCMP Survey 2005:9). This participation has taken the form of IWG representatives interacting with organizations such as Interpol, the International Organization of Migration (IOM), and the Organization for Security and Co-operation in Europe (OSCE), with a view to sharing experiences that will assist in shaping Canada's approach to combating human trafficking (CIC Survey 2005: 8). In the past, Canadian IWG representatives have also participated in various international conferences such as the Regional Conference on Migration held in Mexico in May of 2003 in order to engage other countries on mutually shared concerns pertaining to human trafficking (CIC Survey 2005: 8).

Canada, Passport Office, Privy Council, Public Safety and Emergency Preparedness Canada, Royal Canadian Mounted Police, Social Development Canada, Statistics Canada, Status of Women Canada 
Within Canada, the IWG has attended domestic conferences such as The Forum on Trafficking in Persons, Especially Youth, Children and Women, hosted in Ottawa in March of 2004 by the Canadian Ethnocultural Council, Department of Justice and the Status of Women Canada (CIC Survey 2005: 4). These types of forums are designed to seek input from NGOs, and other interested persons, in order to assist in the development of the government's national anti-trafficking strategy (CIC Survey 2005: 4; Cotler - Forum on Human Trafficking 2004: 3). On August $11^{\text {th }}, 2005$, in Vancouver, the Minister of Justice, Irwin Cotler, hosted a roundtable discussion with NGOs such as the National Alliance of Filipino Women in Canada (NAPWC) with the view to soliciting input on the proposed Criminal Code of Canada (Bill C-49) amendments that create the domestic offence of human trafficking (Womennet.ca 2005: 1).

With respect to the government's enforcement initiatives, the Canadian government ratified the 2000 UN Convention on May $13^{\text {th }}, 2002$ (DOJ Survey 2005: 1). In December 2002, the government provided law enforcement with the necessary mechanism, through the enactment of IRPA, upon which to focus their enforcement strategies. Among the many issues that are addressed in this new immigration legislation, which have been touched upon earlier in Chapter 4, is the specific offence of human trafficking, Section 118 , which introduced the offence of human trafficking for the first time into the Canadian law enforcement environment (DOJ - IRPA 2004: 16). Subsequent to IRPA's creation, the government recently provided further anti-trafficking enforcement direction through proposed amendments to domestic criminal legislation 
(Criminal Code of Canada (CCC)) contained in Bill C-49 which will create the offence of human trafficking within Canada's borders (DOJ Survey 2005: 2).

The RCMP, working collaboratively with other enforcement bodies such as the Canada Border Services Agency (CBSA) and CIC, have responded to this new legislation and developed enforcement strategies to combat human trafficking (RCMP Survey 2005: 7). In accepting the responsibility of lead agency for anti-trafficking enforcement, a component of the RCMP's enforcement strategy has been the creation of a dedicated human trafficking unit at the national level with a mandate to coordinate both domestic and international trafficking investigations that affect Canada (RCMP Environmental Scan 2004: 153). This dedicated unit, in conjunction with other RCMP immigration investigators, will also have a responsibility to develop human trafficking training for domestic law enforcement, promoting the prevention and awareness of antihuman trafficking through identified best practices, and assisting in the development of victim protection measures (RCMP Survey 2005: 7).

Prevention of human trafficking through awareness and educational initiatives are critical to anti-trafficking enforcement success (RCMP Survey 2005: 8-9). In 2003, the IWG created an information booklet, translated into 14 different languages and distributed around the world through Canadian embassies, designed to alert potential victims in other countries to the dangers of human trafficking (DOJ - Trafficking In Persons 2005: 1). More recently, in 2004, the IWG embarked upon producing additional 
publications and posters to alert potential victims and to inform law enforcement, and other concerned agencies, domestically and abroad, about the crime of human trafficking (DOJ Survey 2005: 6; RCMP Environment Scan 2004: 154).

Three main federal departments within the IWG (DOJ, RCMP, CIC) have also embarked upon an educational process within their respective departments to ensure that their personnel are sensitive and responsive to this issue. DOJ, on March $8^{\text {th }}$ and $9^{\text {th }}$ 2005, in partnership with the International Organization for Migration, hosted a human trafficking training seminar in Ottawa that involved personnel from Canadian police departments, crown prosecutors, immigration, customs and consular officials with the objective of bringing together the agencies responsible in combating human trafficking with the view to exchanging strategies, information and best practices (DOJ Survey 2005: 6; DOJ - Trafficking in Persons 2004: 1-2).

The DOJ training seminar led to a second training seminar hosted by the RCMP in May of 2005. At the second training session, the handbook Human Trafficking: Reference Guide for Canadian Law Enforcement was distributed to the participants. This guide has since been made available, either in electronic or hard copy format, to all Canadian law enforcement agencies, NGOs, judiciary and those involved in immigration and border control activities (RCMP Survey 2005: 8). This guide is based on the experiences of law enforcement agencies, primarily Canadian, working within the Trafficking Protocol framework, designed to assist Canadian law enforcement in 
understanding their role in anti-trafficking enforcement, and their responsibilities to trafficking victims (Dandurand et al 2005: 8). In addition, the RCMP has also ensured that an anti-trafficking training manual created by Interpol has been distributed to all of the RCMP immigration enforcement units located across Canada (RCMP Survey 2005: 8).

The RCMP has provided internal human trafficking training to its employees as part of its awareness campaign. This has taken the form of providing antitrafficking training to all RCMP members as they join the immigration enforcement program (RCMP Survey 2005: 8). In addition, anti-trafficking training, designed to provide investigators with the necessary skills sets to combat trafficking, is also provided to the RCMP Liaison Officers (LO) situated around the world in order that they can assist in investigations in source countries (RCMP Survey 2005: 8). Through cooperation with enforcement agencies in the countries in which they are stationed, RCMP LOs assist in identifying potential victims to those agencies as a preventative enforcement strategy (RCMP Survey 2005: 8).

The IWG, as tasked, has been coordinating the anti-trafficking response of the federal government. This includes the coordination of: the enforcement efforts by departments such as the RCMP and CBSA; the public awareness campaigns, locally and internationally by such departments as CIC; and the consultative process between Canada, other countries and international organizations designed to inform the Canadian 
government on shared anti-trafficking issues and experiences such that Canada can develop its own unique anti-trafficking strategy linked to the Trafficking Protocol (RCMP/DOJ/CIC Surveys 2005). Three of the lead agencies in the IWG (RCMP, DOJ \& CIC) have initiated, separately and collectively, educational and awareness practices. The RCMP has also created a national human trafficking enforcement unit which, beyond its responsibility for coordinating human trafficking enforcement in Canada and implementing enforcement strategies internationally, is also responsible for promoting human trafficking awareness (RCMP Survey 2005: 7). However, without the backdrop of a comprehensive national anti-trafficking strategy from the IWG, an assessment of Canada's anti-trafficking efforts is limited to a review of individual department initiatives.

Using a survey questionnaire designed specifically for each of the three federal departments (see Appendix), the three departments were asked if an evaluation had been conducted on any of their anti-trafficking initiatives to determine their effectiveness. In response, all three indicated that no specific evaluation of any initiative had been undertaken but did advise that they continue to explore enhancements to their anti-trafficking efforts on an ongoing basis (RCMP Survey 2005: 3; DOJ Survey 2005: 2; CIC Survey 2005: 4)

Each of the three surveyed agencies of the IWG (RCMP, DOJ \& CIC) confirmed that the IWG is in the process of developing a national strategy but provided 
no details about any proposed strategy in the survey responses. All three agencies reiterated that they are continuing the consultative process, including consultation with NGOs, in order to gather the necessary information from which to derive a national antitrafficking strategy which would include the issue of victim protection.

Quite some time has past since the IWG was tasked with this critical priority and there has been no indication as to when such a strategy will be in place. Why it has taken so long to produce a strategy remains unknown. Arguably, there are many factors that can influence or inhibit the development of a strategy, and only the participants in the IWG know the reasons for the delay.

Without a national strategy that can be subject to discussion and evaluation, questions such as: is Canada attending the right conferences, producing effective awareness/information anti-trafficking campaigns, developing appropriate enforcement approaches, or creating the appropriate victim protection strategy, will largely go unanswered. The answers to these and like questions are fundamental to ensuring that Canada's approach, in compliance with the Trafficking Protocol, will prevent and combat human trafficking while protecting its victims.

\section{Human Trafficking Legislation in Canada}

Two specific legislative initiatives have been undertaken by the Canadian government with respect to the Trafficking Protocol. The first piece of legislation, the 
Immigration and Refugee Protection Act (IRPA), fulfills the requirement of the Protocol's signatories to introduce anti-trafficking legislation as stipulated in Article 5 of the Protocol (United Nations 2000: 2-3). Part 3, Section 118 (1) of IRPA creates, for the first time in Canada, the offence of human trafficking (Department of Justice 2004: 16).

The second legislative initiative, Bill C-49, is currently working through the federal legislative process but has yet to be proclaimed as law. It was tabled in Parliament for first reading on May 12th, 2005 and is awaiting second reading as of October 2005 (Minister of Justice 2005:1-9). This bill contains amendments to the Criminal Code of Canada (CCC) - Sections 279.01 through 279.04, inclusive - which expand the definition of human trafficking to include the offence of domestic human trafficking (Minister of Justice 2005:3-4). Contrary to the human trafficking offence contained in IRPA which requires the illegal crossing of a Canadian frontier, the amendments to the CCC create a trafficking offence within Canada which does not necessitate crossing any of Canada's territorial boundaries.

Although Articles 6 through 8 in the Trafficking Protocol do not obligate the signatory countries to provide specific victim protection provisions within their domestic legislation, it can be argued that there is an inference in the wording of the Protocol that encourages the signatories of the Convention to implement domestic legislation as a means of victim protection. As mentioned in Chapter 5, portions of the wording contained in the three Articles have been deemed vague by NGOs such that 
widely divergent interpretations of the wording and associated obligations can be made by the signatories leading to varying and different results in the application of trafficking protection provisions. For example, Article 6 uses the following wording: "Each State Party shall ensure that its domestic legal or administrative system contains measures that provide to victims of trafficking in persons, in appropriate cases ..." (UN General Assembly 2000: 54). NGOs such as Anti-Slavery International contend that the only way to ensure that there is a 'domestic legal system' that will guarantee that trafficking victims are provided the protections as outlined in Articles 6 though 8 is if each State that signed the Convention passes legislation that guarantees the protections contained in the Protocol (Anti-Slavery International - Migration 2003: 24).

In Canada, the Canadian Council for Refugees (CCR) has criticized the Canadian government for not having introduced legislation that guarantees the Trafficking Protocol protections for trafficking victims (CCR 2004: 1). In particular, the CCR has focused on the claim that trafficking victims are routinely being deported from Canada without benefit of receiving the protection provisions as outlined in the Protocol (CCR 2004: 1). This sentiment is echoed by Anita Sheth of Save the Children Canada who, in an assessment of legislated trafficking protection provisions in Canada, noted that the new immigration law, IRPA, is inadequate because it does nothing to ensure protection for trafficking victims (Sheth 2003: 2).

In September of 2004, Jacqueline Oxman-Martinez and Jill Hanley 
published the research paper: A Follow-up Study of Canadian Policy on Human

Trafficking: Impacts of the Immigration and Refugee Protection Act in which they claim that "in this area of the protection of victims ... the Canadian government has made the least progress..." when compared to the government's overall efforts to comply with the Trafficking Protocol (Oxman-Martinez \& Hanley 2004: 10). Specifically, as a result of reviewing IRPA and interviewing unidentified representatives of the IWG, OxmanMartinez and Hanley conclude that neither IRPA, nor any other legislation in Canada, provides specific legal guidance to ensure the protection of trafficking victims (OxmanMartinez \& Hanley 2004: 10). According to Oxman-Martinez and Hanley, representatives of the IWG that they interviewed indicated that this would be the next area upon which the IWG would focus its efforts (Oxman-Martinez \& Hanley 2004: 10).

In response to the criticism of the government for not enacting specific legislation to protect trafficking victims, DOJ indicated that there are a number of legislated provisions in Canada that provide protection for all victims of crimes within Canada, including human trafficking victims (DOJ Survey 2005: 1-8). My research survey response from DOJ noted that the CCC contains numerous protection provisions for victims of crimes $^{19}$, including provisions for victim safety which is a shared responsibility between the federal, provincial and territorial governments (DOJ 2005: 5).

Although the DOJ survey response did not specify any of the protection provisions contained in the $\mathrm{CCC}$, it is believed that DOJ is referring to such sections as Section 17 - Compulsion by Threats, which protects victims under certain circumstance from being criminally responsible for committing an offence if they were forced into committing the offence by physical violence or the threat of violence (Criminal Code of Canada (R.S. 1985,c.C-46): s. 17; R.S., 1985, c. 27 (1st Supp.), s. 40. 
In addition, the research survey response by DOJ indicated that the federal, provincial and territorial levels of Canadian government have made a public commitment to provide enhanced protection and to respond to the needs of victims of crime by endorsing the Canadian Statement of Basic Principles of Justice for Victims of Crime in 2003 (DOJ

Survey 2005: 3) which reads as follows:

"In recognition of the United Nations Declaration of Basic Principles of Justice for Victims of Crime, Federal and Provincial Ministers Responsible for Criminal Justice agree that the following principles should guide Canadian society in promoting access to justice, fair treatment and provision of assistance for victims of crime.

1) Victims should be treated with courtesy, compassion and with respect for their dignity and privacy and should suffer the minimum of necessary inconvenience from their involvement with the criminal justice system.

2) Victims should receive, through formal and informal procedures, prompt and fair redress for the harm which they have suffered.

3) Information regarding remedies and the mechanisms to obtain them should be made available to victims.

4) Information should be made available to victims about their participation in criminal proceedings and the scheduling, progress and ultimate disposition of the proceedings.

5) Where appropriate, the view and concerns of victims should be ascertained and assistance provided throughout the criminal process.

6) Where the personal interests of the victim are affected, the views or concerns of the victim should be brought to the attention of the court, where appropriate and consistent with criminal law and procedure.

7) Measures should be taken when necessary to ensure the safety of victims and their families and to protect them from intimidation and retaliation.

8) Enhanced training should be made available to sensitize criminal justice personnel to the needs and concerns of victims and guidelines developed, where appropriate, for this purpose.

9) Victims should be informed of the availability of health and social services and other relevant assistance so that they might continue to receive the necessary medical, psychological and social assistance through existing programs and services.

10) Victims should report the crime and cooperate with the law enforcement authorities."

(Department of Justice 2003: 1) 
The research survey response of DOJ also referred to Bill C-2 that received royal assent on July $20^{\text {th }}, 2005$ and Bill C-49 which is currently before Parliament. Bill C-2, through new amendments to the CCC, provides enhanced protection for children and other vulnerable persons from sexual exploitation (DOJ 2005: 1). It will increase penalties for existing offences of sexual exploitation, create new offences such as 'voyeurism' - another form of sexual exploitation, and through procedural reforms facilitate the testimony of young persons in court in response to their special needs as minors (Legislative Summaries 2005: 2). Bill C-49 also provides for amendments to the $\mathrm{CCC}$ which will lead to the creation of the offence of domestic human trafficking (DOJ 2005: 2). Presumably, this will enhance law enforcement's ability to combat human trafficking and thus, through prevention, benefit potential victims.

The DOJ research survey response indicated that CIC is responsible for any protection provisions within IRPA and did not comment on whether or not there was a need to formalize such protection in IRPA (DOJ Survey 2005: 8). The CIC response to the research survey indicates that the protection of trafficking victims is a priority to CIC, the IWG and in turn, the Canadian government (CIC Survey 2005: 1). The response also advises that IRPA and the associated regulations currently provide a managed immigration program and is sufficient legislation to meet Canada's obligations within the Trafficking Protocol and the needs of trafficking victims (CIC Survey 2005: 2).

As outlined by CIC, trafficking victims can avail themselves of certain 
protection provisions contained in IRPA through such areas as refugee claims, temporary residence permits and applications to remain in Canada on the basis of humanitarian and compassionate considerations, all of which afford protection and which are available to all foreign nationals who may not have legal status within Canada (CIC Survey 2005: 2). In addition, like DOJ, the $\mathrm{CIC}$ research survey response also referred to the shared responsibility between the federal, provincial and territorial governments to provide Article 6 protections to trafficking victims such as a safe haven, health treatment, legal and social assistance (CIC Survey 2005: 2).

As noted above, NGOs believe that there should be specific legislation created by each signatory that assures the delivery of the Protocol protection provisions to trafficking victims. It is their position that only through a legislative approach can victims be assured of protection. Conversely, it appears that the IWG representatives surveyed are of the view that all of the protection provisions detailed in the Protocol exist, in some fashion, within current Canadian legislation. But as Oxman-Martinez and Hanley have pointed out, because there is no specific legislation in Canada that articulates exactly what protection will be provided to trafficking victims and how it will be delivered, it leaves the treatment of trafficking victims as a matter of police discretion since the police are the usual first point of contact for victims (Oxman-Martinez \& Hanley 2004: 10). Thus, what protection will be provided to the victim is dependent upon what the police officer understands is available and on their understanding of their role in securing or providing the necessary protection. 
The guide, Human Trafficking: Reference Guide for Canadian Law Enforcement (May 2005), that has been recently provided to law enforcement in Canada attempts to provide guidance to law enforcement on the protection of trafficking victims. It suggests the adoption of a crime prevention 'toolkit' approach used in the United Kingdom as a means of understanding and ensuring that protection of victims is addressed (Dandurand et al 2005: 12). The 'tool kit' approach entails identifying specific steps that the police may take or consider, and resources available to the police, in reaching their decision as to how they will proceed. Unfortunately, although this guide itemizes the human trafficking protection responsibilities of the police, it is only from a 'may include' context (Dandurand et al 2005: 13). Thus, although it is intended to alert the enforcement officer to potential considerations, as Oxman-Martinez and Hanley noted, it still remains at the discretion of the police as to what protection will be provided. As a consequence, this might result in the concern that NGOs have identified, an inequity of protection services being provided to trafficking victims.

It is evident that legislated protection for victims of crime, including trafficking victims, does exist in Canada. The difficulty is to ensure that the trafficking victim is advised of the protection provisions and how to avail themselves of the protection. There is no question that the police, supporting provincial and federal agencies, NGOs and other community organizations respond to the day to day needs of victims of crime in Canadian communities by using the myriad of currently available legislated protection provisions. But, as argued by NGOs, the victims of trafficking are 
so unique that they require specific consideration within Canadian legislation.

By virtue of the government having introduced specific legislation that recognizes the uniqueness of the offence of human trafficking, I would agree with the NGOs that it is a reasonable expectation that the government would also provide specific legislated protection for the victims. Like the need to provide specific protection provisions for certain groups within our society, such as children, as evidenced by Bill C2 , trafficking victims are in a unique situation in our country. I would suggest that by being illegally in Canada, under duress, faced with the uncertainty created by cultural differences and a fear of authorities due to their participation in criminal activity, it necessitates special considerations for trafficking victims (Tzvetkova 2002: 61-63; Chin \& Dandurand 2001: 11-12). It is my view that specific legislation detailing the trafficking victim protection entitlements and in turn, identifying what agency is responsible to ensure the protection provisions are provided, is an imperative.

\section{The Treatment of Trafficking Victims in Canada}

One of the major criticisms made by NGOs, such as Anti-Slavery International, of many of the signatories of the Convention is the view that the signatories should implement a specific and separate immigration process for handling of trafficking victims (Anti-Slavery International - Support (2003): 2). To date, this approach has not been adopted in Canada. 
According to CIC, IRPA and its associated regulations provide the necessary legal framework to address the related Protocol protection provisions as reflected in Articles 7 and 8 (CIC Survey 2005: 2). In particular, IRPA provides trafficking victims with a number of possibilities to remain in Canada for a specified or indefinite period of time such as the refugee claims process, humanitarian or compassionate applications, or the issuance of temporary resident permits due to the stay of removal orders (CIC Survey 2005: 2). In addition, CIC advises that trafficking victims who are subject to removal orders can request a Pre-Removal Risk Assessment (PRRA) which "assesses the risk an applicant may face if repatriated to his or her country of origin" (CIC Survey 2005: 3). Should the assessment reveal that the applicant is at risk, the individual can apply for permanent resident status and the removal order is stayed (CIC Survey 2005: 3).

The main immigration process which trafficking victims may use in order to remain in Canada prior to or after having been interdicted by law enforcement is an application for protection through the Canadian Refugee System (CRS) (CIC Survey 2005:2). As noted above, other avenues exist within the Canadian Immigration System (CIS) but an application through the CRS is the most likely step to be taken in the immigration system by a trafficking victim. Through its refugee determination system, Canada offers protection to refugees, and other persons who may not qualify as refugees, who fear for their safety if they are returned to their country of origin (CIC - CRS 2002: 1). 
The CRS recognizes two categories of applicants that would qualify for refugee protection. The first is a 'Convention Refugee' as defined by the United Nations Convention Relating to the Status of Refugees, 1951 - "people who are outside of their country of nationality or habitual residence and who are unable or unwilling to return to that country because of a well-founded fear of persecution for reasons of race, religion, political opinion, nationality or membership in a particular social group" (CIC - InCanada 2002: 2). The second group is the 'persons in need of protection' group who do not qualify as refugees but their removal to their country of origin might subject them to the possibility of torture, cruel and unusual treatment or punishment, or there would be a risk to their lives (CIC - In-Canada 2002: 2).

According to the CIC website (www.cic.gc.ca), anyone is eligible to make a refugee claim. Once an application has been made and the refugee claimant fingerprinted and photographed, a CIC officer reviews the application and determines if it should be referred to the Refugee Protection Division (RPD) (CIC-In-Canada 2002: 2). The CIC officer can refuse to refer the application if any of the following are applicable:

- "the person has already been given refugee protection under the Immigration and Refugee Protection Act or Regulations;

- a previous claim for refugee protection has been rejected by the IRB;

- the person has been recognized as a Convention refugee by another country and can return to that country;

- the person arrived in Canada from a designated safe third country. A safe third country is one where the person could have sought protection. a previous claim has been declared ineligible by CIC officers;

- a previous claim has been declared withdrawn or abandoned by the RPD;

- the person has been found inadmissible by a member of the Immigration 
Division of the IRB for reasons of security, serious criminality or involvement in organized crime, or for violating human or international rights;

- $\quad$ or the person has been named in an unenforced removal order."

(CIC-In-Canada 2002: 2)

Should the claimant not fall into one of the above noted categories, then the application is processed by the RPD based on the previously mentioned two refugee categories that would qualify the claimant to be deemed a refugee and remain within Canada.(CIC-In-Canada 2002: 3). According to the CIC research survey response, all of the foregoing processes are contingent upon the individual, including trafficking victims, initiating the process by way of application (CIC Survey 2005: 1-2). Therefore, should the individual not avail themselves of the process for a variety of reasons, including a lack of understanding of the process and their rights within it, the trafficking victim could be deemed to be illegally within Canada and deported back to their country of origin with no consideration of their status as a trafficking victim.

NGOs such as the Canadian Council for Refugees (CCR) believe that this response by Canada to use the existing immigration process to handle trafficking victims is inadequate (Oxman-Martinez \& Hanley 2004: 11). The CCR believes that although the refugee determination system, in many respects, is an exceptional system for those seeking protection in comparison to refugee systems existing in other countries, Canada's system continues to retain significant flaws. In particular, the CCR believes that the current government practice of using unqualified political appointees as adjudicating 
members of Immigration and Refugee Boards (IRB) undermines the effectiveness of these tribunals (CCR - Protecting Refugees 2003: 1-2; CCR - Canada's Refugee 2003: 12; CCR - Trafficking 2003: 1-14). The CCR strongly supports the creation of a special status for trafficking victims within the immigration system to ensure that victims receive counseling, support and most importantly, protection through granting asylum for victims, either temporarily or permanently (CCR - Trafficking 2003: 6-7).

The Standing House Committee on Citizenship and Immigration (SHCCI) continuously monitors the immigration system and provides reports and recommendations to Parliament to improve the system and its related processes such as refugee determination (SHCCI 2000 - 1-20; SHCCI 2002: 1-84; SHCCI 2005: 1-2). In one such report, the Committee acknowledged that there are numerous complexities involved in managing immigration in Canada and that the refugee system is in need of improvement. The Committee also advised that it accepts the oversight role of the CIS and the responsibility to provide recommendations to government to improve the system on an ongoing basis (SHCCI 2000: 19). To date, no recommendation has been made to give trafficking victims special status within the refugee determination process as suggested by the CCR.

Special status for trafficking victims through the creation of a separate immigration process designed specifically for victims is a controversial issue. As noted above in Chapter 5 , there is a concern by some countries that by giving trafficking 
victims special refugee status, there would be a flood of fraudulent refugee claims. However, as further noted in the preceding chapter, there is no evidence to support this contention, and Anti-Slavery International, based on their evaluation of Italy's experience using this type of suggested process, specifically rebut this claim (AntiSlavery International - Support 2003:2).

In Canada, the position currently adopted by the government, as outlined above, is that the CIS and by extension, the CRS, meets the protection needs of trafficking victims and fulfills the government's obligations to the Trafficking Protocol. In order to assist in determining the validity of this position, an evaluation of how trafficking victims have been treated within the CRS was completed. This entailed examining all available IRB decisions involving trafficking victims since 1992. Surprisingly, the results do not clarify the issue but rather, introduce a greater complexity.

Research conducted by Professors Christine Bruckert and Colette Parent of the University of Ottawa, on behalf of the RCMP Research and Evaluation Branch, revealed that between 1992 and 2002 only 8 applications for refugee status related to human trafficking, all made by women, were initiated (Bruckert \& Parent 2004: 14) ${ }^{20}$. Of 
the eight applications, only 3 were successful and granted refugee status (Bruckert \& Parent 2004: 14). Bruckert and Parent examined these cases in detail to determine why 3 cases succeeded and the remainder did not.

Based on the evaluation conducted by Bruckert and Parent, the success or failure of the applicant receiving refugee status hinged primarily on the Immigration Review Board's interpretation of the 1993 Supreme Court decision 'Canada v. Ward ${ }^{21}$. In particular, the refugee claims contended that the applicant qualified for consideration as a 'refugee' because they were a member of a 'particular social group' as referenced in the 1951 UN Convention Relating to the Status of Refugees (Bruckert \& Parent 2004: 16-29). The Ward decision clarified Canada's interpretation of a 'particular social group' referenced in the Convention and provided 3 possible categories of social groups relative to a refugee application:

1) "groups identified by an innate or unchangeable characteristic;

2) groups whose members voluntarily associate for reasons so fundamental to their human dignity that they should not be forced to forsake the association; and,

3) groups associated by a former voluntary status, unalterable due to its historic permanence."

(Canada v. Ward [1993]: para 70). 
Bruckert and Parent argue that the primary reason for the failed applications related directly to the refugee tribunals in 5 out of the 8 refugee claims failing to recognize the nexus between the applicants, who were sex trade workers (forced or voluntary), and their fear of persecution if returned to their country of origin by virtue of being a member of a 'particular social group' (prostitutes) as per Category 3 of the Ward definition (Bruckert \& Parent 2004: 16 - 29). For those 5 applications that failed, Bruckert and Parent surmise that the tribunal decisions were "characterized by a lack of sensitivity to the push and pull factors that engender irregular migration, to issues of Asian culture, to economic marginality and to the reality of 'sex trade workers' lives" (Bruckert \& Parent 2004: 29).

I retraced the research conducted by Bruckert and Parent. Using the same Internet electronic tool, Quicklaw, and using similar key word searches such as illegal migrant, trafficking, and prostitution and refugee, I was able to search the electronic data banks for Canadian Judgements (CJ), Canadian Criminal Cases (CCC), Immigration Law Caselaw (IMRQ) and Convention Refugee Determination Division (CRDD). In addition to the 8 CRDD decisions located by Bruckert and Parent in 2004, I was able to locate 2 additional refugee hearings involving 2 male minors who sought refugee protection from forced labour exploitation. ${ }^{22}$

The 2 additional cases, P.G.L. and A.F.W. are unique in that they involved 
2 Asian male children, while the other refugee claimants were all adult females. These two cases also sought refugee status based on a variety of submissions including submissions related to the minors being members of a 'particular social group', in this case - children, as defined by Category 3 in the Ward decision. However, both Immigration and Refugee Board decisions rejected the refugee claims, including arguments that the claimants were members of a 'particular social group' because the claimants were unable to demonstrate the nexus between their identified social group and the projected persecution.

For example, in the P.G.L. decision, the IRB's analysis reflected careful consideration of all issues raised, including the argument that the applicant was a member of a 'particular social group' - children - by virtue of he being a child, and that children are subject to persecution by traffickers in China (P.G.L. [2001] C.R.D.D. No. 150 No. V99-02911). The IRB accepted that the applicant was a member of a 'particular social group' as referenced in Canada v. Ward. It further recognized that P.G.L. had been trafficked to Canada as he was unable to consent to being smuggled by virtue of being a child. However, the IRB disagreed with the applicant's argument that he would be persecuted upon return to China as no evidence had been presented by the applicant that would support the belief that smuggling/trafficking organizations in China were targeting the social group of children (P.G.L. [2001] C.R.D.D. No. 150 No. V99-02911- para. 52). In essence, the applicant could not demonstrate the connection between his social group and the projected persecution. Thus, for this and the many other reasons provided in the 
decision, the application for refugee status was denied and P.G.L. was ordered deported.

In reviewing the 8 cases cited by Bruckert and Parent, and the 2 additional cases that were located, I am not satisfied with Bruckert's and Parent's conclusions with respect to the failed claims. Given the limited number of cases involved and that arguably, there are other equally plausible explanations contained in the IRB's decisions such as the lack of applicant credibility which tended to undermine the respective applications, I believe it is premature to conclude that an inherent bias or lack of sensitivity exists on the part of the Immigration Review Board (IRB) panels involved.

What I did find striking about these decisions is the actual number of applications. Given the public focus that has been placed on human trafficking by both government and NGOs, I had presumed that there would be a significant number of refugee applications by trafficking victims. The lack of claims, in my view, speaks directly to the issue of the scope of the human trafficking problem as discussed earlier in this paper and in turn, raises the issues of what strategies, policies and processes the government is implementing based on a possibly skewed perception of the extent of human trafficking in Canada.

However, I also recognize that other explanations for the small number of refugees claims by trafficking victims may exist such as the view that trafficking victims are not accessing the CRS because they are not fully informed of their rights, that this 
lack of understanding of their rights is further compounded by a complex immigration system which re-enforces the need for a streamlined process dedicated to victims, and/or the fear of reprisals from criminal organizations has dissuaded victims from making claims (Issacs Survey 2005: 1-2). It has also been suggested that trafficking victims are afraid to approach authorities because of the victim's involvement in criminal activity such as prostitution and fear detention and deportation (Tzvetkova 2002: 61-63; Chin \& Dandurand 2001: 12). According to the CIC research survey response, the IWG is exploring various ways to enhance data collection and analysis in order to assist in determining the scope of trafficking in Canada, and in turn, the treatment of victims within the CRS (CIC Survey 2005: 6).

Currently, CIC has no system in place to identify trafficking victims for the purposes of data collection nor to evaluate how trafficking victims are currently being processed within the CRS (CIC Survey 2005: 6). As a consequence, other than the hearings noted above that have become public record, there is no information presently available which would shed further light on how many trafficking victims have been encountered by CIC or any enforcement agency in Canada nor the effectiveness of the CRS process in meeting the needs of trafficking victims, especially with regards to protection. It is clearly evident that immediate measures should be taken to determine the scope of the human trafficking in Canada in order to ensure appropriate strategies are devised and implemented. 
From an enforcement perspective, the first charge for human trafficking under IRPA, Section 118, was made in Provincial Court in Vancouver on April $12^{\text {th }}$, 2005. Vancouver resident, Wei-Chi (Michael) $\mathrm{Ng}$ was charged with trafficking by bringing to Canada two women and forcing them to work in the sex trade (UNIAP 2005: 5). This prosecution is still awaiting disposition before the courts. This is the first charge of human trafficking since the legislation came into force almost 3 years ago. Like the lack of refugee claims by trafficking victims, can the lack of prosecutions be a reflection of the scope of human trafficking in Canada?

The RCMP research survey response indicates that they believe that there are other cases of human trafficking occurring but the 'clandestine nature' of the crime makes the investigation of this offence difficult (RCMP Survey 2005: 5). In addition, the RCMP and DOJ research surveys also indicated that a number of unspecified CCC prosecutions have been used in the past, and are still being used, to successfully prosecute traffickers, although no specifics were provided (RCMP Survey 2005: 5; DOJ Survey 2005: 4). In a follow-up question to the RCMP requesting details of CCC prosecutions of traffickers, the RCMP advised that they have no specific instances that can be provided but advised that it is a generally held belief within the law enforcement community that such prosecutions of traffickers using $\mathrm{CCC}$ offences has occurred (RCMP Survey - follow-up email 2005).

As noted by the RCMP, their records management system was not 
designed to capture this information as the offence of human trafficking did not exist prior to 2002 (RCMP Survey - follow-up email 2005). However, the RCMP has since introduced this capability within their systems so that statistically, investigations and prosecutions are monitored. In addition, beginning in 2003, the RCMP have also initiated an awareness strategy, focused on law enforcement, the public, health care providers, and other government and non-government agencies, in order to encourage more people to come forward with information on trafficking to augment the limited information currently available (RCMP Survey 2005: 5). To date, no evaluation of the effectiveness of the RCMP's awareness campaign has been conducted.

It is evident that there is limited statistical information available from which to draw informed conclusions about the treatment of trafficking victims under Canadian law. Is this a reflection of the scope of the trafficking problem in Canada or is it because victims do not understand what protection is available and how to access that protection? These and other like questions will be a source of debate for some time until government departments participating in the IWG, such as CIC and DOJ, modify their respective data collection practices in order to capture the information necessary to answer these types of questions. Through the gathering of factual data, and subsequent analysis, the IWG will be better positioned to determine the most effective national strategy to combat human trafficking in concert with proven measures to protect trafficking victims. 


\section{Canada's Response to Protection Provision Gaps}

Chapter 5 identified two key areas perceived by NGOs as gaps in the protection of trafficking victims. The chapter examined the global issues of the revictimization of human trafficking victims through their prosecution and deportation, and the ongoing debates related to temporary versus permanent resident status for victims. In Canada, NGOs such as the Canadian Council for Refugees (CCR) have also shared these concerns and have been lobbying the Canadian government to address the two issues (CCR 2004:1).

As previously examined, many countries are treating victims of trafficking as criminals which has led to their prosecution and a resultant deportation from the country, without the benefit of being provided any trafficking protection provisions (US Committee on Refugees 2000: 6). A delay in deportation in some countries, especially in Europe, could be secured by the victim if they were willing to cooperate with law enforcement in order to prosecute traffickers. But, this tactic by law enforcement agencies to only provide protection based on victim cooperation is also viewed as a further victimization of trafficking victims (Pearson 2002: 56; Piotrowicz 2002: 263278). This has led NGOs to promote the concept of a temporary reprieve for victims by suggesting the victims be automatically provided a 'reflection period' during which they would receive necessary support and have the time to consider, without the pressure to cooperate with the police, the options available to them (OSCE 2003: 3; Trafficking Conference 2003: 1). 
In Canada, NGOs, such as the Metro Toronto Chinese and Southeast Asian Legal Clinic (MTCSAL) and the Philippine Network for Justice and Peace (PNJP), have also voiced their concerns regarding the re-victimization of trafficking victims by their criminal prosecution and subsequent deportation (CCR 2004: 1) As explored earlier in Chapter 5, NGOs have argued trafficking victims interdicted during criminal investigations are trapped in highly abusive situations and therefore, any prosecution of them for criminal offences such as prostitution is simply a further victimization of these vulnerable persons. The PNJP, like other NGOs, believes that victims should automatically be provided temporary status and access to protection without conditions (CCR 2004: 1).

Deborah Isaacs, a Canadian advocate for trafficking victim protection, in response to the research survey for this study, strongly supported the concept of a 'reflection period' (Isaacs 2005: 2). Isaccs pointed out that some of the Canadian trafficking victims have been so traumatized by their experience that any proposed 'reflection period' must be of sufficient length to provide time for the victim's recovery (Isaacs Survey 2005: 2). In addition, she did not support the idea of temporary status being tied to the victim's cooperation with law enforcement. Isaac believes that too many of the victims are in fear of their traffickers to the extent that they are afraid to cooperate with the police and lose the opportunity to receive protection (Isaacs Survey 2005: 2). As Isaacs indicated in the survey response to the question on 'reflection periods', Canada has not done enough to protect victims of trafficking and should be 
criticized for its efforts (Isaacs Survey 2005: 2). This view is also shared by another Canadian trafficking victim advocate, Pierrette Boissé of the NGO, Congrégation de Notre-Dame, who believes that Canada's efforts have not met the needs of victims (Boissé Survey 2005: 1).

The survey sent to DOJ, CIC and the RCMP, sought their views on the NGOs' proposal for 'reflection periods'. None of the three agencies provided an opinion as to the worth of such an approach other than to advise that the IWG is "examining issues that affect TIP (trafficking in persons) victims who have no immigration status in Canada" (DOJ Survey 2005: 4). The three agencies did advise that the provision of temporary status in Canada and/or the provision of protection to victims is not contingent upon the trafficking victim's cooperation with law enforcement in order to prosecute traffickers (DOJ 2005:4; RCMP Survey 2005: 4).

With regards to the debates over temporary versus permanent resident status, the CCR advocates that trafficking victims should be allowed to regularize their immigration status within Canada (from illegal to legal) and remain on a permanent basis (CCR - Trafficking 2003: 3). Specifically, the CCR supports trafficking victims receiving temporary status based upon "the inclusion of the category of "trafficked person' in the IRPA's definition of 'person in need of protection'" (Oxman-Martinez \& Hanley 2004: 11). An adoption of this proposal would result in a new recognized class of refugee that would be entitled to apply for permanent resident status in Canada 
(Oxman-Martinez \& Hanley 2004: 11)

The opinion of CIC was sought regarding the issue of temporary resident status for victims in Canada, and on the issue of creating a separate system for trafficking victims as advocated by NGOs. The CIC Survey response indicates that at this time, CIC is of the view that the CRS is a sufficient process to meet the protection of trafficking victims (CIC Survey 2005:1-9). However, CIC did indicate that the IWG continues to examine this and other issues on an ongoing basis in order to strengthen Canada's response (CIC Survey 2005:3).

The solutions for these two issues provided by NGOs, such as the CCR, appear to hinge upon securing a recognition from the Canadian government that trafficking victims are unique victims of a unique crime. Thus, NGOs take the position that trafficking victims require a responsive process separate from the current immigration system in order to address the needs of victims. On the other hand, the survey responses, particularly those of CIC, tend to indicate that the government does not agree with Canadian NGOs, believing that the existing CIS is a reasonable approach to address trafficking victims' needs but the government has not shut the door on considering future alternatives.

\section{Conclusion}

Canada has worked diligently to comply with the Trafficking Protocol's 
requirements. It has successfully created anti-trafficking legislation in the form of IRPA (2002), and continues to pursue this legislative avenue with the recent tabling in Parliament of Bill C-49. Canada, through an enhanced IWG, has ensured that affected government departments have adopted a collaborative anti-trafficking approach. It has engaged communities and NGOs in anti-trafficking discussions through conferences and roundtable meetings in order to seek their input and participation. Various government departments such as DOJ and the RCMP have embarked upon awareness strategies for their employees, Canadian communities, and for the international community. However, most of the accomplishments to date relate to anti-trafficking enforcement and little effort has been undertaken by the Canadian government to protect trafficking victims beyond using existing pre-Protocol 'victim of crime' protection programs and practices.

There is no national federal government strategy concerning antitrafficking which clearly articulates the measures to be undertaken to ensure the protection of trafficking victims. Although there is specific legislation creating the offence of human trafficking, the government has chosen not to introduce legislation that would clearly delineate the protection expectations for the victims of this unique crime. There are no new programs or processes that coordinate the delivery of trafficking victim protection measures nor has any government agency been tasked with this responsibility. In many respects, the Canadian government has chosen a 'laissez-faire' or a 'wait and see' approach to providing specific protection provisions for trafficking victims. As evidenced by the survey responses from DOJ and CIC, the government currently believes 
that existing pre-trafficking legislation and procedures are sufficient to comply with Articles 6 through 8 of the Protocol.

From a purely technical perspective, I would agree with the government's position that it is in compliance with Articles 6 through 8 of the Protocol. With regards to Article 6, Canada does have potential privacy protection provisions for trafficking victims imbedded within legislation, such as the court ordered publication ban process contained in the CCC (DOJ Survey 2005:1). It does have an administrative system in place to ensure all victims of crime, including trafficking victims are informed of proceedings and relevant information. As noted above, all levels of government are cooperating with the view to ensuring that a high level of protection is being provided to victims of crime in relation to physical safety, medical, educational, and employment opportunities. There are also methods for victims of crime to seek compensation from those who commit the crimes against them such as through restitution orders provided by the courts at the time of sentencing. (DOJ Survey 2005: 7).

As noted by the CIC research survey response, the government believes that the CRS fulfills the requirements of Article 7 by providing measures that permit trafficking victims the opportunity to remain in Canada, either temporarily or permanently. And, in terms of Article 8, there is a mechanism in place to ensure the safe return of victims to their country of origin through the CIS as well as the ability to assess the safety of a victim prior to their repatriation to their country of origin, if requested. 
However, from a more philosophical perspective, Canada has missed an opportunity to provide needed leadership on the international stage regarding the protection of trafficking victims.

The NGOs referenced in the preceding pages have voiced their concerns about Canada's approach to protecting victims. Through their gap analysis, NGOs have identified the need for a separate immigration system for the handling of victims in order to focus government efforts; the need for specific legislation that would guarantee the Protocol's protection provisions and designate which agency is responsible for ensuring their delivery; and the need to provide temporary or permanent resident status without the victim having to initiate the process.

Today, trafficking victim protection in Canada is contingent upon the involvement of numerous government agencies at various levels (municipal, provincial and federal) without the benefit of one department being responsible to oversee the provision of protection. Furthermore, many of the personnel within these departments may or may not be sensitive to the needs of trafficking victims if they have not received trafficking awareness training. In many respects, the victims are left to fend for themselves within the complex Canadian legal and immigration systems, with no assurance that adequate protection will be provided as there is no assurance that the victim will be informed of what protection is available or how to access it. The overriding risk to the victim is that the provision of protection may fall through the 
cracks of government bureaucracy and the victim will suffer accordingly.

At the beginning of this chapter, I referenced a quote from Justice Minister, Irwin Cotler, when speaking about the needs of human trafficking victims to the Ontario Bar Association: "The test of a just society .... is how it treats the most vulnerable of its members" (Cotler - Ontario Bar Association 2004: 2). In some respects, Canada does deserve a passing mark in that we are fortunate to live in a society that does legislate the provision of victim assistance programs, does dedicate resources to assist victims of crime, and does have legislation such as the Canadian Charter of Rights to ensure that the rights of the individual are respected and protected. But, I believe that Canada does not deserve high marks for how we have responded to protecting vulnerable trafficking victims.

Canada has missed an opportunity to provide leadership within the international community by setting a high standard for the provision of victim protection through a focused response. Human trafficking is recognized as a serious international issue and Canada recognized the issue's priority and ably implemented anti-trafficking enforcement strategies. However, the gravity of the crime also necessitates an equally aggressive response by Canada to protect trafficking victims beyond just saying that our current 'victim of crime' protection practices are sufficient to comply with Articles 6 though 8 of the Protocol. 


\section{Chapter 7}

\section{The Approaches of the US and the UK}

Chapter 7 is not intended to be an in-depth analysis of the different trafficking victim protection approaches implemented in the US and UK. Rather, the objective of this chapter is to highlight specific aspects of these two victim protection approaches as a means of underscoring certain issues previously discussed in Chapters 5 and 6. Specifically, the focus of the chapter will be on two main issues: the linking of the provision of victim protection services to a trafficking victim's willingness to cooperate with law enforcement and, the potential benefits that are derived by including an evaluation process within a trafficking victim protection program.

The US and UK approaches are very dissimilar in nature. The US implemented a formal legislated protection plan that is very much in line with the suggested approach endorsed by various NGOs in Chapter 5. The UK, however, opted to approach trafficking victim protection from a more informal perspective and did not legislate protection provisions. Yet, the UK did introduce some aspects of structure to their approach by initiating 'pilot' projects as a means of addressing the Protocol's trafficking victim protection requirements.

Although quite diverse in nature, both the US and UK approaches have adopted similar criteria regarding the provision of victim protection and its dependence upon the trafficking victim's willingness to cooperate with law enforcement. In addition, 
both approaches have incorporated an evaluation process in order to assess the effectiveness of their respective programs. This chapter reviews these approaches in terms of these two issues and applies it to the Canadian context.

\section{The US Approach}

In 1999, an assessment of the human trafficking situation in the United States was conducted by the Centre for the Study of Intelligence within the Central Intelligence Agency (CIA). The resultant report authored by Amy O'Neill Richards, International Trafficking in Women in the United States: A Contemporary Manifestation of Slavery and Organized Crime, was designed to identify the extent of trafficking into the US, to suggest various enforcement and prevention strategies, and to identify potential enhancements for the assistance and protection of trafficking victims (Richards 1999: iii). The significance of this report, in terms of this study, is that a portion of the report focused on victim protection in relation to identifying victim protection gaps and deficiencies that existed in the US, many of which are similar to the concerns raised by various NGOs, such as Anti-Slavery International, as noted in the preceding pages.

Richards noted that in 1999 there was a trend to treat victims of trafficking as criminals (illegal immigrants) and deport them from the US without the provision of any protection, including any follow-up measures by the US immigration services to ensure the safety of trafficking victims upon their repatriation to their country of origin (Richards 1999: 39). The CIA study also identified that trafficking victims were not 
receiving adequate shelter, health, psychological or legal services while in the US, with particular reference to the challenges victims face with limited language translation support (Richards 1999: 40-41). Richards noted that there is an increased safety risk posed to existing crime victim shelters in the US due to organized crime's involvement in trafficking and the specter of violence associated to trafficking victims (Richards 1999: 40-41).

With respect to temporary or permanent resident status for victims, the 1999 study revealed that US NGOs and the US Immigration and Naturalization Services (INS) were in agreement that the current immigration approach to trafficking victims is inadequate to address their needs (Richards 1999: 41). It was suggested in the report that a new immigration approach for trafficking victims be considered which would provide greater ease of access to immigration services and a greater opportunity for victims to remain in the US, either temporarily or permanently (Richards 1999: 40-41).

As a result of the growing international concern over human trafficking that emerged during the 1990s, the then pending 2000 UN Protocol on human trafficking, and reports such as the one prepared by Amy O'Neill Richards, the US government responded to the growing crime of human trafficking by creating specific trafficking legislation, the Victims of Trafficking and Violence Protection Act of 2000 (VTVPA) (Bishop 2003: 219-221). The VTVPA was intended to address the issues pertaining to human trafficking prosecutions by providing specific legislated offences, and to also 
ensure that adequate protection is being provided to trafficking victims (Bishop 2003: 221).

Contrary to the Canadian approach, the US government legislated specific trafficking protection provisions within US domestic law. These provisions are contained in Section 107 of Division 'A' - Trafficking Victims Protection Act of 2000 (TVPA) within the VTVPA and correlate with those identified in Articles 6 though 8 of the Trafficking Protocol (VTVPA 2000: Div. 'A', Sec. 107). This approach addressed many of the issues raised by NGOs with respect to providing: a focused victim protection response through legislation, a separate immigration process for victims to address the issue of temporary and permanent resident status, and a monitoring system to oversee the delivery of protection.

Under the TVPA, the US government departments of Health \& Human Services (HHS), Labor, and Legal Services are responsible for the coordination and delivery of protection services to trafficking victims. This includes a legislated requirement on the foregoing departments to expand trafficking victim benefits and services beyond what currently existed in the US at the time the TVPA was enacted (VTVPA 2000: Div. 'A', Sec. 107, b,1,B). The TVPA also introduced a new immigration 'certification' process designed specifically for trafficking victims which results in the issuance of a ' $\mathrm{T}$ ' visa to victims in order that they may remain in the US, either temporarily or permanently (VTVPA 2000: Div. 'A', Sec. 107, b,1,E). 
In October of 2001, the US National Institute of Justice contracted with Caliber Associates, Inc. to undertake a project to evaluate US government efforts to protect trafficking victims. In 2003, Caliber and Associates published their findings in the report, Needs Assessment for Service Providers and Trafficking Victims (Clawson et al 2003: 1-69). The mandate of this study was to review the trafficking victim protection efforts undertaken by various US government departments since the creation of the TVPA, and to provide recommendations to the government to enhance existing victim assistance practices (Clawson et al 2003: 1).

The key findings of the study revealed that in some instances the TVPA was an inhibitor of the delivery of trafficking protection services (Clawson et al 2003: 5, 26-27). In particular, the report noted that with respect to providing temporary sanctuary for trafficking victims, the TVPA criteria for victims to qualify for protection services, including the issuance of ' $T$ ' visas, was too stringent. The result is that many potential victims who do not qualify under the TVPA are left with virtually no protection services (Clawson et al 2003: 26-27). The report also noted that there still remained inadequate shelters and housing available for victims, that accessing and knowledge of services available was still limited, and that awareness training for service providers needed to be more effectively delivered (Clawson et al 2003: 18-30).

The Caliber Associates report provided a number of recommendations, including the need to streamline the trafficking victim 'certification' process in order to 
provide greater ease of access by trafficking victims to the related ' $\mathrm{T}$ ' visa. The report also recommended that a trafficking database be established, a national trafficking victim service provider referral list be created, and an extensive training and awareness program across the breadth of the US government be implemented (Clawson et al 2003: 31-38).

In addition to the Caliber report, other US government reports such as the Trafficking in Persons Report tabled in the US Congress annually and the studies by various US state governments have also assessed the effectiveness of the delivery of victim protection services. For example, the 2004 Washington State Task Force against Trafficking of Persons evaluation for the Department of Community, Trade and Economic Development of the State of Washington echoed many of the recommendations contained in the Caliber report (Office of Crime Victims Advocacy 2004: 1-93). The report was designed to assess current US state practices and to recommend enhancements to the delivery of victim protection services at the state level.

As a reflection of the importance of these evaluations, the US federal and state governments have implemented a number of measures to enhance the delivery of protection for trafficking victims, including new legislation such as the Trafficking Victims Protection Reauthorization Act of 2003 which incorporates many of the issues raised by the Caliber report (Clawson et al 2003: 5). The US government has also established that the Office for Victim Assistance (OVA) at FBI headquarters in Washington will oversee the coordination of the delivery of trafficking victim protection 
services through a system of FBI victim specialists strategically located in the US (FBI Survey response 2005: 2).

In 2004, the US established the Human Smuggling and Trafficking Center which is designed to integrate the enforcement activities of various US government departments combating human trafficking (FBI Survey response 2005: 4). In July 2004, the Department of Justice, the Bureau of Justice Assistance and HHS embarked upon an human trafficking awareness campaign for federal, state and local prosecutors, enforcement agencies, and US NGOs (FBI Survey response 2005: 4). This campaign includes identifying victim protection services and the role of each level of government and agency in the provision of those services (FBI Survey response 2005: 4).

Although the US appears to have made substantial progress in providing protection to trafficking victims, NGOs such as Stop Violence Against Women (SVAW) remain critical of the US government's criteria that victim protection is dependent upon victim cooperation with law enforcement (Stop Violence Against Women 2004: 1; Pearson 2002: 122-124). Those victims who are unable or unwilling to cooperate with law enforcement do not qualify for trafficking victim protection and are deported as illegal immigrants. The SVAW believes that protection services for all trafficking victims should be provided without restrictions, and for those victims who cooperate with authorities, consideration should be given to providing them with permanent resident status (Stop Violence Against Women 2004: 1). 


\section{The British Approach}

Whereas the US approach to providing protection to trafficking victims has been a focused legislated response, the British have implemented, at a much slower pace, a 'pilot' project approach that tests service delivery models of victim protection to selected categories of trafficking victims. In particular, much of the British strategy has been premised on anti-prostitution initiatives and providing support services to trafficked women involved in prostitution, with little attention being paid to other forms of human trafficking (Monroe 2005: p. 101).

In 2000, the British Home Office report, Stopping Traffic: Exploring the extent of, and responses to, trafficking in women for sexual exploitation in the UK, noted that the majority of British law enforcement had limited knowledge and experience in dealing with the issue of trafficking, particularly as it relates to female trafficking victims participating in prostitution (Kelly \& Regan 2000: p. v). The report made a number of recommendations to enhance the British government's response to human trafficking, with particular emphasis on the government's need to partner with NGOs for the purposes of increasing trafficking awareness among law enforcement agencies, and to ensure that necessary support is provided to the female victims of trafficking (Kelly \& Regan 2000: p. vi-vii).

In 2002, the Nationality, Immigration and Asylum Act introduced the offence of human trafficking but the trafficking offence contained in Section 145 of the 
Act was limited to the person who facilitated the movement of another person into and out of Britain for the purposes of prostitution (Monroe 2005: p. 101). The linking of prostitution to trafficking was criticized in Britain by NGOs such as the Global Alliance Against the Trafficking in Women (GAATW) who viewed the Section as too restrictive and failed to recognize the diverse dimensions of human trafficking (Monroe 2005: p. 101-102). Section 145 was later repealed and replaced by Sections 57 through 59 of the Sexual Offences Act 2003 - trafficking into, within, and out of the UK for sexual exploitation - which did little to broaden the offence of trafficking beyond the direct link to prostitution and sexual exploitation, with no other forms of trafficking being considered (Monroe 2005: p. 101).

A 'white paper' produced by the British Home Office in 2002, Secure Borders, Safe Haven: Integration with Diversity in Modern Britain, examined many border related issues including the issue of protection and support for human trafficking victims within Britain. Paragraphs 5.31 through 5.35 identified a government need to implement a protection approach for victims, partnered with British NGOs (UK Home Office 2002: p. 85). This recommendation eventually led to the British government, in 2003, partnered with the British based NGO, Eaves Housing for Women, implementing the 'pilot' project known as the 'Poppy Project'(UK Home Office 2005: 1).

The 'Poppy Project' was a funded government initiative that would test a particular model of support/protection for a specific group of trafficking victims utilizing 
the expertise of government and non-government agencies (Taylor et al 2005: 2). In particular, it was designed to protect and support trafficking victims brought into Britain for the purposes of prostitution (UK Home Office 2005: 1). The project was initially planned to last approximately 6 months and accommodate 25 victims at any one moment in time (UK Home Office 2005: 1). The anticipated support would take the form of providing adequate housing, access to medical and psychological counselling, employment opportunities, legal advice, and assistance with their re-integration back into the victim's country of origin (UK Home Office 2005: 1). The services would be provided for up to 4 weeks during which time the victim was required to make a decision with respect to cooperating with the police (Taylor et al 2005: 4). Continued support to the victim beyond 4 weeks was contingent on the victim actively cooperating with law enforcement in the gathering of intelligence and evidence for the prosecution of traffickers (Taylor et al 2005: 4).

The specific trafficking victims targeted by the project were women who had been transported into Britain for the purposes of prostitution. Thus, if you were not female, not smuggled into Britain, not working as a prostitute or not having recently worked as a prostitute after having escaped a trafficker, and you were unwilling to cooperate with government officials, you would not qualify for assistance (UK Home Office 2005: 1). According to NGOs, such as the Refugee Women's Resource Project (RWRP), the 'Poppy Project' fails to recognize the needs of exploited women and fails to address the broader issue of labour exploitation within the human trafficking debates 
(RWRP 2003: 1). The RWRP has been lobbying that the project be extended indefinitely, that support be provided without a link to cooperation with the police, that the project expand the categories of those eligible to participate and receive protection, that the concept of a 'reflection' period be introduced, and that consideration be given to providing victims with long term sanctuary within Britain (RWRP 2003: 5-6).

Like the Americans, the British have also instituted an evaluation process within their trafficking initiatives, including a comprehensive assessment of the effectiveness of the 'Poppy Project'. The summary of the findings of the evaluation of the 'Poppy Project' were published in September of 2005 while the main report is pending publication. The findings reveal that the police and government expectations for the project were often not met during the life cycle of the project (Taylor 2005: 1-2). Specifically, the government had entered into the project with the anticipation that through the cooperation of trafficking victims, intelligence and evidence would be obtained such that prosecutions of traffickers would be initiated (Taylor 2005: 1-2). However, covering the evaluation period of March 2003 to July 2004, no arrests nor any prosecutions of traffickers have resulted from the information provided by trafficking victims (Taylor 2005: 2). Although the evaluation has led to recommendations that will foresee the continuation of the project and the easing of the criteria for the types of trafficking victims that qualify, the report still promotes the concept of linking victim support to law enforcement cooperation and reflects the continued focus on antiprostitution (Taylor 2005: 2). 
A comprehensive study of the 'Poppy Project' would be an interesting undertaking but is beyond the scope of this study. It is sufficient for this paper to understand that the approach in Britain, like the approach in the US, tied trafficking victim protection to the victim's willingness to cooperate with the police, and incorporated an evaluation process within their victim protection initiative.

\section{Summary}

The British and the US governments, rather than relying on pre-Protocol victim services such as Canada has done, initiated protection programs and processes designed specifically for the victims of human trafficking. The US appears to have made the greatest effort towards ensuring trafficking victim protection. In particular, the US has legislated the provision of protection for victims, ensured the coordination of victim services by holding specific government agencies responsible for the delivery of the services, designed an immigration process solely for trafficking victims, and implemented an ongoing evaluation process in order to determine the effectiveness of their program.

Although the efforts of the US government appear to reflect a sensitivity to the criticisms of various NGOs, especially as it relates to legislating protection and providing a separate immigration process to permit trafficking victims the opportunity to remain in the US, success for their victim protection program has been limited. As noted by the SVAW, the stringent criteria for who qualifies as a victim limits access to 
protection services (Stop Violence Against Women 2004: 1). The evaluation conducted by Caliber Associates, Inc. confirms that as of 2003 only a limited number of ' $T$ ' visas for trafficking victims had been issued (23 approved and 150 awaiting processing versus an available annual limit of 5000) which appears to confirm the criticism that although the process for trafficking victims to remain in the US is available, it is extremely difficult to qualify for consideration (Clawson et al 2003: 6). SVAW noted that even if you qualify to be considered a victim, access to services remains dependent upon the victim's willingness to cooperate with law enforcement (Stop Violence Against Women 2004: 1).

The British government chose not to legislate protection for trafficking victims but did opt to implement 'pilot' projects such as the 'Poppy Project' as a means of evaluating a victim protection service delivery model. The British approach is very limited in that the British government only recognizes females who have been transported across British territorial boundaries for the purposes of prostitution as trafficking victims. It would appear that the British focus has some relationship to the issue of morality as the government's approach for anti-trafficking enforcement reflected by Sections 57 though 59 in the Sexual Offences Act 2003, and the 'Poppy Project', centres upon anti-prostitution efforts and not necessarily the broader anti-trafficking issues.

The protection that is offered by the British government is also directly 
linked to the potential victim's cooperation with law enforcement. Thus, as is the circumstance in the US, if a victim does not meet the criteria for consideration as a trafficking victim, and is unwilling to assist the police, the victim is deported as an illegal immigrant without benefit of protection.

The evaluations conducted by the US and UK demonstrate the value of having a review process within a victim protection program. In these two examples, the assessments conducted identified a number of potential deficiencies within the respective approaches, including problems associated with the above noted qualification criteria for trafficking victims. As a consequence, both countries have attempted to respond to the recommendations within the evaluations although arguably not to the degree that may be desired.

The importance and value of an evaluation process as a critical component of any victim protection program cannot be overstated. It provides a means to assess performance by the government, identify areas for improvement, and hopefully, result in the desired changes. Where Canada could be seen as one of the first signatories of the Convention not to tie victim protection to law enforcement cooperation, Canada has been remiss for not having implemented an evaluation process in order to be able to assess the performance of it's approach to trafficking victim protection.

The issue of trafficking victim protection being contingent upon co- 
operation with law enforcement has been one of the major themes that permeate the debates between NGOs and the signatories regarding the application of the provision of victim protection services. It was examined in Chapter 5 and is revisited in this chapter in order to emphasize my view that this criteria has a significant negative impact upon trafficking victims and their receipt of critical victim services.

Canada has chosen not to implement such a criteria for trafficking victims and I believe this to be a positive attribute of the Canadian approach. Nowhere in the Trafficking Protocol is such a criteria referenced or required. All trafficking victims, regardless of their willingness to cooperate with authorities, should receive their protection entitlements without reservation. 


\section{Chapter 8}

\section{Conclusion}

The protection provisions in the Trafficking Protocol are intended to ensure that each signatory of the Convention recognizes an obligation to provide a minimum level of protection to trafficking victims. In the preceding chapters, many issues have been explored relative to trafficking victim protection, including the concerns expressed by NGOs, such as Anti-Slavery International, that the various interpretations by the signatories of the Convention will lead to an unequal application of victim protection provisions, and an unequal provision of victim protection services.

In order to provide a framework upon which to assess Canada's compliance with the Protocol's protection requirements, this study examined the evolution of white slavery to the present crime of human trafficking, the current human trafficking debates related to the definition of human trafficking and its correlation to prostitution, and explored the relationship between globalization, illegal migration and human trafficking. It also reviewed the gaps and deficiencies, as identified by NGOs, in relation to the Protocol's victim protection provisions.

The study revealed that even though there is a wide divergence over the definition of human trafficking, and that the projected scope of the trafficking problem is virtually unknown, many western countries, including Canada, in response to public opinion have been moving forward quickly to produce anti-trafficking enforcement 
strategies. As a result, governments are running the risk of investing considerable energies into devising anti-trafficking enforcement strategies that are based upon unreliable information which may ultimately produce ineffective programs. To date, no government nor any domestic or international law enforcement agency has been able to define the scope of human trafficking with any certainty. Thus, without a clear understanding of the dimensions of human trafficking, the effectiveness of enforcement strategies will remain suspect.

It has been suggested by some such as Jo Doezema that today's human trafficking panic is simply a reflection of the white slavery panic of the past, both panics founded on a fear of the impact that globalization and immigration would have on a western nation's cultural identity (Doezema 1999:27). To a certain extent, I agree with Doezema. I share her view that today's human trafficking panic is a part of the larger issue of sovereignty and the related fear of globalization. However, contrary to the white slavery panic which was premised on a mythical victim, today's human trafficking panic does involve real victims who are in need of protection.

Although the scope of the problem of human trafficking has yet to be accurately defined, victims, even if only one exists, need to be protected. Victim protection was incorporated into the Trafficking Protocol not based on the number of victims but, in my view, as a recognition of and an assurance that the protection needs of trafficking victims will be met regardless of the depth of the problem. 
Canada has chosen a strategy of 'in-action' in order to meet the Protocol's protection provision obligations. The government believes that pre-Protocol crime victim services in Canada are able to address the needs of trafficking victims and meet the protection obligations of Articles 6 through 8 of the Protocol. As previously indicated, from a purely technical perspective, I believe that Canada is in compliance with the protection provisions of the Trafficking Protocol. However, I also am of the view that Canada missed an opportunity to provide much needed leadership in the important area of trafficking victim protection which might have resulted in a more consistent approach to victim protection by the Convention signatories.

As noted above, the US and Britain have adopted different strategies in an attempt to meet their perceived obligations with respect to the protection provisions of the Protocol but with limited success. However, even though there are flaws in their respective responses, in contrast to Canada, the US and Britain, attempt to meet the needs of trafficking victims through new victim protection strategies. These strategies are subject to ongoing evaluation and presumably will lead to future changes in victim protection to the benefit of trafficking victims. No evaluation of Canada's approach has been conducted such that one can conclude with any level of comfort that the needs of trafficking victims in Canada are being met.

Surprisingly, the research for this study did not disclose an extensive human trafficking problem in Canada. The prevailing impression among the media and 
public is that human trafficking is prevalent in Canada, requiring a significant coordinated government response. In reality, very few cases of human trafficking have been identified. It could be argued that victims are afraid to come forward and that this is the reason for the lack of known victims. In addition, the data collection processes within some government departments such as CIC are not structured in such a way that they can ascertain the number of trafficking victims and related vital trafficking information. This underscores the need for government agencies that have a principle role to play in protecting trafficking victims to establish critical data collection systems and processes. This would assist the government in defining the scope of the problem, the needs of the victim, and the effectiveness of its enforcement and protection strategies through an appropriate evaluation process.

Is there a need to legislate victim protection provisions? In my view, it is critical that Canada incorporate the Protocol's protection provisions into our domestic legislation. It is only through such an approach that Canada will be in a position to clearly define the trafficking victim protection entitlements, and of equal importance, which government departments are responsible for monitoring and ensuring the delivery of the protection services. It is also important that we are mindful of the experiences of other countries such as the US and UK and not introduce the harmful criteria such as victim protection premised on cooperation with law enforcement.

It is my view that if Canada is to ensure that the needs of trafficking 
victims are to be met, there must be some mechanism in place, preferably legislated, which would trigger a responsibility within an existing government department to evaluate the delivery of victim protection services. This process would ensure that the government is informed of the effectiveness of its victim protection strategy and adjust where necessary. As noted above in the US and Great Britain strategies, both governments have implemented review processes which inform the respective governments as to whether or not their strategies are meeting the goals of the government and the needs of trafficking victims.

When I embarked upon this study, I had presumed that Canada would have made a significant effort to ensure the protection of trafficking victims. Given Canada's international reputation of protecting the vulnerable around the globe, it is surprising to learn that the Canadian government has not implemented a specially designed protection program for trafficking victims, has not evaluated the effectiveness of its approach, and has no information publically available on these issues. I hope that in the near future, the IWG that is tasked to create a national anti-trafficking strategy will produce a strategy that incorporates specific trafficking victim protection initiatives that meet and exceed the requirements reflected in the Trafficking Protocol. 


\section{Bibliography}

Altink, Sietske (1995). Stolen Lives: Trading Women into Sex and Slavery, London: Scarlet Press.

- $\quad$ Anti-Slavery International (2002). "Human traffic, human rights: redefining victim protection", retrieved 2005-01-19 from:

http://www.antislavery.org/homepage/resources/humantraffickingrights.htm.

- Anti-Slavery International (2003). "The Migration-Trafficking Nexus", retrieved 2005-05-11 from:

http://www.antislavery.org/homepage/resources/the\%20migration\%20trafficking \%20nexus\%202003.pdf.

- Anti-Slavery International (2003). "Support, assistance and protection of victims of trafficking, particularly in host countries", retrieved from:

http://www.antislavery.org/archive/submission/submission2003-trafficking.htm.

- $\quad$ Aronowitz, Alexis (2001). "Smuggling and Trafficking in Human Beings: The Phenomenon, The Markets That Drive It and The Organisations that Promote It", European Journal on Criminal Policy and Research, Vol. 9, p. 163 - 195.

- $\quad$ Ashcroft, John (2004). “Ashcroft Announces Sentencing for Ten Convicted of Human Trafficking, January 29, 2004", U.S. Department of Justice, retrieved 2005-08-25 from: http://www.usembassy.it/file2004_01/alia/a4012902.htm.

- $\quad$ Australian Government (2004). "UN Convention against Transnational Organized Crime, November 2000, and Protocols on Trafficking in Persons and Smuggling of Migrants", retrieved 2005-02-24 from www.aph.gov.au/house/committee/jset/december2003/report/chapter5.pdf.

- Baldwin, Richard E. and Philippe Martin (1999). "Two Waves of Globalization: Superficial Similarities, Fundamental Differences". In Horst Siebert (Ed.) Globalization and Labor, Tubingen, Germany: Instit fur Weltwirtschaft an der Universitat Kiel, pp. 3-58.

Bandyopadhyay, Nandinee (2004). “'Streetwalkers Show the Way': Reframing the Debate on Trafficking from Sex Workers' Perspective", IDS Bulletin 35.4, p. 104-111.

- Barry, Kathleen (1979). Female Sexual Slavery, New Jersey: Prentice-Hall Inc. 
Brennan, Frank (2003). "Response to Professor Catherine Dauvergne's "Challenges to Sovereignty: Migration Laws for the $21^{\text {st }}$ Century", retrieved 2005-02-14 from http://www.uniya.org/pdf/brennan law_14apr03.pdf.

Brolan, Claire (2003). "An Analysis of the Human Smuggling Trade and the Protocol Against the Smuggling of Migrants by Land, Air and Sea (2000) from a Refugee Protection Perspective", International Journal of Refugee Law, Vol. 14, 4, p. 561 - 596.

- $\quad$ Bruckert, Christine \& Collette (2004). Organized Crime and Human Trafficking in Canada: Tracing Perceptions and Discourses, Ottawa, Royal Canadian Mounted Police (RCMP - Research \& Evaluation Branch).

- Canadian Council for Refugees (2003). "Canada's Refugee and Immigration Programs Fail to Make the Grade", retrieved 2005-09-18 from: http:www.web.net/ ccr/Report\%20releasefin.htm.

- Canadian Council for Refugees (2003). "Protecting Refugees: where Canada's refugee system falls down", retrieved 2005-03-13 from: http:www.web.net/ ccr/flaws.html.

- Canadian Council for Refugees (2003). "Trafficking in Women and Girls", retrieved 2005-09-18 from: http:www.web.net/ ccr/ccrtrafficking.pdf.

- $\quad$ Canadian Council for Refugees (2004). "Canada Must Offer Protection to Trafficked Persons", retrieved 2005-01-14 from: http:www.web.net/ ccr/traffbackgrouder.html.

- Canadian International Development Agency (1996). Refugees and Migration in Central and Eastern Europe, Montreal: Canadian Human Rights Foundation.

Chapkis, Wendy (2003). "Trafficking, Migration and The Law: Protecting Innocents, Punishing Immigrants". Gender \& Society, Vol.17, 6, p. 923-937.

- Chin, Vivienne \& Yvon Dandurand (2001). "Trafficking and Other Transnational Forms of Violence Against Women and Children", retrieved 2004-04-21 from: http://www.lawsite.ca/IAWJ/Traffickingttext.htm.

- $\quad$ Citizenship and Immigration Canada (2000). "Trafficking in Women: Inventory of Information Needs and Available Information", retrieved 2004-04-21 from: http://www.cic.gc.ca/english/research/papers/trafficking/trafficking-a.html. 
- $\quad$ Citizenship and Immigration Canada (2004). "News Release - Safe Third Country Agreement Comes into Force Today", retrieved 2005-07-24 from: http://www.cic.gc.ca/english/press/02/0420-pre.html.

- $\quad$ Citizenship and Immigration Canada (2004). "Fact Sheet: The Safe Third Country Agreement", retrieved 2005-07-24 from: http://www.cic.gc.ca/english/policy/safe-third-fact.html.

- Citizenship and Immigration Canada (2005). "First Statistics Under Canada-U.S. Safe Third Country Agreement Show Decline in Refugee Claimants", retrieved 2005-07-24 from: http://www.cic.gc.ca/english/policy/safe-third-stats.html.

- Citizenship and Immigration Canada (2005). "In-Canada Refugee Process", retrieved 2005-02-14 from: http://www.cic.gc.ca/english/irpa/fs-incanada.html.

- $\quad$ Clawson, Heather J. \& Kevonne M. Small, Ellen S. Go, Bradley W. Myles (2003). "Needs Assessment for Service Providers and Trafficking Victims",Caliber Associates, Inc., retrieved 2005-1-04 from: http:www.calib.com/home/work_samples/pdf/traffick.pdf.

- Cotler, Irwin (2004). "Speech by Irwin Cotler, Minister of Justice and Attorney General of Canada, Forum on Human Trafficking, Ottawa, Ontario, 30 March 2004", retrieved 2005-01-17 from: http:www.justice.gc.ca/en/news/sp/2004/doc 31158.html.

- Cotler, Irwin (2004). "Speaking Notes of Irwin Cotler, Minister of Justice and Attorney General of Canada", Ontario Bar Association, retrieved 2005-01-17 from: http://www.oba.org/en/gen/sep04/speaking.aspx.

- Criminal Intelligence Directorate (CID), Criminal Analysis Branch, RCMP (2002). Trafficking in Human Beings, Ottawa: Royal Canadian Mounted Police.

- $\quad$ Dandurand, Yvon, Riikka Puttonen, Burkhard Dammann, Curt Griffiths, Bill Ard, Norm R. Massie, Claude Menard, Vivienne Chin, Eileen Skinnider, \& Dave Allen (2005). "Human Trafficking: Reference Guide for Canadian Law Enforcement", Abbotsford, BC: University College of the Fraser Valley Press, May 2005, retrieved 2005-09-11 from: http://www.icclr.law.ubc.ca/Site\%20Map/Programs/Human_Trafficking.htm.

- Dauvergne, Catherine (2003). "Challenges to Sovereignty: Migration Laws for the $21^{\text {st }}$ Century", retrieved 2005-02-14 from: http://www.sisr.net/apo/Challengesfind.doc. 
- Dauvergne, Catherine (2004). "Sovereignty, Migration and the Rule of Law in Global Times", The Modern Law Review, Vol. 67, 4, p. 588 - 615.

- Davis, Sylvia \& Martha Shaffer (1994). Prostitution in Canada: The Invisible Menace or the Menace of Invisibility, retrieved 2004-06-17 from: http://www.walnet.org/csis/papers/sdavis.html.

- De Vries, Petra (2005). "An Image of Sexual Danger: The Dutch fight against the 'White Slave Trade' in the early Twentieth Century", Social and Legal Studies, v. 14, p. 39-60.

- Department of External Affairs, Canberra, Australia (2004). "Australian Treaty Series", retrieved 2004-07-10 from: http://www.austlii.edu.au/au/other/dfat/treaties/1949/19.html.

- Department of Justice, Canada (2003). "Canadian Statement of Basic Principles of Justice for Victims of Crime", retrieved 2005-09-11 from: http://canada.justice.gc.ca/en/ps/voc/csbp.html.

- Department of Justice, Canada (2004). "Immigration and Refugee Protection Act (2001, c. 27)", retrieved 2005-07-10 from: http://laws.justice.gc.ca/en/I2.5/64943.html.

- Department of Justice, Canada (2004). "Trafficking in Persons Interdepartmental Working Group on Trafficking in Persons", retrieved 2005-0325 from: http://canada.justice.g.c.a/en/fs/ht/iwgtip.html.

- Doezema, Jo (1999). "Loose Women or Lost Women? The re-emergence of the myth of "white slavery' in contemporary discourses of 'trafficking in women", retrieved 2005-03-17 from: http://www.walnet.org/csis/papers/doezemaloose.html.

- Doezema, Jo (2005). "Now You See Her, Now You Don't: Sex Workers at the UN Trafficking Protocol Negotiations", Social and Legal Studies, v. 14, p. 61-89.

- $\quad$ Ellwood, Wayne (2002). "No-Nonsense guide to Globalization (Excerpts from the book)", retrieved 2005-09-04 from: http://www.thirdworldtraveler.com/Globalization/Globalization_GuideTo.html.

- $\quad$ Engbersen, Godfried and Joanne Van Der Leun (2001). "The Social Construction of Illegality and Criminality", European Journal on Criminal Policy and Research, Vol. 9 , p. 51-70. 
Eraket, Noura, Andrea Fitanides and Kathleen Glynn (2004). "Safety and Slavery: Protecting Victims of Human Trafficking", retrieved 2005-04-29 from: http://www.law.berkeley.edu/cenpro/ihrlc/Transnational\%20Frameworks.pdf.

- European Council on Refugees and Exiles (2001). "An overview of proposals addressing migrant smuggling and trafficking in persons", retrieved 2005-04-29 from: http:www.ecre.org/research/smuggle.shtml.

- $\quad$ Everts, Daan (2003). "Human Trafficking: The Ruthless Trade in Human Misery". In Brown Journal of World Affairs, 10, Issue 1, p. 149-158.

- $\quad$ Friebel, Guido and Sergei Guriev (2002). "Human Trafficking and Illegal Migration", retrieved 2005-06-04 from: http://www.nes.ru/english/about/10thAnniversary/papers-pdf/guriev isnie paper.pdf.

- Haddad, Emma (2003). "Refugee Protection: A Clash of Values", The International Journal of Human Rights, Vol. 7, 3, p. 1 - 26.

- Hobson, Barbara Meil (1987). Uneasy Virtue: The Politics of Prostitution and the American Reform Tradition, New York: Basic Books, Inc., Publishers.

Hollifield, James F. (2000). "The Politics of International Migration: How Can We "Bring the State Back In"?". In Caroline B. Brettell and James F. Hollifield (Eds.) Migration Theory: Talking across Disciplines, New York: Routledge, p. $137-185$.

- Hughes, Donna M., Laura Joy Sporic, Nadine Z. Mendelsohn and Vanessa Chirgwin (1999). "The Factbook on Global Sexual Exploitation: Canada", Coalition Against Trafficking in Women, retrieved 2005-03-23 from: http://www.uri.edu/artsci/wms/hughes/factbook.htm.

Hughes, Donna M. (2000). "The "Natasha" Trade - The Transnational Shadow Market of Trafficking in Women", retrieved 2004-06-04 from: http:/www.uri.edu/artsci/wms/hughes/natasha.htm.

- Icduygu, Ahmet and Sule Toktas (2002). "How Do Smuggling and Trafficking Operate via Irregular Border Crossings in the Middle East?", International Migration, Vol. 40, 6, p. 25 -54.

- Irwin, Mary Ann (1996). "White Slavery" - As Metaphor: Anatomy of a Moral Panic". Ex Post Facto: The History Journal 1996 - Vol. V, retrieved 2005-06-28 from: http://www.walnet.org/csis/papers/irwin-wslavery.html. 
Iselin, Brian (2002). "Barriers to Effective Human Trafficking Enforcement", Presented at The Human Rights Challenge of Globalization in Asia Pacific US: Trafficking in Persons, Especially Women and Children Conference, retrieved 2004-06-17 from: http://www.unodc.un.or.th/factsheet/Barriers.pdf.

- Jiwani, Yasmin and Susan M. Brown (1999). "Trafficking and Sexual Exploitation of Girls and Young Women: A Review of Select Literature and Initiatives", In Feminist Research, Education, Development and Action Centre (FREDA), June 1999.

- Jordan, Ann D. (2001). "Trafficking In Human Beings: The Slavery that Surrounds Us". In The World Revolution, retrieved 2004-04-27 from: http://www.worldrevolution.org/Projects/Webguide/GuideArticle.asp?ID=1441.

- Jordan, Ann D. (2002). "The Annotated Guide To The Complete UN Trafficking Protocol", retrieved 2004-05-20 from: http://www.hrlawgroup.org/initiatives/trafficking_persons/.

- Kelly, Liz and Linda Regan (2000). "Stopping Traffic: Exploring the extent of, and responses to, trafficking in women for sexual exploitation in the UK", UK Home Office, Police Research Series Paper 125, retrieved 2005-05-02 from: http://www.homeoffice.gov.uk/rds/prgpdfs/fprs125.pdf.

- Koser, Khalid (2001). “New Approaches to Asylum?”, International Migration, Vol. 39, 6, p. $85-101$.

- $\quad$ Langum, David J. (1994). Crossing Over The Line: Legislating Morality and the Mann Act, Chicago: University of Chicago Press.

- Levine, Phillipa (2002). "The White Slave Trade and the British Empire". In Louis A. Knafla (ed.) Crime, Gender, and Sexuality in Criminal Prosecutions, Westport: Greenwood Press, p. 133-146.

- Manohar, Sujata (2002). "Trafficking in women and girls", Expert Group Meeting on "Trafficking in women and girls" 18-22 November 2002, retrieved 2005-03-23 from:

http://www.un.org/womenwatch/daw/egm/trafficking2000/reports/WP-

SujataManhar.pdf.

- $\quad$ McLaren, John (1988). "The Canadian Magistracy and The Anti-White Slavery Campaign". In W. Wesley Pue \& Barry Wright (eds.), Canadian Perspectives on Law \& Society: Issues in Legal History, Ottawa: Carleton University Press, p. 329-353. 
- Minister of Justice (2005). "House of Commons Canada - Bill C-49 - An Act to amend the Criminal Code (trafficking in persons)", retrieved 2005-07-11 from: http://www.parl.gc.ca/38/1/parlbus/chambers/house/bills/government/c-49.

- Minnesota Advocates for Human Rights (2004). "Stop Violence Against Women: Victims Protection and Immigration Law", retrieved 2005-04-29 from: http://www.stopvaw.org/Victim Protection and Immigration_Law.html.

- Munro, Vanessa (2005). "A Tale of Two Servitudes: Defining and Implementing a Domestic Response to Trafficking of Women for Prostitution in the UK and Australia", Social and Legal Studies, v. 14: p. 91-114.

- Murphy, Elaine and Karin Ringheim (2005). "An Interview with Jo Doezema, of the Network of Sex Work Projects: Does attention to trafficking adversely affect sex workers' rights?". In Reproductive Health and Rights - Reaching the Hardly Reached, retrieved 2005-06-30 from: http://www.nswp.org/pdf/RHRDOEZEMA.pdf.

- Newton, Janice (1989). "From Wage Slave To White Slave" In Linda Kealey \& Joan Sangster (eds.), Beyond the Vote: Canadian Women and Politics, Toronto: University of Toronto Press.

- $\quad$ OSCE Human Dimension Implementation Meeting (2003). "NGOs Statement On Protection Measures for Trafficked Persons in Western Europe", retrieved 200504-29 from: http://www.antislavery.org/homepage/resources/WEtraffickingNGOstatement200 $\underline{3 . p d f}$.

- Office of Crime Victims Advocacy, State of Washington, (2004). Human Trafficking: Present Day Slavery - The Report of the Washington State Task Force Against Trafficking of Persons, Tacoma, Washington: Department of Community, Trade and Economic Development.

- O'Neill, Maggie (2001). Prostitution and Feminism, Cambridge: Polity Press.

- $\quad$ Oxman-Martinez, Jacqueline \& Jill Hanley (2004). “A Follow-Up Study of Canadian Policy on Human Trafficking: Impacts of the Immigration and Refugee Protection Act", retrieved 2005-06-06 from: http://im.metropolis.net/researchpolicy/research_content/doc.

- $\quad$ Pearson, Elaine (2002). "Half-hearted protection: What does victim protection really mean for victims of trafficking in Europe?", Gender and Development, Vol. 10,1, p. $56-59$. 
- $\quad$ Pearson, Elaine (2002). Human Trafficking, Human Rights: redefining witness protection, London: Anti-Slavery International - Thompson Clarkson House, $\mathrm{p}$. 119-136).

- $\quad$ Pessar, Patricia R. And Sarah J. Mahler (2001). "Gender and Transnational Migration", retrieved 2005-03-22 from:

http:www.transcomm.ox.ac.uk/working\%20papers/WPTC-0120\%20Pessar.doc.pdf.

- $\quad$ Piotrowicz, Ryszard (2002). "European Initiatives in the Protection of Victims of Trafficking who Give Evidence Against Their Traffickers". International Journal of Refugee Law, Vol., 2, p. 263 - 278.

- $\quad$ Public Safety and Emergency Preparedness Canada (PSEPC) (formerly Solicitor General of Canada) (1998). "Organized Crime Impact Study - Highlights", retrieved 2005-07-09 from: http://www.psepc-

sppcc.gc.ca/Publications/Policing/1998orgcrim e.asp.

- Raymond, Janice G. (2001). "Guide To The New UN Trafficking Protocol", European Women's Lobby, retrieved 2004-05-20 from: http://action.web.ca.

- $\quad$ Raymond, Janice G. (2002). "The New UN Trafficking Protocol", Women's Studies International Forum, Vol. 25, 5, p. 491 - 502.

- $\quad$ Raymond, Janice G. (2003). "The Ongoing Tragedy of International Slavery and Human Trafficking: An Overview", The Coalition Against Trafficking in Women, retrieved 2004-04-21 from:

http://action.web.ca/home/catw/readingroom.shtml?.

- $\quad$ Refugee Women's Resource Project (2003). "Home Office help for Victims of trafficking comes with a price tag: Join our campaign now!", In RWRP Women's Asylum News, April 2003, Issue 31, retrieved 2005-04-29 from:

http://www.asylumaid.org.uk/New\%20WRP/RWRP RRP WANArticleIndex A pril2003.htm.

- $\quad$ Richard, Amy O'Neill (1999). "International Trafficking in Women to the United States: A Contemporary Manifestation of Slavery and Organized Crime", Centre for the Study of Intelligence, US Central Intelligence Agency, retrieved 2005-0323 from: http://www.cia.gov/csi/monograph/women/trafficking.pdf.

- $\quad$ Richards, Kathy (2004). "The Trafficking of Migrant Workers: What are the Links Between Labour Trafficking and Corruption?", International Migration, Vol. 42 (5), p. 147-168. 
- $\quad$ Roe, Clifford G. (1910). Panders and Their White Slaves, New York: Fleming H. Revell Company.

- $\quad$ Rolph, Elizabeth (1992). Immigration Policies: Legacy from the 1980s and Issues for the 1990s, Santa Monica: RAND.

- Royal Canadian Mounted Police (2004). "Feature Focus - Human Trafficking", RCMP Environmental Scan June 2004, retrieved 2005-05-10 from: http://www.rcmp.ca/enviro/2004/scan2004_h_e.htm.

- $\quad$ Salt, John (2000). "Trafficking and Human Smuggling : A European Perspective." In Reginald Appleyard and John Salt (eds.) Perspectives on Trafficking of Migrants, Geneva: IOM and OIM, p. 31-56.

- $\quad$ Saunders, Penelope and Gretchen Soderlund (2003). "Threat or Opportunity? Sexuality, Gender and the Ebb and Flow of Trafficking as Discourse", Canadian Woman Studies, Vol. 3/4, p.16-24.

- Schuck, Peter (2000). "Law and the Study of Migration", In Caroline B. Brettell and James F. Hollifield (Eds.) Migration Theory: Talking across Disciplines, New York: Routledge, p. 187 - 204.

- Shelley, Louise (2003). "The trade in people in and from the former Soviet Union", Crime, Law \& Social Change, Vol. 40, p. 231 - 249.

- Sheth, Anita (2003). Background Paper 5: Child Victims of Trafficking, Save the Children Canada, 2003, p. 1-3, retrieved 2005-04-25 from: http://www.ibcr.org/BP5 Trafficking.pdf.

- $\quad$ Shoyele, Olugbenga (2004). "Armed Conflicts and Canadian Refugee Law and Policy”, International Journal of Refugee Law, Vol. 16, 4, p. 547 - 583.

- $\quad$ Simpson, Jeffrey (2005). "Treaty slams door on refugees - Numbers down 405 from 2004". In The Chronicle Herald Newspaper, Halifax, p. A1 \& A9.

- $\quad$ Standing House Committee on Citizenship and Immigration (2000). "Refugee Protection and Border Security: Striking a Balance", retrieved 05-03-22 from: http://www.parl.gc.ca/InfocomDoc/36/2/CIMM/Studies/Reports/cimm02/08-rape.htm.

- $\quad$ Standing House Committee on Citizenship and Immigration (2002). "Building a Nation: The Regulations under the Immigration and Refugee Protection Act", retrieved 2005-03-22 from: http://www.cic.gc.ca/regulations_files/cimmrp04e.htm. 
- $\quad$ Standing House Committee on Citizenship and Immigration (2005). "Fourth Report on procedures on how to review Order in Council appointments", retrieved 2005-09-18 from: http://www.cic.gc.ca/regulations files/cimmrp04e.htm.

- Stop Violence Against Women (2004). "Victim Protection and Immigration Law", retrieved 2005-04-29 from: http:www.stopvaw.org/Victim Protection and Immigration Law.html.

- Sullivan, Barbara (2003). “Trafficking in Women”, International Feminist Journal of Politics, Vol. 5: 1, p. 67-91.

- Taylor, Gina and Kathy Curran, Koonti Dhanani (2005). "Evaluation of the Victims of Trafficking Pilot Project - Poppy”, London: UK Home Office.

- Taylor, Gina (2005). "Evaluation of the Victims of trafficking pilot project Poppy - Summary Findings", retrieved 2005-10-09 from: http://www.homeoffice.gov.uk.

- The Foundation of Women's Forum/Stiftelsen Kvinnoforum, Stockholm (1998). "Trafficking in Women for the Purpose of Sexual Exploitation: Mapping the Situation and Existing Organisations Working in Belarus, Russia, the Baltic and Nordic States", retrieved 2005-03-23 from:

http://www.qweb.kinnoforum.se/papers/traffcikingreport.html.

- Trafficking Conference (2003). "Silent Slavery: Stop the Trafficking of women and children for Sexual exploitation in London - Conference Recommendations". Retrieved 2005-04-29 from:

http://www.jeanlambertmep.org.uk/issues/humanrights civillibs/humantrafficking recommend.htm.

- Tzvetkova, Marina (2002). "NGO responses to trafficking in women", Gender and Development, Vol. 10, 1, p. 60 - 68.

- UK Home Office (2002). “Secure Borders, Safe Have: Integration with Diversity in Modern Britain", retrieved 2005-04-29 from: http://www.official_documents.co.uk/document/cm53/5387/cm5387.pdf.

- UK Home Office, Immigration \& Nationality Directorate (2005). "Victims of trafficking - Guidance" - retrieved 2005-04-29 from: http://www.ubd.homeoffice.giv.uk/ind/en/home/kaws policy/policy instructions lapis/victims_of trafficking. 
- UN Commission on Human Rights (Fifty-ninth Session) (2002). "Protecting the Rights of Victims of Human Trafficking”, In Franciscans International - A NonGovernmental Organisation at the United Nations, retrieved 2005-01-19 from: http://www.franciscansinternationals.org/doc/statement.php?id=179.

- UNIAP China News Digest (2005). "First Human Trafficking Charges Laid", retrieved 2005-09-20 from: http://www.cinfo.org.cn/UNIAP/uniap-2005-01.htm.

- US Committee for Refugees (2000). "Trafficking in Women and Children: “A Contemporary Manifestation of Slavery”. In Refugee Reports, Vol.21, 5, p. 1-7.

- Uherek, Zdenek, Klara Skrivankova and Renata Weinerova (2001). "Women Asylum Seekers and Trafficking", In United Nations High Commissioner for Refugees, retrieved 2005-03-23 from:

http://www.unhcr.ca/dokumenty/study women.doc.

- United Nations (2000). "Protocol to Prevent, Suppress and Punish Trafficking in Persons, Especially Women and Children, Supplementing the United Nations Convention Against Transnational Organized Crime", retrieved 2004-08-29 from: http:untreaty.un.org/english/notpub/18-12-a.E.doc.

- United Nations Department of Economic and Social Affairs Population Division (1998). International Migration Policies, New York: United Nations Publication.

- United Nations Economic and Social Council (2002). "Recommended Principles and Guidelines on Human Rights and Human Trafficking - Report of the United Nations High Commissioner for Human Rights to the Economic and Social Council", retrieved 2005-05-12 from:

http://www.unhchr.ch/huridocda/huridocda.nsf.

- United Nations General Assembly (2000). "United Nations Convention against Transnational Organized Crime, Annex II: Protocol to Prevent, Suppress and Punish Trafficking in Persons, Especially Women and Children", U.N.G.A. Resolution 55/25, retrieved 2004-05-28 from: http://www.unodc.org/adhoc/palermo/convmain.html.

- United Nations General Assembly (2000). "Crime prevention and criminal justice - Interpretative notes for the official records (travaux préparatoires) of the negotiation of the United Nation's Convention against Transnational Organized Crime and the Protocols thereto", retrieved 2005-10-11 from: http:www.uncjin.org/Documents/Convention/dcatoc/final documents/383ale.pdf. 
- United Nations General Assembly (2004). "International migration and development - Report of the Secretary-General", retrieved 2005-07-13 from: http://www.un.org/esa/population/publications/thirdcoord2004/A 59 325.pdf.

- United States Government (2003). "Trafficking in Persons Report - June 2003", retrieved 2004-03-29 from: http://www.state.gov/g/tip/rls/tiprpt/2003/.

- United States Government (2005). "Trafficking in Persons Report - June 2005", retrieved 2005-07-09 from: http://www.state.gov/g/tip/rls/tiprpt/2005/.

- Valverde, Mariana (1991). The Age of Light, Soap and Water, Toronto: McCelland \& Stewart Inc.

- Victims of Trafficking and Violence Protection Act of 2000, Public Law 106-386, Oct. 28, 2000, retrieved 2004-09-19 from:

http:www.state.gove/documents/organization/10492.pdf.

- von Bogdandy, Armin (2004). "Globalization and Europe: How to Square Democracy, Globalization and International Law", The European Journal of International Law, Vol. 15, 5, p. 885 - 906.

- Wolf, Martin (2005). "Will Globalization Survive?", Third Whitman Lecture, Institute for International Economics, Washington, D.C., retrieved 2005-09-10 from: http://www.iie.com/publications/papers/wolf0405.pdf.

- Womennet.ca (2005). "Filipino Women's Alliance Human Claims Trafficking Linked to Globalization", retrieved 2005-09-14 from:

http:www.womennet.ca/news.php?show\&3397.

- Wong, Brad (2003). "Servitude in American Samoa". In the Seattle PostIntelligencer, November 17, 2003, retrieved 2004-06-10 from: http://seatlepi.nwsource.com.

- Yuval-Davis, Nira (2004). "Human Security and Asylum-Seeking", retrieved 2005-03-18 from: http://www.bristol.ac.uk/sociology/ethnicitycitizenship/nyd3.pdf.

- Zhao, Gracie Ming (2003). "Trafficking of women for marriage in China", Criminal Justice, Vol. 3, 1, p. 83-102.

- Zolberg, Aristide R. (2001). "Introduction: Beyond the Crisis". In Aristide R. Zolberg and Peter M. Benda (Eds.) Global Migrants, Global Refugees: Problems and Solutions, New York: Berghahn Books, p. 1 - 16. 


\section{Surveys}

- $\quad$ Boissé, Pierrette (2005) - Congrégation de Notre-Dame, p. 1.

- $\quad$ Citizenship and Immigration Canada (CIC) 2005 - representative - Emina Tudakovic, p. 1-11.

- Department of Justice (DOJ) 2005 - representative - Mathew Taylor, p. 1-11.

- Federal Bureau of Investigations (FBI) 2005 - representative Kathryn Turman, p. $1-5$.

- $\quad$ Isaccs, Deborah (2005) - unofficial liaison between BC Catholic Community and the RCMP, p. 1-2.

- Royal Canadian Mounted Police (RCMP) 2005 - representative - Sgt. Lori Lowe, p. 1-9.

- Royal Canadian Mounted Police (RCMP) 2005 - follow-up email - 2005-09-23.

\section{Case Law/Immigration Hearings}

- $\quad$ Canada v. Ward [1993] 2 S.C.R. 689.

- Litvinov [1994] F.C.J. no. 1061 IMM-7488-93

- Vorobieva [1994] F.C.J. no. 1193 IMM-4863-93

- Y.C.K. [1997] C.R.D.D. No. 261 No. V95-02904

- H.D.O. [1999] C.R.D.D. No. 116 No. T98-07677

- P.Y.M. [1999] C.R.D.D. No. 163 No. U98-01933

- D.J.P. [1999] C.R.D.D. No. 155 No. T98-06446

- N.W.X. [1999] C.R.D.D. No. 183 No. T99-01434

- G.V.P. [1999] C.R.D.D. No. 298 No. T98-06186

- P.G.L. [2001] C.R.D.D. No. 150 No. V99-02911

- A.F.W. [2001] C.R.D.D. No. 215 No. V99-03532 


\section{Appendix}

- Appendix 1: blank RCMP survey

- $\quad$ Appendix 2: blank DOJ survey

- $\quad$ Appendix 3: blank CIC survey

- $\quad$ Appendix 4: blank NGO survey

- Appendix 5: blank US government survey 


\section{Appendix 1}

\section{Royal Canadian Mounted Police (RCMP) Questionnaire}

The 2000 UN Convention against Transnational Organized Crime, Annex II - Protocol to Prevent, Suppress, and Punish Trafficking in Persons, Especially Women and Children, is designed to combat those individuals and criminal organizations that profit from the exploitation of the most vulnerable of society through their forced or coerced illegal migration. As a signatory to this Convention, Canada agreed to a number of obligations, including the provision of protection to the victims of human trafficking. This questionnaire seeks to explore Canada's compliance with fulfilling its obligations of protection for the victims as stipulated in Annex II, Articles 6 through 8 inclusive. For ease of reference, a copy of the pertinent portion of Annex II is appended.

The following questions are very broad in context in order to encourage as great a detailed response as possible:

1) Please describe the RCMP's understanding of what process/approach has been implemented by Canada in order to comply with Articles 6 through 8 of Annex II?

2) Please describe what the roles and responsibilities are of the RCMP within the existing process of protecting victims of human trafficking?

3) Has the RCMP been involved in any evaluation of the current collaborative process/approach for victim protection, or an evaluation of their own role within the current process? If so, what has been the results, and if not, is one intended?

4 If no evaluation has been conducted of the current approach, have any 'gaps' or deficiencies to the existing protection process been identified by the RCMP through the normal course of business?

5) Various reports indicate that Canada uses the Canadian Refugee System (CRS) as its method of compliance with the Convention. Some NGO's believe that a separate system should be created for the victims of human trafficking because they are victims of a crime rather than persons entering the country illegally for the purpose of making refugee claims. What is the RCMP's position in this regard?

6) NGO's have criticized various countries because they link protection of the victim's of trafficking to their willingness to cooperate with the police and prosecutors. How does RCMP approach this issue?

7) Numerous articles, evaluations, and reports regarding the efforts of many 
countries promote the idea of providing a 'cooling off' or 'reflection' period for the victims of human trafficking with no conditions attached. The victim would be provided temporary residence status (including work permit) for a specified period of time regardless of whether or not they agreed to assist the police. During this time, they would be provided legal counsel to ensure they were aware of all their rights and available services. What is the RCMP's viewpoint with regards to this proposal?

8) Has RCMP encountered many cases of human trafficking?

9) If the RCMP encounters a trafficked victim through a criminal investigation in which the victim may be a forced participant in the crime (eg: prostitution) is the victim treated as a criminal or a victim or both?

10) With respect to temporary residence status, does CIC automatically provide same in order to assist the RCMP with any potential investigation or does CIC wait for the law enforcement agency (RCMP) to make the request?

11) If a request is made from the RCMP to CIC for temporary residence status, is it automatically granted or is there a hearing to approve the granting of this request?

12) Does the RCMP have a dedicated unit that deals specifically with the victims of human trafficking? And, does this unit work on the domestic and/or international stage to promote the protection of victims? (Details)

13) If, during the course of an investigation, it becomes apparent to the RCMP that an individual is a potential victim of trafficking, is this person treated differently in any way and/or advised of any additional services or rights?

14) With reference to the federal government's Interdepartmental Working Group Committee, and the sub-committee on the protection of victims that CIC chairs, can you provide an overview of the RCMP's participation in this committee/subcommittee.

15) Does the RCMP provide its personnel any special training that enhances the investigators awareness of the special protection needs of trafficking victims? (Details) 


\section{Protection of victims of trafficking in persons}

\section{Article 6 \\ Assistance to and protection of victims of trafficking in persons}

1. In appropriate cases and to the extent possible under its domestic law, each State Party shall protect the privacy and identity of victims of trafficking in persons, including, inter alia, by making legal proceedings relating to such trafficking confidential.

2. Each State Party shall ensure that its domestic legal or administrative system contains measures that provide to victims of trafficking in persons, in appropriate cases:

(a) Information on relevant court and administrative proceedings;

(b) Assistance to enable their views and concerns to be presented and considered at appropriate stages of criminal proceedings against offenders, in a manner not prejudicial to the rights of the defence.

3. Each State Party shall consider implementing measures to provide for the physical, psychological and social recovery of victims of trafficking in persons, including, in appropriate cases, in cooperation with non-governmental organizations, other relevant organizations and other elements of civil society, and, in particular, the provision of:

(a) Appropriate housing;

(b) Counselling and information, in particular as regards their legal rights, in a language that the victims of trafficking in persons can understand;

(C) Medical, psychological and material assistance; and

(d) Employment, educational and training opportunities.

4. Each State Party shall take into account, in applying the provisions of this article, the age, gender and special needs of victims of trafficking in persons, in particular the special needs of children, including appropriate housing, education and care.

5. Each State Party shall endeavour to provide for the physical safety of victims of trafficking in persons while they are within its territory.

6. Each State Party shall ensure that its domestic legal system contains measures that offer victims of trafficking in persons the possibility of obtaining compensation for damage suffered.

\section{Article 7}

Status of victims of trafficking in persons in receiving States

1. In addition to taking measures pursuant to article 6 of this Protocol, each State Party 
shall consider adopting legislative or other appropriate measures that permit victims of trafficking in persons to remain in its territory, temporarily or permanently, in appropriate cases.

2. In implementing the provision contained in paragraph 1 of this article, each State Party shall give appropriate consideration to humanitarian and compassionate factors.

\section{Article 8 \\ Repatriation of victims of trafficking in persons}

1. The State Party of which a victim of trafficking in persons is a national or in which the person had the right of permanent residence at the time of entry into the territory of the receiving State Party shall facilitate and accept, with due regard for the safety of that person, the return of that person without undue or unreasonable delay.

2. When a State Party returns a victim of trafficking in persons to a State Party of which that person is a national or in which he or she had, at the time of entry into the territory of the receiving State Party, the right of permanent residence, such return shall be with due regard for the safety of that person and for the status of any legal proceedings related to the fact that the person is a victim of trafficking and shall preferably be voluntary.

3. At the request of a receiving State Party, a requested State Party shall, without undue or unreasonable delay, verify whether a person who is a victim of trafficking in persons is its national or had the right of permanent residence in its territory at the time of entry into the territory of the receiving State Party.

4. In order to facilitate the return of a victim of trafficking in persons who is without proper documentation, the State Party of which that person is a national or in which he or she had the right of permanent residence at the time of entry into the territory of the receiving State Party shall agree to issue, at the request of the receiving State Party, such travel documents or other authorization as may be necessary to enable the person to travel to and re-enter its territory.

5. This article shall be without prejudice to any right afforded to victims of trafficking in persons by any domestic law of the receiving State Party.

6. This article shall be without prejudice to any applicable bilateral or multilateral agreement or arrangement that governs, in whole or in part, the return of victims of trafficking in persons. 


\section{Appendix 2}

\section{Department of Justice (DOJ) Questionnaire}

The 2000 UN Convention against Transnational Organized Crime, Annex II - Protocol to Prevent, Suppress, and Punish Trafficking in Persons, Especially Women and Children, is designed to combat those individuals and criminal organizations that profit from the exploitation of the most vulnerable of society through their forced or coerced illegal migration. As a signatory to this Convention, Canada agreed to a number of obligations, including the provision of protection to the victims of human trafficking. This questionnaire seeks to explore Canada's compliance with fulfilling its obligations of protection for the victims as stipulated in Annex II, Articles 6 through 8 inclusive. For ease of reference, a copy of the pertinent portion of Annex II is appended.

The following questions are very broad in context in order to encourage as great a detailed response as possible:

1) Please describe DOJ's understanding of what process/approach has been implemented by Canada in order to comply with Articles 6 through 8 of Annex II?

2) Please describe what the roles and responsibilities are of DOJ within the existing process of protecting victims of human trafficking?

3) Has DOJ been involved in any evaluation of the current collaborative process/approach for victim protection, or an evaluation of their own role within the current process? If so, what has been the results, and if not, is one intended?

4 If no evaluation has been conducted of the current approach, have any 'gaps' or deficiencies to the existing protection process been identified by DOJ through the normal course of business?

5) Various reports indicate that Canada uses the Canadian Immigration System (CIS) as its method of compliance with the Convention. Some NGO's believe that a separate system should be created for the victims of human trafficking because they are victims of a crime rather than persons entering the country illegally for the purpose of making refugee claims. What is DOJ's position in this regard?

6) NGO's have criticized various countries because they link protection of the victim's of trafficking to their willingness to cooperate with the police and prosecutors. How does DOJ approach this issue?

7) Numerous articles, evaluations, and reports regarding the efforts of many 
countries promote the idea of providing a 'cooling off' or 'reflection' period for the victims of human trafficking with no conditions attached. The victim would be provided temporary residence status (including work permit) for a specified period of time regardless of whether or not they agreed to assist the police. During this time, they would be provided legal counsel to ensure they were aware of all their rights and available services. What is DOJ's viewpoint with regards to this proposal?

8) Has DOJ prosecuted many cases of human trafficking? (Details)

9) If DOJ encounters a trafficked victim through a criminal investigation by the RCMP in which the victim may be a forced participant in the crime (eg: prostitution) is the victim treated as a criminal or a victim or both?

10) Does DOJ have a dedicated unit that deals specifically with the victims of human trafficking? And, does this unit work on the domestic and/or international stage to promote the protection of victims? (Details)

11) If DOJ has no dedicated unit focused on human trafficking, does DOJ have any specific initiatives, domestically or internationally, that it has undertaken to heighten awareness of the need to combat human trafficking and protect its victims?

12) If, during the course of an investigation, it becomes apparent to DOJ that an individual is a potential victim of trafficking, is this person treated differently in any way and/or advised of any additional services or rights?

13) With reference to the federal government's Interdepartmental Working Group Committee, and the sub-committee on the protection of victims that CIC chairs, can you provide an overview of DOJ's participation in this committee/subcommittee?

14) Does DOJ provide its personnel any special training that enhances the prosecutors awareness of the special protection needs of trafficking victims? (Details)

15) NGO's have criticized Canada that there are no specific protection provisions for victims of trafficking within current Canadian legislation (Immigration \& Refugee Protection Act - IRPA). What are DOJ's views on this issue? 


\section{Protection of victims of trafficking in persons}

\section{Article 6}

\section{Assistance to and protection of victims of trafficking in persons}

1. In appropriate cases and to the extent possible under its domestic law, each State Party shall protect the privacy and identity of victims of trafficking in persons, including, inter alia, by making legal proceedings relating to such trafficking confidential.

2. Each State Party shall ensure that its domestic legal or administrative system contains measures that provide to victims of trafficking in persons, in appropriate cases:

(a) Information on relevant court and administrative proceedings;

(b) Assistance to enable their views and concerns to be presented and considered at appropriate stages of criminal proceedings against offenders, in a manner not prejudicial to the rights of the defence.

3. Each State Party shall consider implementing measures to provide for the physical, psychological and social recovery of victims of trafficking in persons, including, in appropriate cases, in cooperation with non-governmental organizations, other relevant organizations and other elements of civil society, and, in particular, the provision of:

(a) Appropriate housing;

(b) Counselling and information, in particular as regards their legal rights, in a language that the victims of trafficking in persons can understand;

(C) Medical, psychological and material assistance; and

(d) Employment, educational and training opportunities.

4. Each State Party shall take into account, in applying the provisions of this article, the age, gender and special needs of victims of trafficking in persons, in particular the special needs of children, including appropriate housing, education and care.

5. Each State Party shall endeavour to provide for the physical safety of victims of trafficking in persons while they are within its territory.

6. Each State Party shall ensure that its domestic legal system contains measures that offer victims of trafficking in persons the possibility of obtaining compensation for damage suffered.

\section{Article 7}

Status of victims of trafficking in persons in receiving States

1. In addition to taking measures pursuant to article 6 of this Protocol, each State Party 
shall consider adopting legislative or other appropriate measures that permit victims of trafficking in persons to remain in its territory, temporarily or permanently, in appropriate cases.

2. In implementing the provision contained in paragraph 1 of this article, each State Party shall give appropriate consideration to humanitarian and compassionate factors.

\section{Article 8}

\section{Repatriation of victims of trafficking in persons}

1. The State Party of which a victim of trafficking in persons is a national or in which the person had the right of permanent residence at the time of entry into the territory of the receiving State Party shall facilitate and accept, with due regard for the safety of that person, the return of that person without undue or unreasonable delay.

2. When a State Party returns a victim of trafficking in persons to a State Party of which that person is a national or in which he or she had, at the time of entry into the territory of the receiving State Party, the right of permanent residence, such return shall be with due regard for the safety of that person and for the status of any legal proceedings related to the fact that the person is a victim of trafficking and shall preferably be voluntary.

3. At the request of a receiving State Party, a requested State Party shall, without undue or unreasonable delay, verify whether a person who is a victim of trafficking in persons is its national or had the right of permanent residence in its territory at the time of entry into the territory of the receiving State Party.

4. In order to facilitate the return of a victim of trafficking in persons who is without proper documentation, the State Party of which that person is a national or in which he or she had the right of permanent residence at the time of entry into the territory of the receiving State Party shall agree to issue, at the request of the receiving State Party, such travel documents or other authorization as may be necessary to enable the person to travel to and re-enter its territory.

5. This article shall be without prejudice to any right afforded to victims of trafficking in persons by any domestic law of the receiving State Party.

6. This article shall be without prejudice to any applicable bilateral or multilateral agreement or arrangement that governs, in whole or in part, the return of victims of trafficking in persons. 


\section{Appendix 3}

\section{Citizenship \& Immigration Canada (CIC) Questionnaire}

The 2000 UN Convention against Transnational Organized Crime, Annex II - Protocol to Prevent, Suppress, and Punish Trafficking in Persons, Especially Women and Children, is designed to combat those individuals and criminal organizations that profit from the exploitation of the most vulnerable of society through their forced or coerced illegal migration. As a signatory to this Convention, Canada agreed to a number of obligations, including the provision of protection to the victims of human trafficking. This questionnaire seeks to explore Canada's compliance with fulfilling its obligations of protection for the victims as stipulated in Annex II, Articles 6 through 8 inclusive. For ease of reference, a copy of the pertinent portion of Annex II is appended.

The following questions are very broad in context in order to encourage as great a detailed response as possible:

1) What process/approach has CIC, on behalf of Canada, implemented in order to comply with Articles 6 through 8 of Annex II? (Please provide details of compliance)

2) How was this approach/process decided upon? (Eg: Committee, ADM direction)

3) Do you believe that this process is sufficient to meet Canada's obligations? Why?

4) Prior to implementing the current approach, did any consultation take place with other government departments, Non Government Organizations (NGO's), and/or other countries in order to determine Canada's response?

5) Has an evaluation of the current process/approach been conducted and if so, what has been the results, and if not, is one intended?

6) If no evaluation has been conducted of the current approach, have any 'gaps' or deficiencies to that approach been identified through the normal course of business?

7) Various reports indicate that Canada uses the Canadian Refugee System (CRS) as its method of compliance with the Convention. Some NGO's believe that a separate system should be created for the victims of human trafficking because they are victims of a crime rather than persons entering the country illegally for the purpose of making refugee claims. What is CIC's position in this regard?

8) NGO's have criticized various countries because they link protection of the victim's of trafficking to their willingness to cooperate with the police and 
prosecutors. How does $\mathrm{CIC}$ approach this issue?

9) Numerous articles, evaluations, and reports regarding the efforts of many countries promote the idea of providing a 'cooling off' or 'reflection' period for the victims of human trafficking with no conditions attached. The victim would be provided temporary residence status (including work permit) for a specified period of time regardless of whether or not they agreed to assist the police. During this time, they would be provided legal counsel to ensure they were aware of all their rights and available services. Has Canada considered or will Canada consider adopting such an approach?

10) Has CIC encountered many cases of human trafficking and is there any variance as to how the victims have been processed?

11) With respect to temporary residence status, does CIC automatically provide same in order to assist the police with any potential investigation or does CIC wait for the law enforcement agency to make the request?

12) If a request is made from a law enforcement agency, is it automatically granted or is there a hearing to approve the granting of temporary residence status?

13) Does CIC have a dedicated unit that deals specifically with the victims of human trafficking which coordinates the efforts of CIC with law enforcement, prosecutors, and support agencies?

14) If a victim is granted temporary residence status in order to assist in the prosecution, is there any consideration given to provide permanent residence status outside the normal refugee process after the completion of the prosecution?

15) With reference to Article 6, does the victim automatically receive identity confidentiality during immigration hearings or is the victim required to make such a request?

16) Has CIC monitored the human rights impact of the new Immigration and Refugee Protection Act (IRPA), related CIC policies, and any related interventions?

17) Has CIC initiated any efforts on the international stage to secure a more uniform approach to the application of this protocol in partnership with the other countries that have signed?

18) If, during the course of an immigration hearing, it becomes apparent an individual is a potential victim of trafficking, is this person treated differently in any way and/or advised of any additional services or rights? 
19) With reference to the federal government's Interdepartmental Working Group Committee, and the sub-committee on the protection of victims that CIC chairs, can you provide an overview of the committee/sub-committee roles, responsibilities and objectives.

\section{Protection of victims of trafficking in persons}

\section{Article 6 \\ Assistance to and protection of victims of trafficking in persons}

1. In appropriate cases and to the extent possible under its domestic law, each State Party shall protect the privacy and identity of victims of trafficking in persons, including, inter alia, by making legal proceedings relating to such trafficking confidential.

2. Each State Party shall ensure that its domestic legal or administrative system contains measures that provide to victims of trafficking in persons, in appropriate cases:

(a) Information on relevant court and administrative proceedings;

(b) Assistance to enable their views and concerns to be presented and considered at appropriate stages of criminal proceedings against offenders, in a manner not prejudicial to the rights of the defence.

3. Each State Party shall consider implementing measures to provide for the physical, psychological and social recovery of victims of trafficking in persons, including, in appropriate cases, in cooperation with non-governmental organizations, other relevant organizations and other elements of civil society, and, in particular, the provision of:

(a) Appropriate housing;

(b) Counselling and information, in particular as regards their legal rights, in a language that the victims of trafficking in persons can understand;

(C) Medical, psychological and material assistance; and

(d) Employment, educational and training opportunities.

4. Each State Party shall take into account, in applying the provisions of this article, the age, gender and special needs of victims of trafficking in persons, in particular the special needs of children, including appropriate housing, education and care.

5. Each State Party shall endeavour to provide for the physical safety of victims of trafficking in persons while they are within its territory.

6. Each State Party shall ensure that its domestic legal system contains measures that 
offer victims of trafficking in persons the possibility of obtaining compensation for damage suffered.

\section{Article 7 \\ Status of victims of trafficking in persons in receiving States}

1. In addition to taking measures pursuant to article 6 of this Protocol, each State Party shall consider adopting legislative or other appropriate measures that permit victims of trafficking in persons to remain in its territory, temporarily or permanently, in appropriate cases.

2. In implementing the provision contained in paragraph 1 of this article, each State Party shall give appropriate consideration to humanitarian and compassionate factors.

\section{Article 8}

\section{Repatriation of victims of trafficking in persons}

1. The State Party of which a victim of trafficking in persons is a national or in which the person had the right of permanent residence at the time of entry into the territory of the receiving State Party shall facilitate and accept, with due regard for the safety of that person, the return of that person without undue or unreasonable delay.

2. When a State Party returns a victim of trafficking in persons to a State Party of which that person is a national or in which he or she had, at the time of entry into the territory of the receiving State Party, the right of permanent residence, such return shall be with due regard for the safety of that person and for the status of any legal proceedings related to the fact that the person is a victim of trafficking and shall preferably be voluntary.

3. At the request of a receiving State Party, a requested State Party shall, without undue or unreasonable delay, verify whether a person who is a victim of trafficking in persons is its national or had the right of permanent residence in its territory at the time of entry into the territory of the receiving State Party.

4. In order to facilitate the return of a victim of trafficking in persons who is without proper documentation, the State Party of which that person is a national or in which he or she had the right of permanent residence at the time of entry into the territory of the receiving State Party shall agree to issue, at the request of the receiving State Party, such travel documents or other authorization as may be necessary to enable the person to travel to and re-enter its territory.

5. This article shall be without prejudice to any right afforded to victims of trafficking in persons by any domestic law of the receiving State Party. 
6. This article shall be without prejudice to any applicable bilateral or multilateral agreement or arrangement that governs, in whole or in part, the return of victims of trafficking in persons. 


\section{Appendix 4}

\section{Non Government Organization (NGO) Questionnaire}

The 2000 UN Convention against Transnational Organized Crime, Annex II - Protocol to Prevent, Suppress, and Punish Trafficking in Persons, Especially Women and Children, is designed to combat those individuals and criminal organizations that profit from the exploitation of the most vulnerable of society through their forced or coerced illegal migration. As a signatory to this Convention, Canada agreed to a number of obligations, including the provision of protection to the victims of human trafficking. This study seeks to explore Canada's compliance with fulfilling its obligations of protection for the victims as stipulated in Annex II, Articles 6 through 8 inclusive. For ease of reference, a copy of the pertinent portion of Annex II is appended.

The following questions are very broad in context in order to encourage as great a detailed response as possible:

1) What is your organization's understanding of Canada's approach to handling the victims of human trafficking when they come to the attention of Canadian law enforcement agencies?

2) Does your organization play a role in this process/procedure?

3) Has your organization identified any deficiencies with the current approach implemented by the government of Canada to protect victims, and if so, what solutions do you believe should be implemented to resolve these gaps?

4) Various reports indicate that Canada uses the Canadian Immigration System (CIS) as its method of compliance with the UN Convention. Some NGO's believe that a separate system should be created for the victims of human trafficking because they are victims of a crime rather than persons entering the country illegally for the purpose of making refugee claims. What is your organization's position in this regard?

6) NGO's have criticized various countries because these countries link the protection of the victims of trafficking to their willingness to cooperate with the police and prosecutors. How does your organization approach this issue?

7) Numerous articles, evaluations, and reports regarding the efforts of many countries promote the idea of providing a 'cooling off' or 'reflection' period for the victims of human trafficking with no conditions attached. The victim would be provided temporary residence status (including work permit) for a specified period of time regardless of whether or not they agreed to assist the police. During this time, they would be provided legal counsel to ensure they were aware 
of all their rights and available services. What is your organization's viewpoint with regards to this proposal?

8) Canada has been criticized for not having specific protection provisions for victims of trafficking within current Canadian legislation (eg. Immigration \& Refugee Protection Act - IRPA, Bill C-49). What is your organization's view on this issue?

\section{Protection of victims of trafficking in persons}

\section{Article 6 \\ Assistance to and protection of victims of trafficking in persons}

1. In appropriate cases and to the extent possible under its domestic law, each State Party shall protect the privacy and identity of victims of trafficking in persons, including, inter alia, by making legal proceedings relating to such trafficking confidential.

2. Each State Party shall ensure that its domestic legal or administrative system contains measures that provide to victims of trafficking in persons, in appropriate cases:

(a) Information on relevant court and administrative proceedings;

(b) Assistance to enable their views and concerns to be presented and considered at appropriate stages of criminal proceedings against offenders, in a manner not prejudicial to the rights of the defence.

3. Each State Party shall consider implementing measures to provide for the physical, psychological and social recovery of victims of trafficking in persons, including, in appropriate cases, in cooperation with non-governmental organizations, other relevant organizations and other elements of civil society, and, in particular, the provision of:

(a) Appropriate housing;

(b) Counselling and information, in particular as regards their legal rights, in a language that the victims of trafficking in persons can understand;

(C) Medical, psychological and material assistance; and

(d) Employment, educational and training opportunities.

4. Each State Party shall take into account, in applying the provisions of this article, the age, gender and special needs of victims of trafficking in persons, in particular the special needs of children, including appropriate housing, education and care. 
5. Each State Party shall endeavour to provide for the physical safety of victims of trafficking in persons while they are within its territory.

6. Each State Party shall ensure that its domestic legal system contains measures that offer victims of trafficking in persons the possibility of obtaining compensation for damage suffered.

\section{Article 7 \\ Status of victims of trafficking in persons in receiving States}

1. In addition to taking measures pursuant to article 6 of this Protocol, each State Party shall consider adopting legislative or other appropriate measures that permit victims of trafficking in persons to remain in its territory, temporarily or permanently, in appropriate cases.

2. In implementing the provision contained in paragraph 1 of this article, each State Party shall give appropriate consideration to humanitarian and compassionate factors.

\section{Article 8 \\ Repatriation of victims of trafficking in persons}

1. The State Party of which a victim of trafficking in persons is a national or in which the person had the right of permanent residence at the time of entry into the territory of the receiving State Party shall facilitate and accept, with due regard for the safety of that person, the return of that person without undue or unreasonable delay.

2. When a State Party returns a victim of trafficking in persons to a State Party of which that person is a national or in which he or she had, at the time of entry into the territory of the receiving State Party, the right of permanent residence, such return shall be with due regard for the safety of that person and for the status of any legal proceedings related to the fact that the person is a victim of trafficking and shall preferably be voluntary.

3. At the request of a receiving State Party, a requested State Party shall, without undue or unreasonable delay, verify whether a person who is a victim of trafficking in persons is its national or had the right of permanent residence in its territory at the time of entry into the territory of the receiving State Party.

4. In order to facilitate the return of a victim of trafficking in persons who is without proper documentation, the State Party of which that person is a national or in which he or she had the right of permanent residence at the time of entry into the territory of the receiving State Party shall agree to issue, at the request of the receiving State Party, such travel documents or other authorization as may be necessary to enable the person to 
travel to and re-enter its territory.

5. This article shall be without prejudice to any right afforded to victims of trafficking in persons by any domestic law of the receiving State Party.

6. This article shall be without prejudice to any applicable bilateral or multilateral agreement or arrangement that governs, in whole or in part, the return of victims of trafficking in persons. 


\section{$\underline{\text { Appendix } 5}$}

\section{Protection of Human Trafficking Victims Questionnaire}

The 2000 UN Convention against Transnational Organized Crime, Annex II - Protocol to Prevent, Suppress, and Punish Trafficking in Persons, Especially Women and Children, is designed to combat those individuals and criminal organizations that profit from the exploitation of the most vulnerable of society through their forced or coerced illegal migration. As a signatory to this Convention, Canada agreed to a number of obligations, including the provision of protection to the victims of human trafficking. This study seeks to explore Canada's compliance with fulfilling its obligations of protection for the victims as stipulated in Annex II, Articles 6 through 8 inclusive. A portion of this study also includes examining how other countries, such as the United States and Great Britain, have approached the issue of providing trafficking victims protection in accordance with the UN Convention. For ease of reference, a copy of the pertinent portion of Annex II is appended.

The following questions are very broad in context in order to encourage as great a detailed response as possible:

1) What approach has the United States (US) government implemented with respect to providing protection to the victims of human trafficking in accordance with the UN Convention?

2) Please describe what the role and responsibilities are of your organization within the existing process of protecting victims of human trafficking?

3) Has your organization identified any deficiencies with the current approach implemented by the US government to protect victims, and if so, what solutions do you believe should be implemented to resolve these gaps?

4) Has an evaluation of the current process/approach been conducted and if so, what has been the results, and if not, is one intended?

5) Various reports indicate that Non Government Organizations (NGOs) believe that a separate system should be created for the victims of human trafficking because they are victims of a crime rather than persons entering the country illegally for the purpose of making refugee claims. What is your organization's position in this regard?

6) NGOs have criticized various countries because these countries link the protection of the victims of trafficking to their willingness to cooperate with the police and prosecutors. How does your organization approach this issue? 
7) Numerous articles, evaluations, and reports regarding the efforts of many countries promote the idea of providing a 'cooling off' or 'reflection' period for the victims of human trafficking with no conditions attached. The victim would be provided temporary residence status (including work permit) for a specified period of time regardless of whether or not they agreed to assist the police. During this time, they would be provided legal counsel to ensure they were aware of all their rights and available services. What is your organization's viewpoint with regards to this proposal?

8) How many prosecutions of traffickers has the US Government initiated subsequent to the 2000 UN Convention, and, has an evaluation of these prosecutions been conducted (Results)?

9) If US law enforcement encounters a trafficked victim through a criminal investigation in which the victim may be a forced participant in a crime (eg: prostitution), is the victim treated as a criminal or a victim or both?

10) Does the US have a dedicated unit that deals specifically with the victims of human trafficking? And, does this unit work on the domestic and/or international stage to promote the protection of victims? (Details)

11) If the US has no dedicated unit focused on human trafficking, does the US have any specific initiatives, domestically or internationally, that it has undertaken to heighten awareness of the need to combat human trafficking and protect its victims?

12) If, during the course of an investigation, it becomes apparent to US law enforcement that an individual is a potential victim of trafficking, is this person treated differently in any way and/or advised of any additional services or rights?

13) Does the US government provide law enforcement, prosecutors and magistrates any special training that enhances their awareness of the special protection needs of trafficking victims? (Details)

14) Has the US government enacted any legislation that provides specific protection provisions for the victims of human trafficking, and if so, do those provisions have any limitations? 


\section{Protection of victims of trafficking in persons}

\section{Article 6 \\ Assistance to and protection of victims of trafficking in persons}

1. In appropriate cases and to the extent possible under its domestic law, each State Party shall protect the privacy and identity of victims of trafficking in persons, including, inter alia, by making legal proceedings relating to such trafficking confidential.

2. Each State Party shall ensure that its domestic legal or administrative system contains measures that provide to victims of trafficking in persons, in appropriate cases:

(a) Information on relevant court and administrative proceedings;

(b) Assistance to enable their views and concerns to be presented and considered at appropriate stages of criminal proceedings against offenders, in a manner not prejudicial to the rights of the defence.

3. Each State Party shall consider implementing measures to provide for the physical, psychological and social recovery of victims of trafficking in persons, including, in appropriate cases, in cooperation with non-governmental organizations, other relevant organizations and other elements of civil society, and, in particular, the provision of:

(a) Appropriate housing;

(b) Counselling and information, in particular as regards their legal rights, in a language that the victims of trafficking in persons can understand;

(C) Medical, psychological and material assistance; and

(d) Employment, educational and training opportunities.

4. Each State Party shall take into account, in applying the provisions of this article, the age, gender and special needs of victims of trafficking in persons, in particular the special needs of children, including appropriate housing, education and care.

5. Each State Party shall endeavour to provide for the physical safety of victims of trafficking in persons while they are within its territory.

6. Each State Party shall ensure that its domestic legal system contains measures that offer victims of trafficking in persons the possibility of obtaining compensation for damage suffered. 


\section{Article 7}

\section{Status of victims of trafficking in persons in receiving States}

1. In addition to taking measures pursuant to article 6 of this Protocol, each State Party shall consider adopting legislative or other appropriate measures that permit victims of trafficking in persons to remain in its territory, temporarily or permanently, in appropriate cases.

2. In implementing the provision contained in paragraph 1 of this article, each State Party shall give appropriate consideration to humanitarian and compassionate factors.

\section{Article 8}

\section{Repatriation of victims of trafficking in persons}

1. The State Party of which a victim of trafficking in persons is a national or in which the person had the right of permanent residence at the time of entry into the territory of the receiving State Party shall facilitate and accept, with due regard for the safety of that person, the return of that person without undue or unreasonable delay.

2. When a State Party returns a victim of trafficking in persons to a State Party of which that person is a national or in which he or she had, at the time of entry into the territory of the receiving State Party, the right of permanent residence, such return shall be with due regard for the safety of that person and for the status of any legal proceedings related to the fact that the person is a victim of trafficking and shall preferably be voluntary.

3. At the request of a receiving State Party, a requested State Party shall, without undue or unreasonable delay, verify whether a person who is a victim of trafficking in persons is its national or had the right of permanent residence in its territory at the time of entry into the territory of the receiving State Party.

4. In order to facilitate the return of a victim of trafficking in persons who is without proper documentation, the State Party of which that person is a national or in which he or she had the right of permanent residence at the time of entry into the territory of the receiving State Party shall agree to issue, at the request of the receiving State Party, such travel documents or other authorization as may be necessary to enable the person to travel to and re-enter its territory.

5. This article shall be without prejudice to any right afforded to victims of trafficking in persons by any domestic law of the receiving State Party.

6. This article shall be without prejudice to any applicable bilateral or multilateral agreement or arrangement that governs, in whole or in part, the return of victims of trafficking in persons. 